\title{
Assessment in New Zealand Early Childhood Education: A Foucauldian Analysis
}

\author{
Emma Buchanan
}

A thesis submitted in partial fulfillment of the requirements for the degree of Master of Education

Victoria University Wellington

April 2011 
This thesis aims to problematise and denaturalise the current dominant, empowerment infused early childhood education (ece) assessment discourse in Aoteaora New Zealand through a Foucauldian discourse analysis. It addresses a two-part question: How is contemporary ece assessment constructed in New Zealand, and, what is effected by this construction? Texts about contemporary ece assessment in New Zealand written by local ece scholars and practitioners as well as narrative assessment examples drawn from the Ministry of Education (2004) Kei Tua o te Pae, Assessment for Learning: Early Childhood Exemplars resource provide data for the analysis. The analysis is conducted in procedurally specified as well as open, associative, and playful modes.

Contemporary ece assessment in New Zealand is found to be constructed as a new, post-developmental, morally desirable and secular salvation practice that is underpinned by principles of social justice, plurality and diversity. However, a consideration of key discursive truth-objects and their mobilisation within narrative assessments suggests that ece assessment may be implementing a boundless and normalising regime for the government of selves and others, and producing significant regulatory effects for children, teachers and whānau/ family.

It is argued that ece assessment, as a technology of government, works to construct self responsible, self optimising, and permanently performing child-subjects. Such norms for self government map closely onto those that are promoted within neoliberal governmentalities. Ece assessment can therefore, at least in part, be understood as both a technique and effect of neoliberal rationalities of government. The ongoing status and dominant construction of ece assessment as an empowering, socially just practice is seen to be problematic. It stifles debate about early childhood spaces, and it is implicated in the constraint of multiple possibilities for the government of selves and others. 


\section{Acknowledgements}

I am very grateful to Judith Loveridge, my thesis supervisor. I am particularly thankful for her patience, encouragement and kind, attentive listening. Warm thanks also to Jayne White for her assistance with the preparation of an initial proposal for this thesis. Many thanks to Jeremy Coubrough for his time and assistance.

I also acknowledge the interest and encouragement of a range staff and students at the Faculty of Education: Carmen Dalli, Sarah Te One, Sophie Alcock, Alison Stephenson, Mary Jane Shuker, Sue Cherrington, Sue Cornforth, Bradley Hannigan, and members of the Post-structural and Ethical frameworks thesis group. A special acknowledgement to the late Jim Neyland, who ran a wonderful post-graduate paper in the form of a critical reading, writing and discussion club, and whom I was fortunate to have as a teacher during the early part of 2009 . 


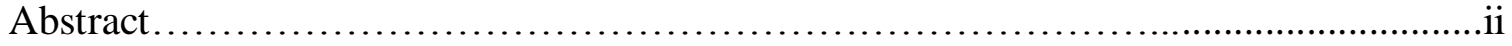

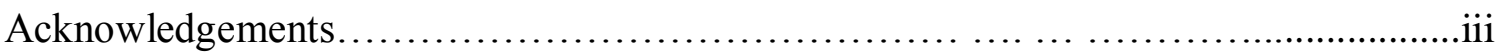

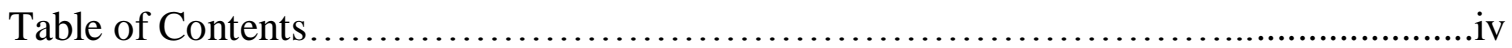

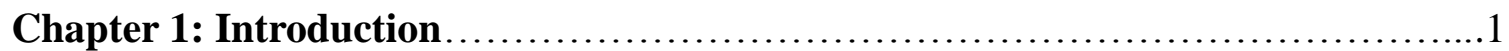

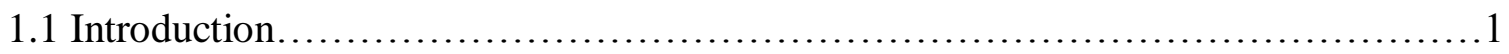

1.2 Setting the scene: contemporary ece assessment in New Zealand....................

1.3 Contemporary ece assessment in New Zealand: a mainly enthusiastic

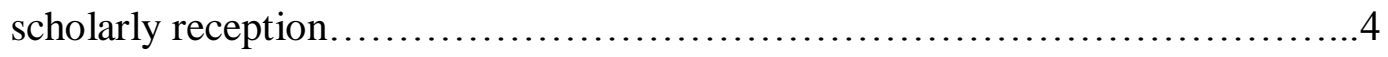

1.4 Rationale, thesis aims and questions addressed in the study ...................... 4

1.4.1 Thesis questions and key arguments................................6

1.4.2 My interest in the study ..............................................

1.5 Ethics, reflexivity and limitations.......................................... 10

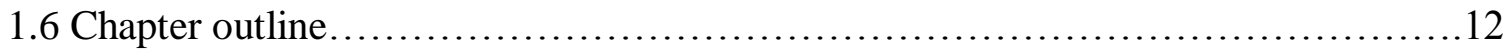

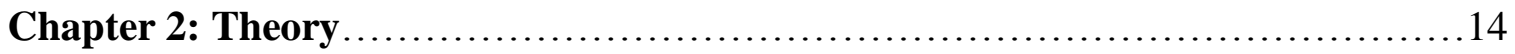

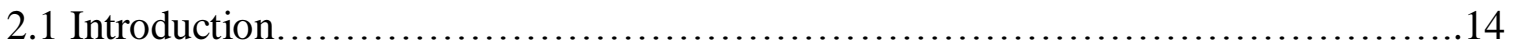

2. 2 Orientation: an indication of Foucault's general themes..........................14

2.2.1 The subject..................................................... 15

2.2.2 Power, knowledge, truth: produced and productive ..................... 16

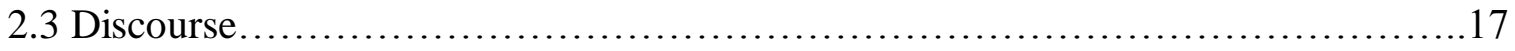

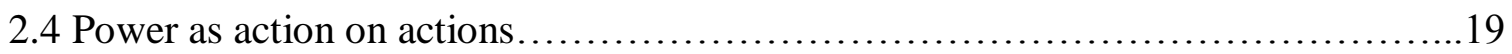

2.4.1 Concrete analysis of the techniques of power.............................19

2.4.2 Power as productive ................................................... 19

2.5 Government as techniques for conducting conduct..............................20

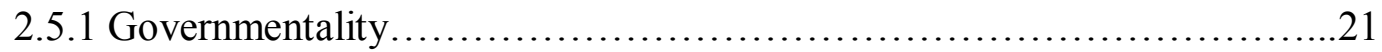

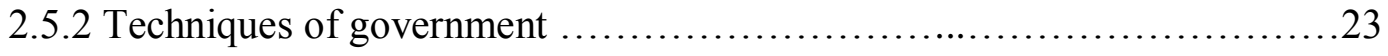


2.5.3 Technologies of power: normalisation, surveillance, knowledge. 23

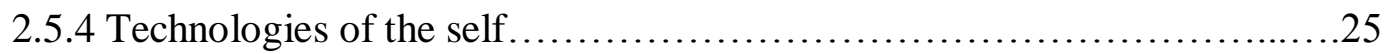

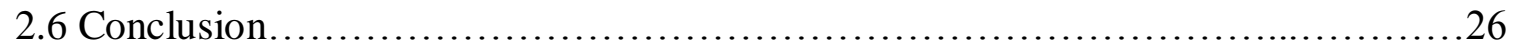

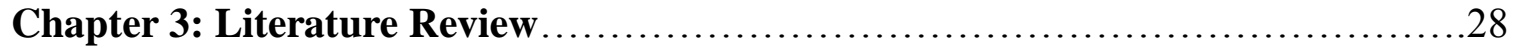

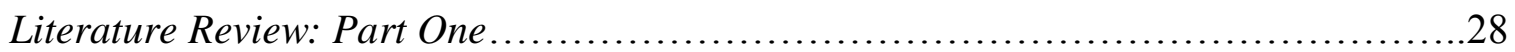

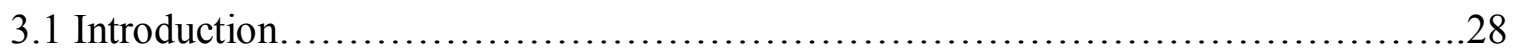

3.2 Ece curriculum and assessment in New Zealand before Te Whäriki.................29

3.2.1 Developmentally appropriate programmes..........................29

3.2.2 Child observation to support developmentally appropriate practice...........30

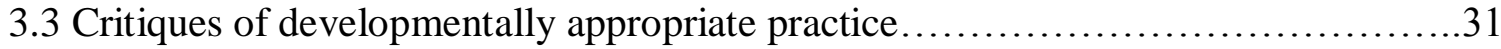

3.4 The development of Te Whäriki and related assessment approaches ................33

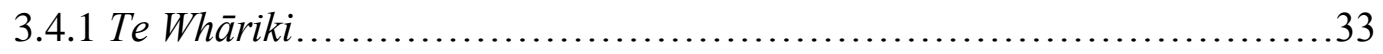

3.4.2 Assessment in the context of Te Whäriki................................36

3.5 Recent ece assessment studies conducted in New Zealand........................42

3.6 Commentary on contemporary ece assessement approaches in New Zealand... .....43

3.6.1 Recent framings of ece assessment in New Zealand.....................43

3.6.2 Concerns about contemporary ece assessment approaches........................46

3.7 Conclusion Part One....................................................... 49

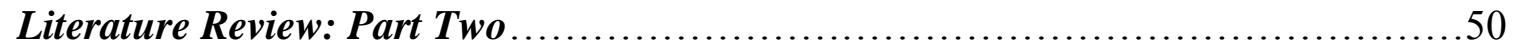

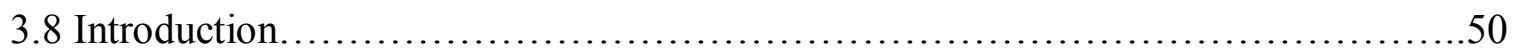

3.9 The use of Foucault's ideas in contemporary New Zealand ece research and commentary ....................................................... 50

3.10 Foucauldian analyses of DAP and its related observation and

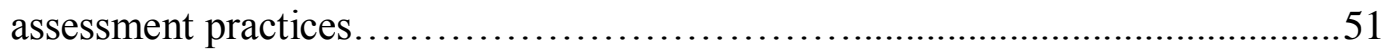

3.11 Recent analyses of contemporary educational discourses of participation

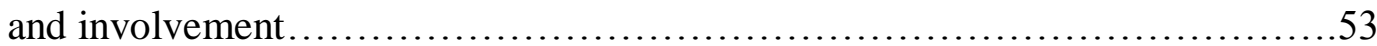

3.11.1 Capable, interactive and flexible subjects of

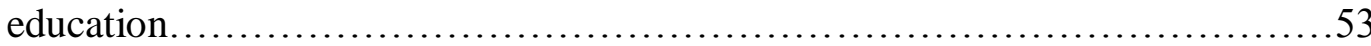

3.11.2 Subjects of ece in New Zealand: lifelong, processing, flexible learners...55 
3.11.3 Participation and voice as techniques of self government.

3.12 Contemporary educational discourses of participation and competence

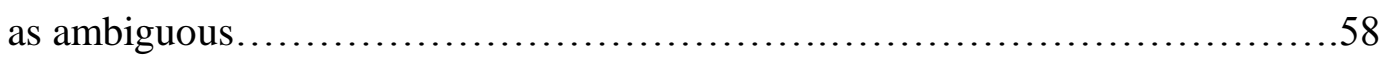

3.13 Conclusion: Literature Review Parts One and Two.............................59

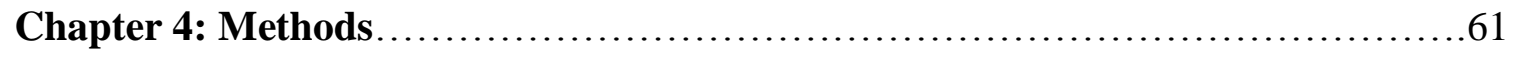

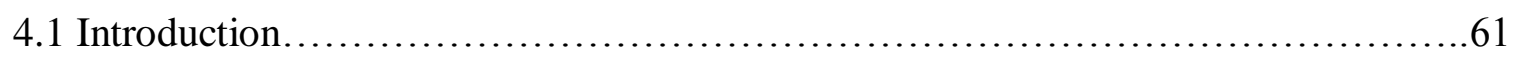

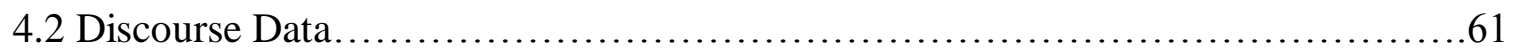

4.2.1 Selection....................................................6 61

4.2.2 Ethical considerations..........................................62

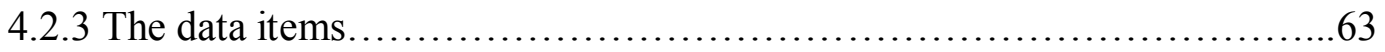

4.3 Developing a method and approach to analysis ..............................64

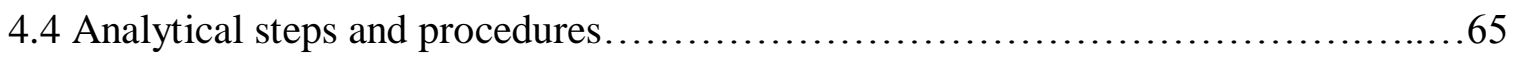

4.5 Limitations.............................................................. 75

4.6 Evaluating this thesis........................................................ 76

4.7 Conclusion....................................................... 77

Chapter 5: Analysis \& Discussion I: ................................... 78

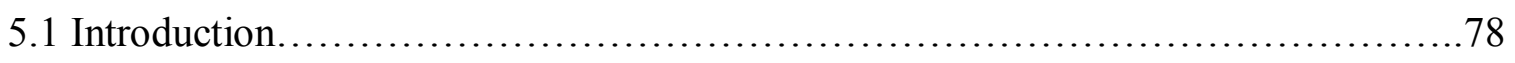

5.2 Discursive strategies................................................ 79

5.2.1 Contemporary ece assessment as other than past approaches ..............79

5.2.2 Contemporary ece assessment as a secular salvation practice .............82

5.3 Key discursive truth-objects......................................... 85

5.3.1 Learning: the ongoing process of being and becoming a learner..........85

5.3.2 The child as a competent, confident learner with voice..................88

5.3.3 The future as changing and uncertain............................90

5.4 Contemporary ece assessment: a superpragmatic amalgam of knowledge and

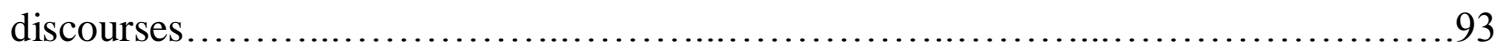

5.5 Conclusion...........................................................94 
Chapter 6: Analysis \& Discussion II..........................................96

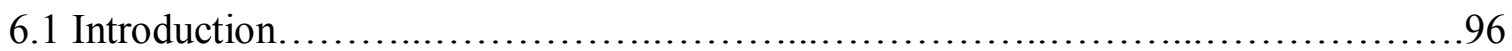

6.2 Learning and narrative assessment as technologies of government.................97

6.2.1 Learning as a normalising technology ............................... 98

6.2.2 Narrative assessments as inscription devices...........................100

6.2.3 The child's voice and learning portfolios as technologies of the self........104

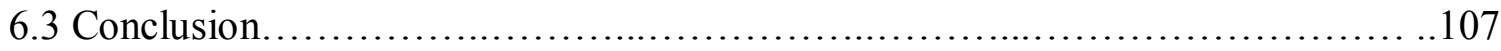

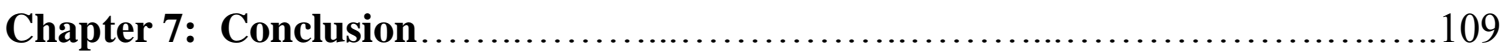

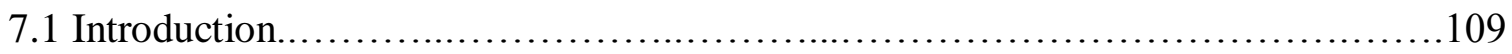

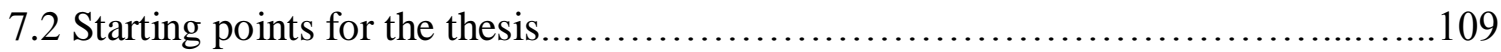

7.3 The enablements of a Foucauldian analytic ....................................110

7.4 Key findings of the thesis: summary, synthesis and some extrapolations............111

7.4.1 Extrapolation \# 1. Contemporary ece assessment: constitutive of particular norms for living ............................................ 113

7.4.2 Extrapolation \# 2. Contemporary ece assessment: governing permanently performing selves-as-learners...........................115

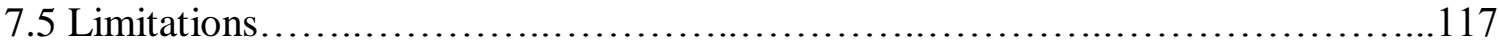

7.6 Indications for further research................................................. 117

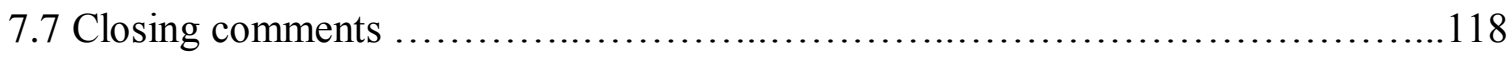

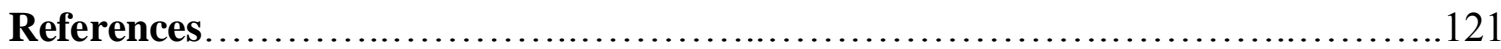

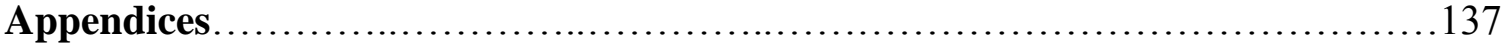

Appendix A Reference details for discourse data .........................137

Appendix B Indication of working inductive analytical codes

developed during analysis..................................139

\section{List of Tables}

Table 3.1 The Learning Stories framework of learning dispositions..........38

Table $4.1 \quad$ Theoretically informed analytical codes .........................69 


\section{List of Figures}

Figure 4.1 Early themes in the analysis of assessment discourse.......... 70



Figure 4.3 A model of the construction of contemporary ece assessment in

New Zealand............................................... 112 


\section{Chapter 1: INTRODUCTION}

\subsection{Introduction}

The focus of this thesis is a critical analysis of contemporary approaches to assessment in early childhood education in New Zealand. Currently, formative, narrative, sociocultural assessments are promoted and endorsed as being integral to quality provision in licensed early childhood services (e.g., Carr, 2009; Education Review Office, 2008; Ministry of Education, 2004, 2007a, 2009a, 2010; Mitchell, 2008). In this thesis I provide a critical analysis of texts and assessment examples that are concerned with and exemplify these prevailing approaches. I draw on the thinking of Michel Foucault to inform the analysis.

\subsection{Setting the scene: contemporary ece assessment in New Zealand}

Educational assessment literature often draws a key distinction between two types of assessment: formative and summative (Broadfoot, 2007; Carr et al., 2005; Ministry of Education, 2010). In general, formative assessment tends to refer to practices which are undertaken with the aim of improving learning such as teacher-student interactions, informal feedback and various forms of observation and written records (Carr et al., 2005). Broadfoot (2007) describes formative assessment as practices that "are designed to support and guide the learning process" (p. 178). On the other hand, summative assessment refers to practices that describe or measure learning that has been achieved according to pre-defined criteria. Summative assessment is primarily seen to serve purposes such as reporting to interested parties, awarding qualifications, and also, for teacher and institutional accountability (Broadfoot, 2007; Carr et al., 2005).

The potentially negative effects of summative assessments on teaching and learning are often cited within the educational assessment literature, including literature 
that takes a particular focus on assessment in early childhood education (ece). There is concern that an over emphasis on summative assessments or "“end point" testing" (Ministry of Education, 2010, p. 5) can contribute to a narrowing of the curriculum available to or enacted with students; the de-motivation of students; the development of performance oriented learning goals rather than intrinsically motivated learning goals; and limitations on the enactment of individualised, contextually responsive teaching and learning experiences (Black, 1995, cited in Carr et al., 2005, pp. 50-52; Carr, 1999a; Cowie \& Carr, 2009; Ministry of Education, 2010).

From the late 1990s, and increasingly so in the past decade, formative and narrative assessments of children's learning have been actively endorsed as a key vehicle for enacting and improving quality in ece services in New Zealand. The contemporary emphasis on formative assessment approaches, and an increased attention to dispositional learning outcomes in ece connects with broader trends within New Zealand compulsory schooling curriculum and assessment policy, and current Ministry of Education assessment vision (Hipkins, 2007; Ministry of Education, 2010).

Several Ministry of Education funded projects have been integral to establishing current ece assessment approaches. The first of these, the Project for Assessing Children's Experiences in Early Childhood Settings (PACE) (Carr, 1998a), produced the Learning Stories narrative assessment framework. This framework focuses on the assessment of children's positive learning behaviours, which are seen to be indicative of children's developing dispositions for learning (see Table 3.1). A formative, narrative approach to assessment has been further elaborated via the Early Childhood Learning and Assessment Exemplar Project. A key aspect of this project was the publication of a series of books containing examples of assessments conducted in ece services in New Zealand titled Kei Tua o te Pae/Assessment for Learning: Early Childhood Exemplars (Ministry of Education, 2004, 2007a, 2009a; referred to hereafter in short form as Kei Tua o te Pae, with reference details included where a specific book is being discussed).

In the introductory book to the Kei Tua o te Pae series it is noted that the exemplars are underpinned by a view of assessment as "a powerful force for learning" (Ministry of Education, 2004, book 1, p. 2). Later in the text it is stated that "increasingly now there is a need to harness the dynamic power of educational assessment to motivate 
and empower learners" (Broadfoot, 2000, p. 201, cited in Ministry of Education, 2004, book 1, p. 18). Both the Learning Stories framework and the Kei Tua o te Pae resource are seen to support an enactment of curriculum that is informed by the principles of $T e$ Whāriki: He whāriki Mātauranga mō ngā Mokopuna o Aotearoa, New Zealand's national ece curriculum (Ministry of Education, 1996b; hereafter referred to as Te Whāriki, referencing details included only where a specific citation requires). In particular, these resources are seen to support the fundamental Te Whäriki principle of empowerment (e.g., May \& Carr, 1998), by working to strengthen children's "sense of themselves as capable, competent learners, secure in their identity and sense of belonging" (Ministry of Education, 2006, cited in Stuart, Aitken, Gould, \& Meade, 2008, p. 13).

Early childhood services in New Zealand that are licensed by the Ministry of Education are currently required, as they have been since 1996 (Ministry of Education, 1996a), to undertake assessment in a manner that is consistent with the principles of $T e$ Whäriki and reflective of "current research, theory and practices in early childhood education" (Ministry of Education, 2008, p. 8). The ece regulations do not specify the use of any particular assessment form as a regulatory requirement (Ministry of Education, 2008). However, a consideration of several evaluation and regulatory documents (Education Review Office, 2008; Ministry of Education, 2008, pp. 5, 8, 9) clearly indicates that assessment as promoted and conceptualised in Kei Tua o te Pae and the Learning Stories framework is deemed to be indicative of current notions of best practice in ece assessment. The Education Review Office (ERO), the government body that is responsible for evaluating the quality of provisions in ece centres and schools recently reviewed the quality of assessment in ece services. The use of Kei Tua o te Pae was seen to indicate that a service's assessment policy and practice was "based on current theories about assessment” (Education Review Office, 2008, p. 12; see also Blaiklock, 2009). Moreover, in the published report of ERO's review, Learning Stories were frequently mentioned in highlighted vignettes which aimed to provide examples of good assessment practice (Education Review Office, 2008, e.g., pp. 10, 14, 15, 20). 


\subsection{Contemporary ece assessment in New Zealand: a mainly enthusiastic scholarly reception}

Many local early childhood scholars, professional development facilitators and practitioners - some of whom have been involved in Ministry of Education assessment

projects - have provided favorable and often times enthusiastic and supportive commentary on contemporary ece assessment approaches in New Zealand (e.g., Bayes, 2006; Carr, 2009; Carr et al., 2001; Cooper, 2009; Cowie \& Carr, 2009; Davis, 2006; Farquhar \& Fleer, 2007; Hatherly, 2006; Smith, 2007; Steele, 2007; Te One, 2005). Smith (2007) for example, has stated that narrative assessments "have the power to excite and energise teachers, parents and children" (p. 5). Further, as will be elaborated in Chapter 3, Smith describes Learning Story assessments as respecting the agency of children and empowering them by focusing on the assessment of "behaviours which are central to children becoming competent and confident learners and communicators" (p. $5)$.

Internationally, New Zealand's contemporary ece assessment approaches have also been described in very positive terms (Broadfoot, 2007; Carter, 2008; Drummond, 2003). Carter (2008) a professional development facilitator in the United States describes New Zealand's approaches as "radical” (p. 119). While Drummond, an English academic and proponent of formative assessment approaches, whose definitions of assessment have informed contemporary approaches in New Zealand (see Chapter 3, pp. 36, 41) comments that "we all have much to learn" from the approaches in New Zealand. She continues,

Learning Stories are about children's developing identities as learners ....[and adopt] the dominant metaphor of story in place of the tape measure .... the New Zealand approach emphasises learning as a moving event, dynamic and changeful, practically synonymous with living. (Drummond, 2003, pp. 185-186)

\subsection{Rationale, thesis aims and questions addressed in the study}

To date, there has been limited critical engagement with the currently promoted ece assessment approaches in New Zealand, with White's (2009; see also White, 2007; White \& Nuttall, 2007) Bakhtinian analysis of assessment practice in an ece centre being a 
notable exception. The paucity of critical engagement is particularly worthy of note in the context of local and international scholarly discourses which emphasise quality as a highly contestable construct (e.g., Dahlberg \& Moss, 2005; Dahlberg, Moss, \& Pence, 1999, 2007; Farquhar \& Fleer, 2007; Moss \& Dahlberg, 2008). Local scholarly discourse emphasises that the implementation of Te Whäriki is an interpretive practice (Nuttall, 2003a, 2003b; Te One, 2003; see also Farquhar, 2008). The curriculum document is described as a non-prescriptive framework which seeks to acknowledge "a diversity of belief systems" (Carr, 1991, p. 5, cited in Te One, 2003, p. 32). Nuttall (2003a) suggests that Te Whäriki requires a curriculum implementation that is "woven from local and particular thinking and circumstances....it requires teachers, parents, and children to collaboratively explore their own perspectives on what counts as "teaching", "learning", and "knowledge" (pp. 162-163).

As has been indicated in this chapter, and as will be elaborated on in Chapter 3, much of the commentary about contemporary ece assessment in New Zealand is imbued with the rhetoric of empowerment and it is characterised by a celebratory, and at times hyperbolic tone. Nicoll and Fejes (2008) comment that analysis that is informed by Foucault's ideas can be "helpful in promoting a critical attitude towards our present time and the truths that are promoted today" (p. 1). By applying a Foucauldian lens to contemporary ece assessment approaches in New Zealand I aim to contribute to early childhood scholarship by unsettling and problematising the current status of contemporary ece assessment as indicative of "right', 'best' and 'ethical'" practice (MacNaughton, 2005, p. 2).

The idea of discourse functions as a key analytical construct in this thesis. My interpretation of this concept, and related ideas, is the concern of the following chapter. However, I note here that discourse is used to refer to systems that are made up of various forms of knowledge, practices and truths. These systems are understood to have regulatory effects in terms of structuring (but not determining) the possibilities about what can be perceived, experienced, said and done (e.g., Fendler, 2010; Foucault, 1980a; Mills, 2003). In the context of this thesis ece assessment, taken as discourse, is seen to govern and regulate what it is possible "to think, say, do and be" (Cruikshank, 1999, p. 2) in early childhood spaces. 
The analysis I undertake is diagnostic in its intent (Dean, 2010; Duhn, 2006). It is not the work of this study to prescribe an alternative to current forms of ece assessment in New Zealand. However, by critically interrogating assessment and its current position as a practice that is integral to quality ece, I do aim to contribute to the construction of spaces for thinking "differently about the present by taking up a position outside our current regimes of truth" (Arribas-Ayllon \& Walkerdine, 2008, p. 101). By denaturalising current ece assessment I aim to contribute to keeping the social practice of ece open to question and contestable (Baker \& Heyning, 2004). In expressing these aims I am informed by Mouffe's (2000; see also Mouffe, 1992) notion of pluralistic and agonistic democracy. In this conception of democracy the recognition and articulation of multiple "social logics" (Mouffe, 1992, p. 14) and visions of the good life is seen to be integral to establishing and maintaining a vibrant democracy.

\subsubsection{Thesis questions and key arguments}

As I pursue an analysis of contemporary ece assessment I consider both what is said and done in relation to assessment as a discursive construction that has regulatory effects in terms of knowledge and government of selves and others. I pose the following broad twopart question as a guide to the discourse analysis I undertake:

How is contemporary ece assessment constructed in New Zealand, and what is effected, or brought about, by this construction?

I will argue, based on an analysis of selected texts related to ece assessment in New Zealand (see Chapter 4, p. 63, for details of the data items), that contemporary ece assessment does not give children (or teachers and whānau) more (or less) power, and nor is it closer (or further away) from the truth about children's nature, their subjective qualities or innate motivations. I will contend, contrary to dominant narratives, that contemporary forms of ece assessment do not depart from normalising frameworks for the assessment of children, but rather, presume and promote new norms for the childsubjects (as well as adults) of ece. These normalities in my analysis, are based on the dominance of a particular construction of learning, and a correlating truth of the child as 
learner. I will contend that these normalities are promoted via a range of techniques of government, many of which aim to foster forms of self government and self constitution according to principles of reflexivity, performance and self optimisation. Moreover, this government is to take place within a boundless domain of government: the space of the learning opportunity, experience, and possibility.

Furthermore, by drawing on governmentality scholarship such as that conducted by Rose $(1996,1999)$ and Dean (2010) I will suggest that these normalities can be connected with, and indeed considered effects of, neoliberal or advanced liberal mentalities of government. In light of my analysis I will suggest that the ongoing status of contemporary ece assessment in New Zealand as a morally valorised practice is problematic. It smoothes out and marginalises debate about the complexities, tensions and ambiguities that are part of contemporary assessment.

\subsubsection{My interest in the study}

The focus for investigation and choice of theoretical lens arises from my experiences in New Zealand over the past decade as an ece student teacher, teacher, and most recently postgraduate education student. Over the past decade, formative, narrative, socioculturally framed assessment approaches that often take a dispositional focus have become an increasing point of focus in ece. Indeed, White (2009) has suggested that current assessment approaches in New Zealand ece are "positioned as part of the 'golden triangle' alongside curriculum and pedagogy" (p. 4).

During the mid to late 2000s I noticed that assessment practices were a frequent focus for ece centre quality improvement and centre self-review processes (see Ministry of Education, 2006). To assist with such quality improvements teaching teams could attend professional development courses about aspects of narrative assessment such as creative writing, "the power of narrative" and "positive learning dispositions as outcomes for children” (Wellington, Hutt, Rimutaka Kindergarten Associations, 2008).

Many key terms that stood for good practice in early childhood education during my teacher training in the early 2000s such as respectful, collaborative, inclusive, authentic and empowering, seem to have converged over the course of the decade around storied, collaborative assessment approaches. During the mid to late 2000s I was very 
involved with my colleagues in establishing narrative assessment practices. Indeed, around that time I was considering undertaking a Master's study that would research ece teacher leadership practices in relation to assessment.

However, I was also beginning to develop discomfort with current ece assessment approaches. Two changes in my teaching circumstances were important to this unease. First, for considerable parts of 2008 I was unable to handwrite or type. Instead, I dictated narrative assessments for later transcription. Using a dictaphone meant that I frequently revisited and listened to my teacher voice. It also created a time-lag between what I noticed as being a subject for documented assessment and the subsequent construction of a formal narrative. This time-lag was often mediated by photographs, which functioned as prompts for the later dictation of an assessment. Second, during that time I worked as a reliever in a number of ece centers. As a relieving teacher I sought to cohere with established centre assessment style and tone.

Both of these changed teaching circumstances promoted reflexivity about my own and other teacher voices. I became ambivalent about my position in relation to assessment and was no longer wholly comfortable in my position as 'responsible teacher, committed to implementing best assessment practice'. I found that I struggled at times to construct narratives to accompany the photo documentation I was making prior to the dictation of assessments. For example, I remember taking photos of clusters of children as they worked to decorate a stage backdrop for 'a show', and taking some zoom-in shots of children's hands as they tried to hang preposterously oversized papier-mâché suns for this backdrop. I recall other photos of paintings that were graduated studies in colour and which were connected to memories of children chanting in delight about 'the colours' as they painted. I also recall innumerable happenings, events, encounters, gestures, expressions of kindness, distress, beauty and so on, many of which I did not want to write about and could not or did not want to photograph, but which made up the time in the early childhoods spaces that I was part of.

It was a challenge to make what I felt would be acceptable assessments based on such documentation (and un-documentation). For example, I did not want to write about 'the decorating children' as 'becoming competent communicators and collaborators, persisting with their plans, and increasingly able to negotiate with others in their self set 
aims to put on a show', or to speak about them as 'becoming increasingly competent with a range of media'. I tried replacing some of the formal language used in the reflections about learning that were expected within narrative assessments with more colloquial language. For instance, phrases such as 'Marcus persevered with making a picture for the playdough recipe' became 'Marcus, you worked so hard...it was a really tricky job...but you just kept going'.

But neither prefacing assessment comments with a child or parents name, nor using informal and emotive language in assessments allayed my sense of unease. When I listened to what I said in my teacher voice about such events I felt that I was not being faithful to my personal and my intersubjective experience and construction of those events. I can best describe this as a feeling of profound disingenuousness and a sense of infidelity to the "space outside the actual" (Dahlberg \& Moss, 2005, p. 114, on Deleuze). To be doing my job as an ece teacher it seemed that I had to bring all events, interactions and emotions to account as learning experiences. Not only that, I had to show in a narrative, or in reflective comments following one, what I would do to optimise these learning experiences and to support a child's development as a learner.

I suggest that I was experiencing a dissonance between how I was being positioned (Davis \& Harre, 1990; Parker, 1992; Willig, 2008a, 2008b) as a teacher within assessment discourse, and how I was beginning to position myself with reference to, broadly speaking, discourses and philosophies "of the other" (Hanssen, 2000, p. 187). What were the parameters within which I could express and write about children? What could be said and what could be heard? (Wetherall, 2001b). And, did I want to express my teacher voice or call on that of children and families within these parameters? From this dissonant position as ece teacher, my sense of infidelity was to do with a failure to meet, what for me, was a moral obligation to maintain the alterity of others, and to resist a closure of meaning (see Dahlberg \& Moss, 2005).

Such feelings and reflections seemed to be at odds with the ece discourses in New Zealand that spoke about narrative, dispositionally focused assessments as being exciting, empowering, meaningful and authentic for children, families and teachers (e.g., Drummond, 2003, Smith, 2007). A reading of Cannella and Viruru's (2004) Childhood and postcolonization: Power, education, and contemporary practice introduced me to 
some Foucauldian ideas. Of particular interest was the idea that in order for a practice to be viewed as empowering it requires the establishment of particular truths and assumptions about who the subjects being empowered are (or should be). Further reading and postgraduate study suggested that such ideas would have relevance to my questions about ece assessment. I came to see discourse as an important investigative concept, and as I read work that applied Foucault's ideas about discourse and techniques of government to ece, the focus for this thesis began to emerge. In one essay, for instance, I commented that "viewed discursively, an assessment framework not only defines valued learning, it also sets the parameters for our field of vision, and determines what will be heard (Britzman, 2000; Dahlberg \& Moss, 2005)”(Buchanan, 2009).

\subsection{Ethics, reflexivity and limitations}

In this study I see adopting a reflexive orientation as being important to addressing issues of ethics and validity, or trustworthiness (Johnson \& Christensen, 2008). Interpretations of what researcher reflexivity may or should involve vary considerably, often in relation to the degree in which the knowledge claims arising from any given study are seen to be partial or limited in one way or another (e.g., Johnson \& Christensen, 2008; Wetherall, 2001a). In this thesis I identify researcher reflexivity as primarily being about positioning myself clearly within this study, and acknowledging the perspectival nature of the analysis produced (Taylor, 2001a; Wetherall, 2001a). It also involves a consideration of the purposes I see being served by this work. I will further address some of these issues in Chapter 4, Methods, but there are a number of important comments to make at this point.

It is my intention to analyse the construction and possible effects of contemporary ece assessment in New Zealand from a specific epistemological and ontological position. But it is not my aim to question the intentions and causes that have been pursued by those who have been involved in developing or using contemporary assessment approaches. Furthermore, as indicated in this chapter, I consider myself to be multiply positioned in relation to ece assessment. As an ece teacher I have, as described, been an advocate of formative, sociocultural, narrative approaches, and more recently I have been in positions that have required me to comment on ece student teachers assessment practices. I am very aware of the regulatory environment that teachers work in, and the impact of 
evaluative frameworks such as those adopted by ERO. It is for reasons such as these, as well as a commitment to the notion of pluralistic democracy (Mouffe, 2000), that I see it as being important to critically engage with contemporary ece assessment.

Also, I note that my analysis is based on a limited and selective text sample. I have made a number of deliberate exclusions. First, while constructs of biculturalism are embedded in current assessment in policy (e.g., Ministry of Education, 1996b, 2004), I have not made discourses of biculturalism a focus of my analysis. This is because in my initial analysis of discourse data which focused on scholarly and practitioner texts about assessment there was limited — and in several texts non-existent-reference to bicultural assessment. The limited data relating to bicultural assessment, coupled with the need to set parameters around the scope of this study, has meant that I have not included the Kei Tua o te Pae book Bicultural Assessment in my data set (Ministry of Education, 2004, book 3). Others have begun to make critical comments regarding discourses of biculturalism in relation to Te Whāriki (Duhn, 2006) and other contemporary ece documents, including Kei Tua o te Pae (Cederman, 2008; Farquhar, 2008). Second, questions regarding the congruence of mainstream contemporary assessment approaches with Te Ao Māori (a Māori world view) and Kaupapa Māori (plans of action created by Māori, expressing Māori aspirations and values) approaches to ece are being addressed by others (Paki, 2007; see also Ministry of Education, 2009b), and are not part of my focus.

Further, I note, as have others working with Foucauldian perspectives in relation to early childhood (Duhn, 2006; Millei, 2007), that on the whole I refer to the child in abstract terms, as a concept and construct. This is because I am concerned with the child as the subject of various educational discourses. In the discursive analysis of ece assessment that I undertake, I am particularly interested in the treatments and constitution of the child as an entity. That is, a thinkable object of knowledge, a governable subject, and an effect of contemporary ece assessment in New Zealand (Foucault, 1980b; Rose, 1999). 


\subsection{Chapter outline}

In Chapter 2, Theory, I discuss the aspects of Foucault's thinking that inform the analysis of ece assessment that is pursued in this thesis. This chapter also serves as a backdrop to some of the literature reviewed in Chapter 3, which is structured in two parts. The first section of the Literature Review provides background to the development of contemporary ece assessment approaches in New Zealand. It elaborates on the brief outline of contemporary approaches that has been provided in this chapter. It also provides insights into the dominant narratives about contemporary assessment in New Zealand ece, which have also been briefly indicated during this chapter. In part two of the review a selection of Foucauldian scholarship that is primarily concerned with early childhood educational discourses is considered in order to provide a scholarly context for this discursive analysis. This section also indicates that Foucauldian perspectives can provide particular insights into some of the ambiguities and tensions within contemporary ece assessment discourse.

In Chapter 4, Methods, I describe how I conducted a discourse analysis of ece assessment and detail the discourse data that was analysed. I further discuss ethics and reflexivity, elaborate on the limitations of the study, and propose several criteria for the evaluation of this thesis. In Chapters 5 and 6, I present and discuss my analysis. Chapter 5 particularly addresses the first aspect of my research question, focusing on the construction of assessment. In Chapter 6, I discuss my analysis of the possible effects of this construction, with a particular focus on the forms of subjectivity that are promoted for children via contemporary ece assessment in New Zealand. Finally, Chapter 7 concludes the thesis with a summary of key findings, some speculative comments that aim to extend several analytical claims, and some indications for further research.

Before proceeding a few clarifying notes on terminology are required:

1. Narrative assessment is used to refer to the contemporary assessment forms that are promoted for use in Kei Tua o te Pae, and I consider these forms to include the ideas that are espoused within the Learning Stories framework. I note that in much commentary about current narrative assessments, Learning Stories and Kei Tua o te Pae are referred to interchangeably (e.g., Carr, 2009; Mitchell, 2008; Smith, 2007). Where a text refers particularly to Learning Stories, I adopt this specific term. 
2. In referring to early childhood education (ece), early childhood services or ece centres, I am adopting the current dominant terminology. At times, to emphasise my view that purposes of these settings for children are contestable, I use, following Moss and Petrie (2002), the term early childhood spaces.

3. I use the names for this country New Zealand and Aotearoa interchangeably. 4. I refer to a Foucauldian lens for brevity, but emphasise that in doing so I am not proposing that there is any single perspective informed by the ideas of Foucault.

5. I use the terms neoliberal and advanced liberal (Rose, 1999) to refer to approaches to government that have arisen as responses to, and critiques of, the Welfare State (with local variations and often in an ad hoc fashion) in many liberal democracies (e.g., Dean, 2010; Duhn, 2006; Rose, 1996, 1999). In particular, I use the terms to point to the forms of moral regulation that, in a Foucauldian sense, are integral to governing in a neoliberal manner (Burchell, 1996; Peters, 2001, 2006). This moral regulation will be discussed in subsequent chapters. More generally, the terms neoliberal and advanced liberal are also intended to point to the "market fundamentalism" (Codd, 2005b, p. xv), the emphasis on "government by and through the market" (Peters, 2006, p. 414), and the commitment to global economies and free trade that characterise neoliberal government (Peters, 2001). It is outside the scope of this study to discuss the New Zealand situation specifically, but I contend that advanced or neoliberal approaches to government have prevailed in New Zealand since the mid 1980s, including in the context of so-called third way approaches enacted during the 2000s (e.g., Codd, 2005b; Duhn, 2006; Hope \& Stephenson, 2005; Janiewski \& Morris, 2005; O’Neill, 2005; Peters, 2001). 


\section{Chapter 2: THEORY}

\subsection{Introduction}

In the introduction to this thesis I indicated the context and rationale for the application of a Foucualdian lens to ece assessment in New Zealand. I stated my intention to unsettle the widely accepted status of contemporary approaches to ece assessment as indicative of “"right', 'best' and 'ethical”" (MacNaughton, 2005, p. 2) practice. In this chapter I now detail the theoretical position taken in support of this denaturalisation aim (Baker \& Heyning, 2004). I set out the ideas that will inform the analysis of contemporary ece assessment that is undertaken in this thesis by discussing some of Foucault's ideas about truth, power, knowledge, discourse, government and subjectivity.

Foucault, and others, discuss and interpret many of his ideas in a range of ways. In this chapter I focus on presenting the interpretations of concepts that are most relevant to this thesis. Although they are presented discretely the interconnectedness of the ideas discussed must be emphasised. Accordingly, the chapter should be read as a whole. I also note that the scope for addressing the complexities and debates about the ideas considered has been limited due to the constraints of space. Before considering the key concepts that inform this thesis I provide a brief orienting section indicating what might be described as Foucault's main research themes, in order to indicate the research orientation — at a very broad level—of this thesis.

\subsection{Orientation: an indication of Foucault's general themes}

Foucault (1982) suggests that the subject is the "general theme" of his research (p. 209). Many of his studies focus on investigating the various ways that the subject has been established "as a possible, desirable, or even indispensable object of knowledge" (Foucault, 1997c, p. 87). On one occasion Foucault (1982) stated that the overall aim of 
his research "has been to create a history of the different modes by which, in our culture, human beings are made into subjects" (p. 208).

Interconnected with the theme of the subject is the theme of power. Much of Foucault's work investigates the actions, modes of operation, and effects of power within democratic contexts. In Foucault's view the government of a range of entities, not least subjects, primarily occurs through non-legalistic means and without recourse to physical violence (Fendler, 2010; Holligan, 1999). For Foucault, questions of government and subjectivity are interconnected (e.g., Dean, 2010; Foucault, 1982, 1997b; Peters, 2001; Rose, 1996, 1999). Foucault's investigations into the techniques and practices of government link with his research into the construction of subjects and subjectivities in relation to various forms of knowledge/practice.

\subsubsection{The subject}

Foucault has several meanings in mind when he uses the term subject. For instance, "subject to someone else by control and dependence, and tied to...[ones]...own identity by a conscience or self-knowledge" (Foucault, 1982, p. 212). According to Fendler (2010, p. 54) Foucault's notion of the subject encapsulates these as well as a range of other, sometimes contradictory, meanings. For example the subject as: an actor or agent, an acting subject; as topic, or "focus under investigation"; as "object of our perception" (including the subject as the object of its own perception); as one who is governed; and, as a term for an academic discipline.

Subjects and subjectivities are understood to be discursive constructions (Besley \& Peters, 2007; Fejes \& Nicoll, 2008; Foucault, 1980b; Henrique, Hollway, Urwin, Venn $\&$ Walkerdine, 1984). For Foucault, there is no essential or universal subject. He suggests that "the individual is not to be conceived as a sort of elementary nucleus, a primitive atom" (1980b, p. 98). Henriques et al. (1984) describe subjectivity as "individuality and self-awareness - the condition of being a subject..." (p. 3). But they emphasise that in their usage of the term they understand subjects and subjectivities to be "dynamic and multiple, always positioned in relation to particular discourse and practices and produced by these" (Henriques et al., 1984, p. 3). Subjectivity then, as "the experience that one may have of oneself and the knowledge that one forms of oneself' (Foucault, 1997c, p. 
87) or “knowing one's mind" (Besley \& Peters 2007, p. 11), is seen to be a discursive effect of techniques of power.

\subsubsection{Power, knowledge, truth: produced and productive}

Foucault's approach to philosophy has been described "as an interrogative practice rather than as a search for essentials" (McHoul \& Grace, 1998, p. viii). In his various histories of the subject Foucault turns from a modern Cartesian approach to philosophy that is focused on a search for foundational and essential truth (Fendler, 2010). Of interest, rather, is an analysis of the "effects of truth [that] are produced within discourses which in themselves are neither true nor false" (Foucault, 1980a, p. 118, emphasis added).

According to Foucault, truth - or what is taken to be true - in any given sociohistorical context is the product of a complex range of interplaying factors, including forms of knowledge and interconnected practices. Foucault uses the term games of truth to refer to the processes of changing forms of knowledge or systems of thought, and the truths that are connected to these (Fendler, 2010; Foucault, 1997a). By games of truth Foucault (1997a) means "a set of rules by which truth is produced ....a set of procedures that lead to a certain result" (p. 297). Games of truth also suggests the idea that what is taken to be true is an effect of a range of played techniques and manoeuvres, and as in any game, the rules can change: "in a given game of truth, it is always possible to discover something different and to more or less modify this or that rule, and sometimes even the entire game of truth" (Foucault, 1997a, p. 297).

Foucault suggests that forms of knowledge that function as truths can, in part, be understood as outcomes - or effects - of relations of power (Fendler, 2010). Various forms of knowledge involve a range of practices or techniques of power, and these practices in turn sustain the truths from which they derive. As an example, Foucault (1980a) speaks of medical discourse and notes that at particular times certain “"true' propositions" (p. 112) can be formulated within the discourse. Foucault argues that true propositions, or what is taken to be true knowledge at any given time, will be connected with particular "ways of speaking and seeing... [as well as a] whole ensemble of practices" (p. 112) that serve as supports for the discourse and its true propositions. For 
Foucault, then, knowledge, truth and power are interrelated and mutually generative (e.g., Foucault, 1980a, 1980b).

In arguing thus, Foucault (1980a) turns from "a biological image of a progressive maturation" (p. 112) of knowledge. Instead he argues that particular knowledges or propositions within a discourse are "not simply new discoveries", but rather "new 'regimes' [s] in discourse and forms of knowledge" (p. 112). This position informs the view taken in this thesis about forms of pedagogical knowledge. The knowledge that determines true or acceptable ways of speaking, seeing and practicing in ece is taken to be discursively produced and sustained. It is understood to be a discursive construction whether it is derived from "paradigmactically modern" (Burman, 1994, p. 157) child development knowledge, from cultural historical or sociocultural perspectives on learning and development, or informed by a new paradigm of childhood studies (Smith, 2007). Changing forms of pedagogical knowledge are not taken to be, as Foucault (1980a) puts it, simply new discoveries representing the progressive maturation of early childhood education knowledge/practice.

\subsection{Discourse}

Foucault's ideas about discourse are also interconnected with his thinking about truth, knowledge and power. In this thesis the notion of discourse functions as an overall analytical-theoretical construct. It incorporates - but does not simply function as a short hand for-ideas about truth, knowledge, power and government. Foucault speaks about discourse in a range of ways. On one occasion he notes that he has not reduced the "rather fluctuating" meaning of the term, but rather "added to its meanings: treating it sometimes as the general domain of all statements, sometimes as an individualizable group of statements, and sometimes as a regulated practice that accounts for a certain number of statements" (Foucault, 1972, p. 80). Statements, which might be described as components of discourse, are interconnected with systems of knowledge, which in turn can be seen as effects of particular relations of power. Statements are the not the same as speech acts or language, but they may involve these elements. They can be understood as "functional units. They do things, bring about effects" (McHoul \& Grace, 1998, p. 37). 
Mills (2003) suggests that discourse can be "seen as a system which structures the way that we perceive reality" (p. 55), mediating our apprehension and experience of the world, including our experiences of ourselves. Discourse might also be understood as "a regulatory system" (Fendler, 2010, p. 87) that governs - but does not determineour thoughts, feelings and actions (MacNaughton, 2005) according the truths that are constructed and sustained by discourse.

The power and truth effects of discourse can be described broadly as the production of knowledges, truths, practices and subjectivities. Foucault (1972) points to these productive effects when he refers to discourses as "practices that systematically form the objects of which they speak" (p. 49). The important point for this thesis is that discourses - understood as regulatory systems constructed via (and also sustaining) relations of power - are taken to be productive, generative of, and in circular relation with power and truth effects. Further, in my use of the term discourse I am referring to ideas, concepts, written and spoken texts, as well as practices, routines, the organisation of space, and so forth.

Additionally, the idea of dominant discursive regimes is important for this thesis. Foucault describes a set of truths within any given discursive field that generate an "authoritative consensus about what needs to be done... and how it should be done" as a regime of truth (Gore, 1993, cited in MacNaughton, 2005, p. 30). Dahlberg and Moss (2005) use the term dominant discourses to refer to Foucault's regimes of truth. They suggest that dominant discourses, which function via various techniques of government, such as "concepts, conventions, classifications, categories and norms", provide a basis for determining "what is true and false, normal or abnormal, right or wrong" (p. 17). MacNaughton (2005) argues that dominant discourses in early childhood education produce authoritative understandings about what is "'right', 'best' and 'ethical"” for early childhood practice (p. 2). Dominant discourses enable and promote particular actions, thoughts, feelings, and knowledge, and they constrain others (e.g., Foucault, 1982; MacNaughton, 2005). 


\subsection{Power as action on actions}

Foucault's thinking about power differs from 'everyday' conceptualisations of power (Nicoll \& Fejes, 2008). Foucault (1982) asserts that power-conceived as a monolithic entity_ “does not exist” (p. 217). Instead, he emphasises a view of power as mechanism, as circulating networks that traverse the "whole social body" (Foucault, 1980a, p. 119). He proposes that "power is neither given, nor exchanged, nor recovered, but rather exercised... it only exists in action" (Foucault, 1980b, p. 89, emphasis added).

The use of the term power, for Foucault (1997a), is a short hand for relations of power (p. 291, emphasis added). Foucault (1982) describes a relationship of power as “a mode of action which does not act directly and immediately on others. Instead it acts upon their actions: an action upon an action, on existing actions or on those which may arise in the present or the future" (p. 220). A concept of power as actions on actions presumes that subjects are capable of action (Fendler, 2010; Foucault 1982, 1997a; Rose, 1999). Conversely, for Foucault (1997a) a "state of domination" refers to a situation where power relations are immobilised, "blocked, frozen" by an individual or group and where the possibility for the dominated subject(s) to resist or modify the relation is “extremely constrained and limited" (p. 283).

\subsubsection{Concrete analysis of the techniques of power}

Foucault (1982) argues for a concrete analysis of power focused on identifying its techniques and effects. He suggests an analytical focus on the how of power by asking for instance "“By what means is it exercised' and 'What happens...?"” (Foucault, 1982, p. 217). The how and what of power takes precedence in analysis, rather than, for example, a focus on identifying an "internal rationality" (Foucault, 1982, p. 211) directing the workings of power. Foucault (1980b) suggests that the researcher study power "in its more regional and local forms .... [at] the point[s] where power... invests itself in institutions, becomes embodied in techniques, and equips itself with instruments" (p. 96).

\subsubsection{Power as productive}

Foucault (1980a) speaks of power as involving "positive mechanisms" (p. 120) that produce "real effects" (1980b, p. 97). This contrasts with thinking about power as that 
which dominates, oppresses or represses. Power is understood to be productive: "it induces pleasure, forms knowledge, produces discourse" (Foucault, 1980a, p. 119). According to Foucault (1980b), the individual as a subject who conducts herself in particular ways, is animated by particular desires, gestures, and certain knowledges of herself, is a prime power and truth effect (pp. 97-98), constituted in discourse (Henriques et al., 1984). Foucault (1997a) speaks of the subject as a "form" rather than substance, and he sees this form as being constituted via "certain practices that ...[are]...also games of truth, practices of power..." (p. 290).

Foucault's (1995) use of the term soul reflects this view that subjects and subjectivities are constituted and shaped via discourse: "the modern 'soul'.... exists, it has a reality....it is the element in which are articulated the effects of a certain type of power and the reference of a certain type of knowledge" (p. 29). For Foucault (1995), and scholars working with his ideas, the soul, or "subjectivity... consciousness...etc.," (p. 29) is an effect of particular power/knowledge relations rather than an essential, a priori substance (Foucault, 1997a; see also e.g., Fendler, 2001, 2010; Popkewitz, 2003, 2004; Rose, 1996).

\subsection{Government as techniques for conducting conduct}

The notion of power as techniques and practices interconnects with Foucault's thinking about government. The term government is used broadly to refer to "the way in which the conduct of individuals or of groups might be directed: the government of children, of souls, of communities, families..." (Foucault, 1982, p. 221). Government as a practical activity can be understood as the application of various technologies that direct, guide and shape the conduct of selves and others (Rose, 1999) and which therefore "structure the possible field of actions" (Foucault, 1982, p. 221; see also Dean, 2010, p. 22).

Foucault proposes that within democracies power operates in a range of modes, for example: sovereign, disciplinary, pastoral, and bio-political (Fendler, 2010). Today, power that operates in a sovereign mode might be described as governing conduct through laws that involve sanctions, penalties, and rewards (Fendler, 2010). Scholars working with Foucault's ideas about government emphasise that governing within liberal democracies mainly takes place outside of sovereign modes. Furthermore, the shaping of 
subjectivities is understood to be a key governmental activity (e.g., Dean, 2010; Fendler, 2010; Rose, 1996, 1999). For instance, Rose (1996) suggests that "from at least the eighteenth century, the capacities of humans, as subjects, as citizens, as individuals, as selves, have emerged as a central target and resources for authorities" (p. 152).

\subsubsection{Governmentality}

Foucault's thinking about government then, tends to blur distinctions between notions of government at the micro (in terms of the government of self) or macro level (in terms of the government of the subjects of State/Nation) (Burchell, 1996; Rose, 1996, 1999). The term governmentality, a neologism constructed by Foucault, and subsequently used by others, points to the multiple senses of government that are encapsulated in his use of the term government. Dean (2010) proposes that governmentality, or rationalities/ mentalities of government is to do with "how we think about governing" (p. 24).

Various rationalities of government are understood to be differing responses to the questions and problems of government that are faced by all liberal democracies. These questions include: "What or who is to be governed and how?" (Rose, 1999, p. 7). Who should govern, and according to what ideals, values, limits, and truths about the subjects of government? What counts as governing well, and what constitutes the wellbeing of each and all? (e.g., Dean, 2010; Rose, 1999, Simons \& Masschelein, 2006). For example, Keynesian welfare-state models or various neoliberal models of government (e.g., Besley \& Peters, 2007, Rose, 1996, 1999) are representative of different approaches to the questions of government. They have differing visions of how to achieve the good of each individual and the good of the whole - which might be conceived of as society, communities, nation, economy (national, transnational, or global) or a combination of these constructs (Dean, 2010; Rose, 1996, 1999).

Moreover, government, whether it is considered in terms of the government of selves or other entities "entails a teleology" (Dean, 2010, p. 27). That is, it is directed towards particular aims or ends — whether or not they are stated explicitly — such as to achieve an individual state of happiness (however conceived), or to foster an "active citizenry" (Dean, 2010, p. 27). While the goals of government and its techniques may be 
more or less explicitly rationalised, they are not taken to be reducible "to the explicit intentions of any one actor" (Dean, 2010, p. 32; see also Rose, 1999).

Rose (1996) suggests that neoliberal approaches to government represent a mentality of government that sees national well-being in both political and social dimensions as being secured and promoted through the enablement of enterprising actions for all governed entities — be that businesses or persons. He argues that enterprise encapsulates a series of rules for conduct. To be enterprising, whether as an individual or an organisation, involves vigour and boldness, risk taking in the pursuit of goals, and a striving for "fulfillment, excellence and achievement" (p. 154). At the level of self government enterprise

designates an array of rules for the conduct of one's everyday existence: energy, initiative, ambition, calculation and personal responsibility. The enterprising self will make an enterprise of its life, seek to maximise its own human capital, project itself a future, and seek to shape itself in order to become that which it wishes to be. (Rose, 1996, p. 154)

Thus, in advanced or neoliberal governmentalities, governing is primary achieved through moral regulation and the promotion of "the ethics of enterprise" (Rose, 1996, p. 157; see also Burchell, 1996; Peters, 2001).

Govermentatlity perspectives provide valuable insights for this study of ece assessment. While the aims of government and practices of power are not seen to originate from specific individual wills they can be analysed as being animated by particular ways of thinking about government. Scholars of education working with governmentality perspectives have argued that the aims of enterprise and related entrepreneurial behaviours such as self reliance, initiative, risk taking, self responsibility, and flexibility are currently promoted through policy, curricula and pedagogical practices within advanced liberal democracies such as New Zealand (Duhn, 2006; O’Neill, 2005; Peters, 2001) and the United Kingdom (Bragg, 2007). 


\subsubsection{Techniques of government}

Foucault describes a range of techniques of government as part of his investigations into the establishment of the subject within various discourses. In the following two sections I address those techniques of government that have particular relevance to this thesis.

\subsubsection{Technologies of power: normalisation, surveillance, knowledge}

Foucault describes a myriad of concepts, practices, physical structures, and devices (e.g., Foucault, 1995) that function as "technologies of power, which determine the conduct of individuals and submit them to certain ends..." (Foucault, 1997d, p. 225, emphasis added). Many of these techniques are described in relation to power in a disciplinary mode. Disciplinary power involves the application of a range of techniques that are primarily focused on the body and its operations and conduct (Foucault, 1980b). In contrast to power in sovereign modes, disciplinary power functions continuously via technologies such as normalisation and surveillance. Disciplinary techniques enable access to "the bodies of individuals, to their acts, attitudes and modes of everyday behaviour" (Foucault 1980a, p. 125). Of the many techniques of power described by Foucault normalisation is particularly relevant to this thesis. I understand normalisation and the concept of the norm as a key technique of power, and see it as working in conjunction with a range of other disciplinary techniques. Accordingly it is discussed below in relation to the techniques of surveillance, examination, and forms of knowledge.

Foucault $(1995,2000)$ describes Jeremy Bentham's seventeenth century plans for a Panopticon, a design for a prison that could ensure the desired conduct of prisoners without recourse to direct punishments or force, as a way of illustrating key aspects of the operations of disciplinary power. The design involves a central observation tower surrounded by a ring shaped structure of individual cells. In the central tower the observer - a guard, a teacher - unable to be seen by those in the individualised cells, is able to see all. The Panopticon illustrates that within a disciplinary mode of power the awareness of the possibility of being watched and supervised is sufficient for disciplinary effects (Fendler, 2010). Conduct can be governed and directed towards particular norms for behavior, attitudes and desires within a particular discursive field with minimal external intervention because of a subjects' knowledge of possible surveillance. 
Foucault (2000) speaks about panopticism as a type of power that functions via "continuous individual supervision" (p. 70). He argues that it enables "the molding and transformation of individuals in terms of certain norms" (p. 70). The examination is a technique of power that relates to panopticism. Foucault (2000) suggests that within a disciplinary mode of power examination functions as a companion to surveillance. Examination focuses less on ascertaining what has happened (for example ascertaining what has been learnt), but rather involves continuous supervision that is focused on "whether an individual... is... behaving as [s] he should, in accordance with the rule or not, and whether [s]he...is...progressing or not" (p. 59). Foucault (2000) argues that through the application of techniques such as surveillance, observation and examination, individuals become particular types of subjects who are disciplined according to the norm: "what ...[is] normal or not, correct or not, in terms of what one must do or not do" (p. 59).

In ece contexts child observation, record keeping, assessment records and child profiles can be viewed as techniques of surveillance that involve forms of examination and normative judgments (e.g., Cannella, 1999; Holligan, 1999; Campbell \& Smith, 2001; see Chapter 3, pp. 51-52, for a more extended discussion). These practices can be viewed as instances of discipline that function via the "panoptical gaze" (Holligan, 1999, p. 139). Holligan (1999) argues that children and adult's awareness of possible observation and assessment processes in ece settings renders them "vulnerable to selfcontrol" (p. 139).

Various forms of disciplinary knowledge such as medicine, psychiatry and psychology are also identified as disciplinary technologies by Foucault (Fendler, 2010; Foucault, 1980a, 1982). Forms of knowledge that are taken as true, or that function as uncontested guides for action, function as techniques of normalisation. As Olssen (2006) suggests, various forms of disciplinary knowledge are implicated "in producing the conceptions of normality that they claim to uncover" (p. 59). In Foucault's view normative knowledge becomes inscribed in the practices of daily life and through various techniques such as surveillance, categorisation and classification, subjects are known (constituted) and disciplined in particular ways (e.g., MacNaughton 2005; Olssen, 2006). Fendler (2010), for instance, suggests that knowledge that has the status of truth forms 
the basis of how we know ourselves and others, and it "allows us to govern ourselves [and others] in particular ways" (p. 45).

The modern discipline of developmental psychology is a form of knowledge that is widely described as being (or, in some cases, having been) a key informant for ece (e.g., Anning, Cullen \& Fleer, 2009; Burman, 1994; MacNaughton, 2005). In Foucault's terms, this knowledge has installed itself in ece settings (and elsewhere), and it animates a wide range of practices or technologies of power that govern and regulate the subjects of ece according to its various truths (e.g., Burman, 1994; Cannella, 1997, 1999; Dahlberg \& Moss; 2005; MacNaughton, 2005; see also Chapter 3, pp. 51-52).

\subsubsection{Technologies of the self}

Foucault (1997d) emphasises that technologies power and the self do not function discretely but are rather in "constant interaction" (p. 225). Technologies of the self are described in a range of ways by Foucault, including as "the procedures...[that are] ...suggested or prescribed to individuals in order to determine their identity, maintain it, or transform it in terms of a certain number of ends, through relations of self-mastery or self-knowledge" (Foucault, 1997c, p. 87).

In Foucault's research about the various techniques of the self that were used in Greek ascetic and early Christian monastic traditions he describes techniques such as self writing, forms of confession, and self examination. Foucault argues that such techniques were integral to the construction of particular forms of subjectivity (Foucault, 1997b; see also Besley \& Peters, 2007). As an example, Foucault (1997b) suggests that some forms of confession within early Christian monastic traditions tended toward "the continuous verbalization of all the impulses of thought" (p. 84). He argues that this type of confession was "an indispensable component in the government of men by each other" (Foucault, 1997b, p. 84). Foucault (1997d) also argues that from around the eighteenth century onwards such confessional practices have been applied in a range of settings, with, for example "various techniques of verbalization" being inserted into "the so-called human sciences (p. 249). He proposes that unlike past monastic technologies of the self that were aimed at achieving a renunciation of the self, modern techniques are applied in order to "constitute, positively, a new self" (p. 249). 
Practices related to the norms of self expression have been identified as an example of contemporary confessional techniques that are at work in early childhood services (Holligan, 1999). Through practices seeking to elicit children's expression, such as the extensive encouragement of children's conversation, or the noting of children's ideas in documentation, Holligan (1999) argues that children's “'souls' are made available to the surveillance of normalising social agents such as teachers" (p. 140). Holligan's description of practices aimed at promoting children's self expression as pedagogical confessional techniques illustrates Foucault's argument that techniques of the self and power interact in the processes of governing.

Techniques of the self is an important concept for this thesis because it assists an analysis of the productive effects of assessment, including the effects of those practices that, for example, emphasise an agentic, empowered self or collaboratively assessing child. The idea of technologies of the self enables an analysis of subjectivity as an effect, in part, of techniques applied primarily by the self to oneself (Foucault, 1997c).

\subsection{Conclusion}

The Foucauldian concepts discussed in this chapter frame my analysis of contemporary ece assessment in New Zealand. The idea of discourse provides an overall analyticaltheoretical framework for the analysis. It refers to a productive regulatory system that is constituted by (and also sustains) relations of power, and forms of knowledge and practice, and it brings about material effects. The methodological implications of this position will be elaborated in Chapter 4, Methods. To close, I restate the key points of this chapter by way of a series of perspective statements. The analysis of contemporary ece assessment that is pursued in this thesis is informed by the following understandings:

- Ece assessment, as discourse, is understood as being made up of a productive cluster of truths, knowledges, discourses, and techniques of government.

- Power, as action on actions, is embodied in techniques and practices which interconnect with particular truths and knowledges. Practices of power are understood to have real effects. 
- The subject(s) of ece are constituted in (but not ultimately determined by) discourse(s), and are understood to be prime power and truth effects.

- The knowledge and practices that function as truth in ece and provide an accepted guide for seeing and practicing are understood to be discursive constructions.

- Ece assessment is taken to be a technology of government. Whether its techniques are self administered, mutually enacted, or applied by detached teachers/experts, it is understood to be a productive technology.

Having outlined the theoretical framings of this thesis, I turn in the next chapter to a Literature Review. The review serves two main functions. In the first part of the review a context for this thesis' focus on contemporary ece assessment in New Zealand is provided via a review of primarily local literature concerned with assessment in ece. In the second part of the review a range of Foucauldian scholarship which is mainly focused on ece is considered. The review of this material adds to the theoretical, and to a lesser extent methodological insights, that have been provided in this chapter, and it provides a scholarly context for the application of a Foucauldian analysis to ece assessment in New Zealand. 


\section{CHAPTER 3: Literature Review}

\section{Literature Review: PART ONE}

\subsection{Introduction}

In the previous chapter I laid out the theoretical framings for this study. I now turn to a two-part review of relevant literature in order to detail the context for the analysis of ece assessment discourse that I undertake in this thesis. In this first part of the review I discuss what contemporary ece assessment in New Zealand involves, and I work to indicate how it is dominantly framed. I consider a range of primarily local commentary, research, and the ece policy and resource documents Te Whäriki and Kei Tua o Te Pae in order to do this.

The review begins with an indication of how of ece programmes and related assessment approaches are described in a "pre-Te Whāriki" (Davis, 2006, p. 18) developmental context. I draw upon local and some international material to do this. Before I turn to literature that gives an account of Te Whäriki's development and the "reconceptualised" (Carr, 1998c, p.16) assessment approaches that this involved, I indicate the broader international ece scholarly context at the time, through a consideration of critiques of developmentally appropriate practices. The emergence of contemporary narrative, formative and sociocultural assessment approaches via the Learning Stories framework and the subsequent ece assessment Exemplars project is then considered. Recent research about current ece assessment in New Zealand is reviewed. I close this section of the review with an indication of links that are made between contemporary ece assessment approaches in New Zealand and a number of broader ece discourses. I also discuss the limited local critiques of contemporary ece assessment. 


\subsection{Ece curriculum and assessment in New Zealand before Te Whäriki}

\subsubsection{Developmentally appropriate programmes}

This first section of the review is structured according to what I have discerned as the dominant accounts describing the development of contemporary ece assessment approaches in New Zealand. In these accounts the development of Te Whäriki is positioned as a significant landmark in New Zealand's assessment story, signaling "a reform of assessment practices in the early years" (Turnock, 2009, p. vii).

Prior to the sociocultural framings of ece in New Zealand that were signaled by Te Whäriki, approaches to early childhood programmes in New Zealand are described as being dominated by traditional child development knowledge (e.g., Anning, Cullen \& Fleer 2009; Davies, 2006; Schurr, 2009; Turnock, 2009). As a body of knowledge informing ece programmes, child development knowledge is widely referred to in the literature as developmentally appropriate practice (DAP), after guidelines issued by the American organisation The National Association for the Education of Young Children (e.g., Bredekamp, 1987; Bredekamp \& Rosegrant, 1992). This foundational knowledge is described as involving an amalgam of twentieth century child development theories, including most recently, Piagetian constructivism (Burman, 1994, Cannella, 1997; Davis, 2006; Fleer \& Robbins, 2004; Silin, 1987).

Piagetian developmental theory emphasised each child's individual construction of knowledge (Cannella, 1997). Piaget drew on the biological concepts of "assimilation, accommodation and adaptation" (Burman, 2008, p. 244) in order to construct a theory of the development of logical thinking and the organisation of knowledge in children (Burman, 2008). Piaget's theory envisages learning (changes in developmental stage) as an outcome of the resolution of cognitive conflicts that arise as the individual child interacts with the material world. It is seen to involve a view of development as a cumulative process where the individual child progresses towards increasingly rational and abstract thought and functioning (Burman, 2008; Cannella, 1997).

When applied to early childhood education, Piaget's constructivist theory is described as placing an emphasis on facilitating a child's progression through developmental stages via the provision of environments that enable children's self directed, explorative play (Burman, 2008; Cannella, 1997; Cannella \& Viruru, 2004). In 
New Zealand the influence of this developmental perspective is evidenced by a strong tradition of providing "informal-play-based programmes" (Anning, Cullen \& Fleer 2009, p. 20).

\subsubsection{Child observation to support developmentally appropriate practice}

Within the context of developmentally appropriate practice ece assessments are described as focusing on the observation of individual children with "scientific distance" (Fleer \& Surman, 2006, p. 139). The concept of children's developmental domains: "physical, cognitive, emotional, and social" (Fleer \& Robbins, 2004, p. 23) provided the framework for observation and subsequent assessment. Children were observed with reference to expected developmental norms (Anning, Cullen \& Fleer 2009), in order to ascertain their developmental level (Davis, Gunn, Purdue \& Smith, 2007).

Normative child development knowledge influenced both the assessment of children and the subsequent provision of appropriate environments and experiences. This is evident in the New Zealand report Assessment of Children in Kindergartens and Childcare Centres (Wilks, 1993). The report included a review of contemporary assessment literature. Wortham (1990) stated that "young children develop rapidly and their level of development changes continually. By observing frequently, teachers can track the child's development and respond to changes and advances in development, with new opportunities and challenges" (cited in Wilks, 1993, p. 21). Wilks (1993) further noted, also drawing on Wortham (1990), that with knowledge about child development observers are able to "convert the child's behaviours into information that can be used to understand the child's level of development and the need for experiences that will further that development" (p. 24).

Davis (2006) described her assessment experiences as an ece student teacher in New Zealand the early 1990s. This involved instruction in the "the task of observation for assessment" (p. 9), a task that she recalls emphasised the ideas of objectivity, completeness and detachment. The rules for conducting observation included: "write what you see, not what you think you see... don't include your personal opinion-remain objective... write everything — don't leave anything out ... sit away from the child to observe... you want to capture them in their true state" (Davis, 2006, p. 9). 
These rules were enacted with a range of observation techniques including time sampling, event recording and running records (see McMillan \& Meade, 1985 for an example of these methods). The resulting observational data was interpreted according to universal stages of development, and lead to particular learning objectives being set for children (Davis, 2006). Davis' (2006) account of observing for assessment coheres with Wilks' (1993) finding that child observation based on developmental perspectives was the most commonly used assessment tool in ece centres.

Carr (2001), in Assessment in early childhood settings: Learning Stories described the folk model of assessment that she used as a kindergarten teacher during the 1980s in New Zealand. According to her account, the purpose of assessment within this model was to sum up a child's knowledge and skill with reference to "a predetermined list" (p. 2); the learning outcomes of interest were "fragmented and context free" (p. 4) skills and knowledge; the desirable assessment tools were "objective observations" (p. 2), which ensured the validity of the observational data; the focus for intervention if the observational data indicated gaps in a child's attainment of pre-defined learning outcomes was on the deficits, "the missing pieces" (p. 11); and, the learning that was assessed was conceived as developing in a "linear and sequential" (p. 6) manner.

Davis (2006) considered her own, as well as Carr's (2001, cited in Davis, pp. 4756) "pre-Te Whāriki view of assessment" (p. 37) to be dominated by a "culture of objectivity" (p. 40), exemplifying the assumptions of a positivist paradigm, such as a "view of the world as being made up of observable, measurable discrete 'facts' that have an objective reality" (p. 46).

\subsection{Critiques of developmentally appropriate practice}

Critiques of developmentally appropriate practice as the foundation for ece thinking and practice began to emerge in international scholarship during the 1980s. These critiques drew on a range of theoretical resources including Foucauldian and feminist poststructural perspectives (e.g., Burman, 1994; Cannella, 1997, 1999; Dahlberg et al., 1999; Walkerdine, 1984); sociology of the curriculum and critical educational theory (e.g., Kessler \& Swadener, 1992b); and sociocultural theory (e.g., Fleer, 1995a, 1995b). 
Early critiques of DAP informed by Foucauldian notions of discourse, power and knowledge argued that child development knowledge, positioned as scientifically derived, objective and universally true, enabled wide scale regulation of children and families (Burman, 1994; Cannella, 1997). Various child observational and assessment practices, such as "nursery record cards" (Walkerdine, 1984, p. 158), which documented children's behaviour in relation to various developmental domains, were identified as key technologies of governing: practices that constructed the truth of the subjects that they observed and assessed (Walkerdine, 1984). Burman (1994) and Cannella (1997, 1999) called for those involved in ece to turn from primary recourse to DAP, which was seen to be a normative discourse that pathologised and marginalised those who did not adhere to its norms.

A range of early childhood scholarship that has broadly been clustered under the reconceptualist title also criticised developmentally appropriate practice (e.g., Bloch, 1992; Graue, 1992; Kessler \& Swadener, 1992a). DAP and related child development research was seen to be informed by "Eurocentric, often middle-class, notions of optimal early childhood experiences" (Kessler \& Swadener, 1992a, p. 291) and, as such, perpetuated social injustice and inequality. Kessler and Swadener (1992a) urged educators and researchers to engage with ece as a political and philosophical endeavour, and to interrogate their continued adherence to a developmentally appropriate curriculum by asking, for example, "whose voices are being represented by what is taught and experienced, and whose interests are being served?" (p. 290).

Bloch (1992) argued that the dominance of positivist child development knowledge constructed ece practice that was focused on assessing and facilitating individual development according to normative models. Bloch argued that if normative models for ece that were informed by the psychological sciences continued to dominate, then appropriate ece programs would continue to function as a tools of institutional injustice: A continued focus on ece with reference to notions of developmental appropriateness would, Bloch maintained, serve to "distract attention from structural analyses of the problems that help to maintain oppression and inequalities in achievement" (p. 16). 
Critiques of developmentally appropriate practice were also framed with reference to sociocultural theories of learning and development (e.g., Fleer, 1995a, 1995b, 2002). Fleer (1995b) argued that a Piagetian perspective conceptualised learning as an "isolated internal activity" (p. 3). Drawing on Vygotsky and subsequent cultural psychological scholars, Fleer (2002) argued in favour of a view of learning and development as socially constructed and "embedded within the whole sociocultural context" (p. 107), seeing learning and subsequent development as an outcome of various forms of participation within communities.

The "ethnocentric nature" of ece based upon Piagetian perspectives was also noted by Fleer (2002, p. 105), who considered a range of cross-cultural studies of childhood to highlight the diversity of interaction patterns and formats for learning that are promoted in various sociocultural contexts. Fleer (2002) proposed adopting an assessment and programme planning approach based on Barbara Rogoff's multiple lenses for the analysis of learning and development. Rogoff (2003) explains that the personal, interpersonal and cultural-institutional lenses help to describe the processes involved in development as transformation of participation: "Together, the interpersonal, personal and cultural-institutional aspects of the event constitute the activity. No aspect exists or can be studied in isolation from the others.... the focus of analysis stems from what we as observers choose to examine" (p. 58).

\subsection{The development of Te Whäriki and related assessment approaches}

\subsubsection{Te Whäriki}

In 1991 Helen May and Margaret Carr won the Ministry of Education contract for the development of a national early childhood curriculum for all licensed early childhood services in New Zealand. The draft curriculum document was released for trial and evaluation in 1993 (Ministry of Education, 1993), with the final version (Ministry of Education, 1996b) released in 1996 (May \& Carr, 1998). Carr and May (1993b, 1996) empahsise that consultation was a priority in the curriculum development process. This included the establishment of a partnership with the Kohanga Reo Trust, who were also responsible for the development of a Māori immersion curriculum (Carr \& May, 1996). A wide range of other representatives from various early childhood sector groups were 
involved in the curriculum development. The goal of achieving a curriculum framework that could accommodate a diversity of ece services and philosophies whilst making a shared statement about "quality early childhood practice" (May \& Carr, 1998, p. 1) was paramount.

Developers and commentators note that Te Whäriki was developed during a time of widespread socio-political and educational reforms in New Zealand (e.g., Duhn, 2006; Te One, 2003). Within a political climate dominated by "new right" (May \& Carr, 1998, p. 2) perspectives, relationships between education and New Zealand's "economic success" (May \& Carr, 1998, p. 2) gained increasing attention. According to Carr and May (1996) there was some hesitance within ece communities regarding the development of a national curriculum, with concerns about a possible loss of diversity and independence within the sector. However, Carr and May (1996; May \& Carr, 1998) suggested that within the context of increased accountability, there was a danger that if a "philosophy of quality early childhood practice" (May \& Carr, 1998, p. 1) was not articulated, then what they saw as inappropriate models of both curriculum and assessment, focused on "specific content-based knowledge and skills" (May \& Carr, 1998, p. 2) could be externally imposed.

Te Whäriki has been described as a "reconceptualised curriculum framework" (Carr, 1998c, p.16), reflecting a "radical" (Carr, 1998a, p. 1) approach that challenges traditional developmental approaches to ece curriculum, by attending to ideals and issues related to "democracy and social justice" (Te One, 2003, p. 24). Carr and May (1993a) note that in its development the themes of "biculturalism, multiculturalism, equity, [and] linking with families and parents" (p. 15) were important. Additionally, by incorporating both traditional developmental and sociocultural development perspectives Carr and May (1993a, 1996) have noted that the framework represented a departure from a sole recourse to traditional child development knowledge. While Te Whäriki did not entirely depart from modern developmental perspectives - with Piaget (and also Erkison) as well as Vygotsky and Bruner being described by Carr and May (1993a) as key theoretical guides - scholarship over the past decade has foregrounded the sociocultural underpinnings of the document (Anning, Cullen \& Fleer, 2009). 
In various ways, explicitly and also implicitly, such commentary about the emergence of Te Whäriki positions the curriculum document within the broader context of scholarly critiques of DAP, such as those outlined in the previous section of this review. For example, in a 1998 paper, Carr (1998c) appears to suggest the influence in the construction of Te Whäriki of early childhood reconceptualist, feminist poststructuralist, and cultural psychological scholarship, which was according to Carr, beginning to foreground the connections between ece curriculum and sociopolitical issues to do with social justice, culture, gender and identity (e.g., Davis, 1989; MacNaughton, 1997; Salomon, 1993; Sapon-Shevin, 1992; cited in Carr, 1998c, p. 8).

Te Whäriki, the final curriculum document that emerged from the process of sector consultation is envisaged as a framework that is structured around four underpinning principles: empowerment/ whakamana, holistic development/ kotahitanga, family and community/ whānau tangata, relationships/ngā hononga, and five learning strands: well-being/mana atua, belonging/mana whenua, contribution/mana tangata, communication/mana reo, exploration/mana aoturoa, with each strand having a series of indicative learning goals or outcomes. Te Whāriki, which translates from Māori as 'a woven mat' functions as a central metaphor for the curriculum, indicating for instance the intention that these principles and strands will be negotiated, interpreted and implemented at each ece site. Empowerment is, as noted, the foundation principle (Carr \& May, 1996; May \& Carr, 1998), informing the overall curriculum aspirations for children to grow up as competent and confident learners and communicators, healthy in mind, body, and spirit, secure in their sense of belonging and in the knowledge that they make a valued contribution to society. (Ministry of Education, 1996b, p. 9)

May and Carr (1998) describe Te Whāriki as a curriculum that adopts a "spider web" as opposed to a "step or staircase" metaphor for learning and development (p. 3, citing Eisner, 1985, p. 143). They propose that a step or staircase model is associated with a view of development and learning as a linear process that culminates in "grown up ways of thinking and learning" (Carr, 1998c, p. 8), a view that they suggest tends to be operationalised via "the more traditional developmental curriculum map of: physical, 
intellectual, emotional and social (PIES) skills" (May \& Carr, 1998, p. 4). They argue that in Te Whäriki learning is conceptualised as "the development of more complex and useful understanding, knowledge and skill attached to cultural and purposeful contexts rather than as a staircase of individually acquired skills" (May \& Carr, 1998, p. 5). Accordingly, in Te Whäriki the "critical role of socially and culturally mediated learning and of reciprocal and responsive relationships for children with people, places, and things" is emphasised (Ministry of Education, 1996b, p. 9).

\subsubsection{Assessment in the context of Te Whäriki}

In the context of Te Whāriki, developmentally framed child observations and assessments were no longer seen to be appropriate (May \& Carr, 1998). Between 1995 and 1997 Carr led the Ministry of Education funded Project for Assessing Children's Experiences in Early Childhood Settings (PACE). The project worked to develop a framework for assessment that would cohere with Te Whäriki and its turn from conceptualising learning outcomes in terms of the individual development of universal knowledge and skills towards an emphasis on socially mediated learning. The project involved three phases. The first focused on developing a framework for assessment, the second trialled the framework in five varied ece settings, and the final phase involved the establishment of resources for teachers and professional development (Carr,1998a, 1998b, 1998c).

Drummond's (1995) definition of assessment guided the PACE project: "effective assessment is a process in which our understanding of children's learning, acquired through observation and reflection, can be used to evaluate and enrich the curriculum we offer” (p. 13, cited in Carr, 1998a, pp. 5-6). By the third phase of the project the definition of assessment put forward to practitioners was "the ways in which, in our everyday practice, we observe children's learning, strive to understand it, and then put our understanding to good use" (Drummond, 1993, p. 13, cited in Carr, 1998b, p. 33).

The development of children's "dispositions about learning” (Carr, 1998c, p. 9) became the focus for the assessment framework. Carr (2001) has described learning dispositions in a range of ways, for example as "situated learning strategies plus motivation - participation repertoires from which a learner recognises, selects, edits, responds to, resists, searches for and constructs learning opportunities" (p. 21), and as 
"being ready, willing and able to participate in various ways" (p. 21). According to Carr (1999a) "dispositions are more than attitudes, and they can be seen to include skills. One way to make the static concept of skill (an ability that one has) more dynamic (an ability that one uses) is to look at strategy and disposition (p. 83).

Dispositions were understood, as was indicated in Te Whäriki, as the key learning outcomes of the curriculum (Carr, 1999a). In Te Whāriki (Ministry of Education, 1996b, pp. 44-45) the outcomes of knowledge, skills and attitudes are understood to combine for children in two ways (a) as working theories "about themselves, and about the people, places and things in their lives" (p. 44), and (b) as dispositions, which are described as "habits of mind" or "patterns of learning" (p. 44). Dispositions are described in Te Whäriki as providing "a framework for developing working theories and expertise" (p. 45; see also Carr, 1999a, p. 83). In relation to these described curriculum outcomes Carr (1998c) has also described the focus for assessment in the Learning Stories framework as being on children's "emerging working theories about what it is to be a learner, and about themselves as learners" (p. 9).

The focus on dispositions for learning was also tied to the central curriculum theme of empowerment and the aspiration to support children to become competent and confident learners (Carr 1998a). Five key learning dispositions were identified for the Learning Stories framework in relation to the five strands of Te Whariki, and related observable behaviours were also described. The links between the learning dispositions, Te Whäriki strands, and observable behaviors have been described by Carr in slightly different ways across a range of publications (e.g., 1998a, 1998c, 1999a, 1999b). (see Table 3.1 for details).

According to Carr (1998a, 1998c) during phase one of the PACE project it was noted that in ece settings children were often making a series of decisions and taking actions that were related to developing learning dispositions. This led to the notion of the Learning Story. Carr proposed that children, as learners in action, were often deciding whether valued knowledge lies here or elsewhere, whether there's anything of interest going on... whether to get involved or not...whether to engage with challenge, and to persist when difficulties arise ...whether to express a point of 
view, and what form that will take ... [and] whether to take responsibility in this social setting. (Carr, 1998a, p. 22)

These steps or "packages of decisions and actions" were described by Carr (1998a, p. 22) as Learning Stories. When Learning Stories accumulated, they were understood to "develop the dispositional quality of a 'template' or a learning narrative” (Carr 1998a, p. 23).

Table 3.1 The Learning Stories framework of learning dispositions

\begin{tabular}{|c|c|c|}
\hline $\begin{array}{l}\text { Te Whāriki } \\
\text { Strand }\end{array}$ & Learning Disposition & Related behaviour \\
\hline $\begin{array}{l}\text { Belonging } \\
\text { Mana Whenua }\end{array}$ & $\begin{array}{l}\text { Courage (and curiosity) to } \\
\text { find something of interest here }\end{array}$ & $\begin{array}{l}\text { taking an interest, finding } \\
\text { something of interest }\end{array}$ \\
\hline $\begin{array}{l}\text { Well-being } \\
\text { Mana Atua }\end{array}$ & $\begin{array}{l}\text { Trust that this is a safe enough } \\
\text { place to be involved and to } \\
\text { focus one's attention }\end{array}$ & being involved and attentive \\
\hline $\begin{array}{l}\text { Exploration } \\
\text { Mana Aotu-roa }\end{array}$ & $\begin{array}{l}\text { Perseverance to persist when } \\
\text { things get difficult }\end{array}$ & $\begin{array}{l}\text { persisting with difficulty or } \\
\text { uncertainty, to tackle and } \\
\text { enjoy difficulty and } \\
\text { uncertainty }\end{array}$ \\
\hline $\begin{array}{l}\text { Communication } \\
\text { Mana Reo }\end{array}$ & $\begin{array}{l}\text { Confidence to express a point } \\
\text { of view or a feeling }\end{array}$ & $\begin{array}{l}\text { expressing ideas, a point of } \\
\text { view and feelings }\end{array}$ \\
\hline $\begin{array}{l}\text { Contribution } \\
\text { Mana Tangata }\end{array}$ & $\begin{array}{l}\text { Responsibility for justice and } \\
\text { fairness and the disposition to } \\
\text { take on another point of view }\end{array}$ & $\begin{array}{l}\text { taking responsibility, taking } \\
\text { another point of view }\end{array}$ \\
\hline
\end{tabular}


During the course of the PACE project, and in subsequent writing, Carr (e.g., 1998a, 1999a, 1999b, 2001) elaborated quite a number of assessment ideas and principles that were integral to the framework. These included the ideas that effective assessment in ece services:

- Is credit-based; it pays attention to children's strengths by focusing on the dispositions that they are demonstrating and works to support these.

- Is conducted in context, focusing on "the child in action" (Carr, 1998a, p. 10) in a learning environment that involves interactions between people, places and things.

- Acknowledges the complexity and affective dimensions of complex learning situated in "real-life early childhood setting[s]" involving "the learner-inaction" (Carr, 2001, p. 13). Adopting a narrative form, with insights from ethnographic, interpretive research perspectives can support the recognition of this complexity.

- Invites the input of a range of participants and perspectives, such as those from children, teachers, family and whānau.

- Involves observation and a negotiated interpretation of what has been observed.

- Is formative and used to "enhance learning" (Carr, 2001, p. 3).

- Is ongoing and based in everyday practice, with most assessment being undocumented.

Following the PACE project the Ministry of Education funded a large-scale ece project that focused on service resources and professional development (Stuart et al., 2008). In 2001 Margaret Carr and Wendy Lee were contracted to lead the Early Childhood Learning and Assessment Exemplar Project which ran parallel to the National Assessment Exemplars Project for schools. The project resulted in Kei Tua o te Pael Assessment for Learning: Early Childhood Exemplars, a collection 20 books/ booklets that were published in three series between 2004-2009 (Ministry of Education, 2004, 
2007a, 2009a). Accompanying professional development contracts to support the resource began in 2005 (Carr, 2009, Davis 2006).

The assessment exemplars were gathered from around fifty ece settings. The booklets, which were distributed to all licensed ece services and primary schools in New Zealand, are described as "a best practice resource that will help teachers continue to improve the quality of their teaching " (Ministry of Education, 2011). They were designed to illustrate and assist learning communities to conduct assessment in a manner consistent with the principles and strands of Te Whäriki, and to guide learning communities in negotiating how they would use formative assessment to support Te Whäriki's overall vision for children to become competent and confident learners (Carr, 2009; Ministry of Education, 2004). The assessments included in the resource are considered to be exemplary in the sense that they provide "examples of assessments that make visible learning that is valued so that the learning community (children, families, whānau, teachers, and others) can foster ongoing and diverse learning pathways" (Ministry of Education, 2004, book 1, p. 3).

Each series of Kei Tua o te Pae contains an introductory book that examines the key assessment themes of the series. Each book contains assessment examples drawn from participating centres, and the assessments are annotated by the Ministry of Education in order to focus on particular assessment concepts. After an introduction to the resource as a whole, the first series focuses on the assessment themes of: sociocultural assessment; bicultural assessment; children contributing to their own assessment; assessment and learning: community, competence, and continuity; and, assessment for infants and toddlers. The second series (Ministry of Education, 2007a, books 10-15) focuses on assessment in relation to the strands of Te Wharriki. The final series (Ministry of Education, 2009a, books 17-20) is focused on assessment in relation to "symbol systems and technologies for meaning making” (Ministry of Education, 2009a, book 17, p. 2).

Kei Tua o te Pae describes assessment as the everyday processes of "noticing, recognising and responding" (Ministry of Education, 2004, book 1, p. 6) to children as learners, a conceptualisation that is drawn from Cowie (2000, cited in Ministry of Education, 2004, book 1, p. 6). These everyday processes are described as progressive 
filters: "teachers notice a great deal as they work with children, and they recognise some of what they notice as "learning". They will respond to a selection of what they recognise" (Ministry of Education, 2004, book 1, p. 6). Drummond's (1993) definition of assessment, which informed the Learning Stories framework, is combined with Cowie's assessment definition to provide the following elaborated definition of assessment for learning:

[the] ways in which, in our everyday practice, we [children, families, teachers, and others] observe children's learning [notice], strive to understand it [recognise], and then put our understanding to good use [respond]. (Ministry of Education, 2004, book 1, p. 6)

The assessment examples in the resource tend to involve a narrative about a particular event, incident, or series of events. The primarily teacher written narratives are often supplemented with photos and comments or quotes from a child or family member. Reflections on the significance of the learning are sometimes woven through the narrative assessment or included as a separate section, which is sometimes termed a Short-term review. Many of the assessments also have a final section, which is often termed What next, where ideas and questions about further learning possibilities are considered or sought (e.g., Ministry of Education, 2004, book 2).

In addition to a focus on assessment as a narrative, credit-based process involving multiple participants, many other ideas about assessment that were indicated within the Learning Stories framework are also evident in Kei Tua o te Pae. For example, the idea that assessment is an ongoing and integral aspect of curriculum enactment continues to be emphasised. It is noted in Kei Tua o te Pae that most assessment for learning is undocumented, involving moment-to-moment decisions and responses. Documented assessment is understood to play a role in improving the quality of the broader, interactive and ongoing assessment process: "a major purpose of documentation is that it will inform everyday, undocumented, interactive teaching and spontaneous feedback [to children as learners], making children's interactions richer and more reciprocal" (Ministry of Education, 2004, book 1, p. 12). 


\subsection{Recent ece assessment studies conducted in New Zealand}

Approaches to contemporary ece assessment have been the subject of several recent government funded reviews (Education Review Office; 2008; Stuart et al., 2008) as well as a survey conducted by the New Zealand Council for Educational Research (NZCER), an independent educational research organisation. The NZCER survey (Mitchell, 2008) investigated assessment practices as part of a broader national survey of ece services. It followed from a survey conducted in 2003, and aimed to "document participants' perceptions of assessment and curriculum practices and issues" (Mitchell, 2008, p.vii) and to track any changes in these. The study reported

a growing use of narrative and credit modes of assessment, and greater participation by parents, whänau, and children in assessment processes....[with] a large positive shift in the use of Learning Stories [94\% reported usage, up from $78 \%$ reported in the 2003 survey] .....and negative shifts in the use of anecdotal records...time sampling....and checklists. (Mitchell, 2008, pp. vii-viii)

In coherence with literature presented earlier, the move away from the use of assessment tools such as time sampling and checklists is interpreted positively, indicating a move towards qualitative and interpretive approaches which are described by Mitchell (2008) as supporting the "assessment of complex outcomes, such as dispositions, which are not all pre-determined" (p. vii). In addition, the Kei Tua o te Pae resources and supporting professional development provisions were identified by teachers as having a positive impact on their assessment practices, by supporting their understanding of assessment for learning, their ability to include children, families, and the broader learning community in the assessment process, and their ability to promote children's self assessment. Mitchell (2008) comments that these findings about teacher assessment practice suggests that the

use of Kei Tua o te Pae is contributing to a curriculum that is "permeable", open to contribution from all comers (Carr et al., 2001, p. 31), that is enabling teachers/educators to work with families' "funds of knowledge" (Moll, 2000), and that is enhancing teachers/educators' understanding of sociocultural theory. (Mitchell, 2008, p. 47) 
A number of recent New Zealand postgraduate studies have investigated the implementation of, as well as teacher understanding about, contemporary ece assessment approaches at specific centres (Davis, 2006; Schurr, 2009; Turnock, 2009). The view that the assessment practices that are exemplified in Kei Tua o te Pae are highly desirable is common to these recent research studies, and it is also evident in the NZCER survey (Mitchell, 2008).

Davis (2006), for example, conducted a qualitative case study at an ece center, which explored teachers "experiences, ideas, motives, practices and beliefs" (p. 58) in relation to what Davis described as New Zealand ece's new, interpretivist assessment paradigm. Davis, an ece professional development facilitator, positioned herself as an advocate of contemporary sociocultural assessment, arguing that "there is ample literature to support a change in assessment practice .... The message for the early childhood education sector in this country is that it is time to take on a new view, with new purposes and methods for assessing" (p. 57).

Individual and group interviews, observation and analysis of existing documents related to assessment, such as records of staff planning meetings, were analysed and framed by interpretive and phenomenological perspectives. Davis (2006) found that teachers understanding and practice of assessment was a complex process involving negotiations and explicit and implicit tensions between a range of assessment purposes, audiences, and paradigms. She described teacher's assessment meanings and practices as involving both rejections and entrenchments (see Davis, 2006, p. 144) of positivist assessment traditions. Davis (2006) concluded that "authentic, meaningful change will only come when it is situated within authenticity and meaning for those this change affects" (p. 147). This theme of the challenge of change is also evident in other recent theses investigating assessment practices at specific ece sites (Schurr 2009; Turnock, 2009).

\subsection{Commentary on contemporary ece assessment approaches in New Zealand}

\subsubsection{Recent framings of ece assessment in New Zealand}

New Zealand's reconceptualised approach to ece assessment in the context of Te Whäriki is a localised development. However, it is also linked by local scholars with a number of 
other, what I term, post-DAP approaches to observation and assessment, which in various ways have re-visioned or rejected the modern ece approaches that emphasised developmentally based observation and assessment.

The development of a new sociology of childhood and discourses of childhood rights are connected to the use of a range of participatory research methods in early childhood services. In contrast to traditional, universalising developmental assessments of children, various participatory research and documentation approaches aim to work with and listen to children's voices, in order to gain insights into their perceptions, priorities and experiences within early childhood services (Clark \& Moss, 2001, 2005). These participatory methods include child-lead centre tours, child-constructed documentation such as photographs, drawings and portfolios, and various "conversational encounters" (Clark, 2005, p. 493) amongst children and adults.

Theses practices are informed by a view of children as competent social actors who are able to participate and contribute to decision making about their own lives, including their experiences in early childhood spaces (e.g., Clark, 2005; Clark \& Moss, 2001, 2005; Pascal \& Bertram, 2009). Listening to children's voices is conceived as a multi-modal activity, with children's communicative repertoire understood to extend beyond verbal utterance (Clark, 2005). It is noted that listening to children in early childhood spaces is promoted for a range of purposes, including to research children's perspectives, to consult with children either as routine event, or in relation to a particular projects, and to improve learning (Moss, Clark, \& Kjørholt, 2005).

New Zealand ece assessment approaches are linked with these participatory methods via the emphasis on children's contribution to assessment and the promotion of the inclusion of the child's voice in assessments (e.g., Stuart et al., 2008; Ministry of Education, 2004, book 4). It must be noted that the emphasis on the child's voice and participation in the context of assessment in New Zealand is for the purposes of documenting and improving learning. However, despite this, there is some recent ece commentary in New Zealand that has actively framed current sociocultural, narrative assessment approaches in relation to the discourses of children's rights and a sociology of childhood (Smith, 2007; Te One, 2005). Smith (2007) for instance considers Te Whāriki and the Learning Stories assessment framework to exemplify key aspects of both child 
rights and childhood studies perspectives. Smith (2007) explains that within the "new paradigm of Childhood Studies" (p. 3) the focus is on multiple childhoods and that children are viewed as competent and agentic, as having voice and being capable of participating in defining their needs. Voice and agency are identified as two key components of these childhood studies and rights perspectives. The child's voice is defined as "that cluster of intentions, hopes, grievances, and expectations that children guard as their own" (Pufall \& Unsworth, 2004, p. 8, cited in Smith, 2007, p. 4), and agency is described by Smith (2007) as "how children express their voice" (p. 4). According to Smith (2007) Te Whāriki is a curriculum model that values children's voices and agency because it views children as "as active learners who choose, plan and challenge" (p. 5), and, the related Learning Stories framework is described as seeing children as "active participants in their own learning" (p. 5).

Local scholars have also framed New Zealand's collaborative, narrative ece assessment approaches in relation work that focuses upon approaching early childhood centres as spaces to promote democracy, civil society (Dahlberg \& Moss, 2005; Dahlberg et al., 2007), and social justice (e.g., Fleet, Patterson, \& Robertson, 2006). Within these approaches pedagogical documentation is seen to be integral to destabilising and challenging normalising concepts about the purposes of ece, and it is seen to play an important role in fostering multiple interpretations of events within early childhood spaces. The term pedagogical documentation is used to refer to both a content and process. The content involves the documentation, in any number of forms, of children's words, actions, and possibly work, as well as teacher's interactions. The process involves the use of this material as a prompt for critical debate and reflection on pedagogical work "in a very rigorous, methodical and democratic way" (Dahlberg, et al., 2007, p. 148).

Contemporary assessment approaches in New Zealand have been positioned within these discourses of early childhood spaces as sites for democratic, socially just practice. For instance, in a recent edited collection about documentation, local scholars Gould and Pohio (2006) identify Learning Stories as "one form of pedagogical documentation that can be used to create sites of shared dialogue" (p. 83). Similarly, Carr et al. (2001) argue that narrative assessments can contribute to democratic communities 
due to their collaborative approach which can "provide social spaces for everyone to contribute to the curriculum" (p. 29).

\subsubsection{Concerns about contemporary ece assessment approaches}

While the commentary and recent research about New Zealand's contemporary ece assessment approaches has largely been very positive locally and internationally, some concerns have been raised about contemporary assessment forms by local scholars within a number of journal articles (Blaiklock, 2008, 2009; Bone, 2001; Cullen, 2001; Nuttall, 2005) and doctoral theses (Farquhar, 2008; White, 2009). The various concerns raised represent two overall lines of critique.

The first line of criticism is to do with the efficacy and appropriateness of dispositions as a basis for assessment. Some of these concerns are indicative of an ongoing debate regarding the weighting of content vs. process based learning outcomes within curriculum and assessment approaches (e.g., Carr \& May, 1993b). Cullen (2001) expressed concern that foregrounding dispositional learning might provide insufficient guidance for the assessment and promotion of learning in areas such as literacy and numeracy skills (see also Blaiklock, 2008; Nuttall, 2005). Blaiklock (2008) strongly questioned whether the Learning Stories framework was an appropriate and useful assessment tool, arguing that it was unclear that the qualitative criteria for the validity of the assessment framework proposed by Carr (e.g., 2001) could be met.

The second line of criticism regarding contemporary ece approaches is centered on various ethical issues. Cullen (2001), reflecting a liberal conception of ethics, raised concerns regarding privacy, respect, and adequate consent procedures within an assessment and curriculum context that sees everything as being related to learning and development, and therefore as being potentially assessable (see also Farquhar, 2008, pp. 176-177).

Another area of concern about the impact of assessment on children was with the nebulous and ill-defined nature of the construct dispositions. Cullen (2001) suggested that dispositions may be interpreted as individual traits or characteristics located within the child as in "earlier psychological interpretations" (p. 8), and thus used to label children. Bone (2001) was concerned that by defining a set of desirable or "acceptable" (p. 28) 
dispositions, and then using their related behaviours as a basis for assessment, dispositions might become tools with which "adults judge the behaviour of children" (p. 28), and thereby support "institutional stereotypes" (p. 28).

White (2009) and Farquhar (2008) also raised ethical issues, albeit from varying theoretical stances. Their work views ece assessment as having implications for self-hood or subjectivity, and, as is the case in this thesis, it considers ece assessment to be constitutive of, or to play a role in forming, aspects of experience. Farquhar (2008) worked with Riceour's notion of the intersubjective, dialogic constitution of narrative identity. Three narratives of ece in New Zealand - the liberal, the economic, and the social — were presented and evaluated with reference to Riceour's dialogic identity. Aspects of Foucault's thinking were also drawn upon in parts of the analysis. Farquhar considered ece policy documents, as well as constructs of the child during these narrative analyses, and she proposed that Te Whäriki can be interpreted in a range of ways, and that it "signifies a number of...discursive possibilities" (p. 33).

In Farquhar's (2008) view, “curriculum texts such as Te Whāriki and Kei Tua o te Pae are implicit statements of participatory democracy founded on notions of reciprocity, sharing and negotiation between child and adult; mutual reconstruction through community, intergenerational dialogue, project and inquiry" (p. 29). Non-prescriptive narrative assessments, with a focus on dispositional learning, "rather than skills" (p. 31) were seen to have the potential to inform ece practice that could affirm Riceour's narrative identity. However, it was noted that there was a lack of research about the enactment of narrative assessments in New Zealand ece, and therefore limited information about the veracity of narrative assessments to support interpretive assessments, children's "authentic voice” (p. 177), and power sharing.

Farquhar's (2008) analysis of an economic narrative of ece was linked to neoliberal forms of government in New Zealand. These included approaches to government within more recent (e.g., up to the mid-late 2000s) third way approaches. The analysis of this economic narrative mainly focused on the macro elements of neoliberal government, considering, for example, the privatisation of some ece services, and the increased purview of regulations and educational accountability regimes. The latter two features of neoliberal government were related by Farquhar to a standardisation 
of learning and assessment. They were therefore evaluated as being contrary to the establishment of ongoing dialogic identity. However, what the particular "standardised assessment" (p. 27) practices were taken to be in context of ece assessment in New Zealand was unclear. For Farquhar (2008), on my reading, fluid, open-ended, narrative pedagogies and assessment methods were not considered to be animated by neoliberal rationalities. This contrasts with the arguments presented in this thesis, which draw on specific narrative assessment examples.

White (2009; see also White, 2007; White \& Nuttall, 2007), in a Bakhtinian analysis of toddler metaphoricity based in an ece centre in New Zealand, presented assessment as an ethical and dialogic act of authoring. White explained that authoring involves "entering into and evaluating a particular act" (White \& Nuttall, 2007, p. 22). She argued that ece assessment as an interpretive and aesthetic act of authoring should seek "to retain the uniqueness of other and avoid finalisation at all cost" (White, 2007, p. 2). In White's (2009) argument, current ece assessment functions as an authoritative discourse that focuses on the seemingly unproblematic constructs of disposition and voice. According to White (2009), a dispositional focus "demands that adults make deeply interpretive, subjective claims about children based on their judgments regarding the child's cognitive motives and interests" (p. 8). Furthermore, White (2009) maintained that New Zealand's authoritative, dispositonally focused assessment discourse requires teachers to notice, recognise and respond to children according to nationally and (purportedly) locally defined priorities for valued learning.

In the studied ece centre, these assessment requirements were found to permeate and dominate pedagogy and assessment. White (2009) therefore challenged the extent to which, in the context of dominant contemporary ece assessment discourse, the voices of children, families and teachers are able to contribute to, in Bakhtinian terms, ethical, polyphonic, multi-perspectival, and non-finalising authoring. Nuttall (2005) also raised issues about the contestability of valued knowledge and learning by questioning whose interpretations of valued knowledge and learning would be privileged at the point of noticing within contemporary ece assessment processes. While White's (2009) analyses of ece assessment has theoretical framings that are quite distinct from those utilised in 
this thesis, the findings of her study are of relevance, and will be referred to in later chapters.

\subsection{Conclusion Part One}

This review of mainly local ece literature about assessment and curriculum indicates that currently, formative, sociocultural, narrative and dispositionally framed assessment is widely endorsed and enthusiastically supported in a range of contexts. On the whole, contemporary ece assessment in New Zealand has been subject to limited critique. Within these critiques there has been a limited appraisal of assessment in terms of its implications for the constitution of subjectivity or a consideration of contemporary assessment as actively constituting and framing possibilities for thinking about the purposes of early childhood spaces.

The literature review indicates that contemporary ece assessment in New Zealand tends to be framed as a reconceptualised approach that is other than, and departs from positivist, developmentally appropriate, detached, objectifying, and decontextualised approaches to assessment. Thus framed, contemporary assessment has been presented as a desirable, but at times challenging approach to realise. Further, the contemporary ece commentary reviewed indicates that current approaches to assessment in Aotearoa have been positioned within discourses of social justice, democracy and human rights. Taken together, the literature reviewed in this section suggests that ece assessment in New Zealand tends to be characterised as an empowering, participatory and democratic practice that is supportive of meaningful learning for every child and family via a focus on the complex, culturally situated and ongoing outcome of becoming a learner. 


\section{Literature Review: PART TWO}

\subsection{Introduction}

In this second part of the literature review I will consider a range of mainly early childhood research that draws on Foucault's ideas. This material provides some indication of the particular analytical perspectives that can be offered by the application of a Foucauldian lens to contemporary ece assessment. First, I indicate some of the uses of Foucault in recent New Zealand ece research. A number of early Foucauldian critiques of developmentally appropriate practice that were briefly noted in Part One of the review are then considered. I then review some more recent discursive work that is engaging with contemporary educational themes, many of which are exemplified in New Zealand's current approaches to ece assessment. I work to indicate the theoretical and methodological implications of these studies.

\subsection{The use of Foucault's ideas in contemporary New Zealand ece research and commentary}

To date, I have not identified local scholarship that draws particularly on Foucault's ideas to specifically analyse contemporary ece assessment in New Zealand. Where Foucault's ideas have been used in relation to assessment it has tended to be in the context of scholarly discussions that compare contemporary assessment approaches with past, preTe Whāriki approaches. In these discussions, pre-Te Whāriki developmentally framed assessment methods are seen to exemplify techniques of normalisation and surveillance (Carr, Jones \& Lee, 2005; Farquhar \& Fleer, 2007). Interestingly, Carr (2001) comments that Foucault and Rose's notions of the gaze and surveillance may be applicable to the Learning Stories approach: "reframing the rules and redefining curriculum and achievement may simply be exchanging one form of surveillance for another" (p. 20). However a reading of a subsequent text (Carr, Jones \& Lee, 2005) suggests that this observation has not been pursued.

Foucauldian framings have recently been applied to range of other aspects of ece in Aotearoa, including the construction of heteronormativity within ece services (Gunn, 2008; Surtees, 2006); discourses of learning across a primary school and ece 
setting and their implications for subjectivity (Duncan, 2005); the discursive constructions of the subjects of ece within a hypothetical ece centre (Duhn, 2009), and also, as envisaged within Te Whäriki (Duhn, 2006); and, the constructions of the playing child subject in ece discourses (Gibbons, 2007b). The latter two investigations are particularly relevant to this thesis and they will be considered later in the chapter.

\subsection{Foucauldian analyses of DAP and its related observation and assessment practices}

As indicated in Part One of this review, Foucauldian analytics have been, and continue to be, applied to child-centred and developmentally appropriate educational discourses, including in relation to observational and assessment practice (e.g., Burman, 1994; Campbell \& Smith, 2001; Cannella, 1997, 1999; Cannella \& Viruru, 2004; Dahlberg \& Moss, 2005; Dahlberg et al., 1999, 2007; Holligan, 2000).

Early Foucauldian analysis focused on identifying the constituent elements and the effects of child-centred and developmental discourses (Burman, 1994; Cannella, 1997; Walkerdine, 1984). In these analyses, child observation and assessment practices were understood as techniques of power. Walkerdine (1984), in the seminal work Developmental psychology and the child-centred pedagogy: The insertion of Piaget into early education analysed child-centred pedagogy and the related idea of the developing child as discursive constructions emerging due to "certain historically specific conditions of possibility" (p. 154). Walkerdine worked to identify the knowledge and practices that were required by and used to construct the truths of child-centredness. She argued that the developing child was produced by psychological knowledge, and that the various “apparatuses and mechanisms...[of child-centred pedagogy, such as]... curriculum materials and techniques of assessment" (p. 155) that were produced by the truths of developmental psychology simultaneously sustained "the possibility of a developmental psychology itself' (p. 154). Walkerdine's overall argument was that disciplinarily knowledge and practice were working in a mutually reinforcing manner.

Cannella (1997), in another influential text, also conducted an analysis of childcenteredness, a discourse that she considered to be dominating ece. Cannella took the position that "truth(s) and knowledge(s)... whether presented as cognitive structures, 
universal human logic, or stages of development, are human constructions" (p. 12). She sought to identify the rules, knowledge and practices that constituted the discourse of child-centeredness, in order to "systematically describe the discourse as object" (Foucault, 1972, cited in Cannella, 1997, p. 14).

Child-centredness was connected to "a universal childhood discourse" (Cannella, 1997, p. 43) that was constructed via child development knowledge. As a western, modernist construct, child development knowledge was seen to be imbued with enlightenment ideas about individual reason, progress, science, and universal truths. Cannella (1997) contended that the dominance of child-centredness meant that the application of a very particular set of assumptions and ideals about how learning takes place (via a child's individual action as an explorative learner), how to support it (by providing appropriate environments to match a child's level of development), and what constitutes development and learning (the progression through developmental stages towards increasingly logical thought) had the position of truth.

Child observation was identified by Cannella (1997) as essential practice within the discourses of developmental appropriateness, enabling an understanding (a knowledge) of children as other than adults, a categorisation of their levels of growth and development, and the subsequent administration of appropriate experiences to support and optimise their progress. Cannella argued that developmentally appropriate practice had disciplinary effects for all involved. The techniques of child observation, for both the observer and observed, were viewed as being integral to the power effects of the discourse: governing and regulating social life, disciplining the behaviours of children and adults according to the norms of child development knowledge.

In a subsequent paper Cannella (1999) described child observation as one of a proliferation of techniques of "evaluation as educational practice... [that] whether labeled as formal or informal, called assessment, authentic, or portfolio...is the ultimate objectification of bodies" (p. 41), producing "docile bodies as objects that yield to the discourse" (p. 38). 


\subsection{Recent analyses of contemporary educational discourses of participation and involvement}

While I have not located Foucauldian inspired work that takes a particular focus on a ece assessment as it is currently framed in the New Zealand context, there is a range of recent Foucauldian work that is relevant to this thesis. Broadly, this scholarship has involved various problematisations of contemporary educational discourses that focus on the concepts of participation and involvement and which emphasise children as active, competent participants and co-constructors of their ongoing learning (e.g., Bragg, 2007; Duhn, 2006; Fendler, 2001; Gibbons, 2007b; Hultqvist, 1998, 2001, 2004; Masschelein $\&$ Quaghebeur, 2005; Millei, 2007; Popkewitz, 2003, 2004). The educational discourses and constructs of the child that are analysed in this research are very similar to those indicated in Part One of this review, and as such these studies provide a scholarly context for this thesis.

\subsubsection{Capable, interactive and flexible subjects of education}

The construction of the educated subject within contemporary early childhood and broader pedagogical discourses that emphasise participation and ideas such as interactivity, the co-construction of knowledge and ongoing learning has been the focus of recent Foucauldian research, often in the context of broader genealogical investigations (Hultqvist, 1998, 2001, 2004; Millei, 2007; Popkewitz, 2003, 2004).

In several genealogical investigations of the pre-school child in Sweden, Hultqvist $(1998,2004)$ noted the emergence of a "new-ish" (2004, p. 153) type of preschool subject within educational, as well as other socio-political, discourses during the late twentieth century. This subject was the capable and contextual child (1998), the "autonomous, participatory and flexible" subject (2004, p. 156). According to Hultqvist (2004) the emergence of this new subject was interconnected with shifting political rationalities of government, and shifting conceptions of the State and Nation within Sweden, and many other liberal democracies. Hultqvist (2004) argued that the autonomous, flexible and participatory subject favored in the new Swedish political imaginaries could "be found almost everywhere" (p. 153), within the private sector, as well as in discussions about citizenship and democracy. 
Hultqvist (2004) proposed that such a subject was being inscribed in curricula and the methods of teaching and instruction in pre-schools. Interactive observation was discussed as a device of such inscriptions. Hultqvist observed that in Sweden contemporary forms of qualitative, educational observation involve a "continuous stream of mutual interaction" (p. 175), with the observer and observed engaged as coconstructors and producers of knowledge. He noted that interactive forms of observation, and other participatory, qualitative research approaches tend to be characterised as "part of an emancipatory process" (p. 175). The notion of power from below was noted as a frequent theme in discussions of such practices. However, Hultqvist (2004) contended that it is unclear what is being emancipated by these interactive practices, and he offered the following reflection: "Before "we" accept this version of power from underneath, however, one important question probably remains to be answered: What regimes of power construct those subjects that will govern themselves in the name of themselves?" (p. 176).

Popkewitz (2003; see also Popkewitz, 2004) considered the changing forms of governing children and families through schooling in the United States. Like Hultqvist $(1998,2004)$ he emphasised that the subjects of education are interconnected with the forms of reason that shape different approaches to government. As part of his study he analysed contemporary pedagogical discourses that construct children as interactive, flexible, lifelong learners and problem solvers. He proposed that these interrelated concepts and pedagogical practices functioned as "inscription device[s] of governing" (Popkewitz, 2003, p. 36), mapping particular rationalities onto the interiors of children (and parents) and thereby governing the conduct of conduct, according to principles such as personal responsibility, self management and improvement. Reflecting on the effects of such forms of government, Popkewitz (2003) noted that the "keywords" of contemporary pedagogy such as: lifelong learners, community and partnership are "not merely words, but an amalgamation of practices that order, classify, and normalize that qualify and disqualify individuals to act and participate" (p. 55). 


\subsubsection{Subjects of ece in New Zealand: lifelong, processing, flexible learners}

Two local scholars, Duhn (2006) and Gibbons (2007b), have also analysed the construction of the child with reference to contemporary local and international early childhood discourses. Gibbons (2007b), drawing on the work of Foucault and also Lyotard considered the early childhood metanarrative of process over product via an analysis of a range of texts about children's play in New Zealand and elsewhere.

Gibbons (2007b) argued that current constructions of play are dominated by the notion of the processing child. He asserted that whether within developmental or "postmodern" (p. 306) treatments, play can be considered to be a technology of governing that is integral to the production of certain norms for subjectivity, as well as notions about what constitutes quality ece practice. He proposed that contemporary configurations of the playing child within "competence oriented process discourse" are related to a "broader performance oriented information society" (p. 310).

The emphasis on process as an outcome of education was seen by Gibbons (2007b) to be consistent with a performative society within which a desirable subject is envisaged as one who "accepts the necessity to work on the self in order to become something - however the something is less important than the process of working on the self, and perhaps the product is the self that works upon the self" (p. 308). Gibbons' analysis of the dominance of process oriented discourses in ece is relevant to current assessment commentary in New Zealand which, as was shown in the first part of this review, tends to emphasise the significance of ongoing, open-ended learning outcomes in ece.

Duhn (2006) also analysed the construction of the educated subject in ece. She took a specific focus on the construction of the child as learner via a discourse analysis of Te Whäriki. This analysis was conducted as part of a broader cartographical (see Braidotti, 2002, cited in Duhn, 2006, p. 5) project that mapped, over several centuries, some of the shifting constructions of the child as an "object of power relations" (p. 2), and childhood as an "effect of changes in political rationalities" (p. 10). Duhn approached Te Whäriki as a construction that was traversed by, and sustained by multiple and sometimes contradictory discourses, such as those of biculturalism and neoliberalism. 
Duhn's (2006) analysis of the latter neoliberal discourses is of particular relevance to this thesis and it is the focus of the comments that follow.

Te Whäriki was considered to be both an effect and technique of neoliberal rationalities of government. It was seen to enable a "cosmopolitan pedagogy" (Popkewitz, 2004, cited in Duhn, 2006, p. 18), which Duhn (2006) argued was constituted by the interconnected discourses of globalisation and neoliberalism. A cosmopolitan pedagogy, Duhn proposed, seeks to construct the ideal neoliberal enterprising, flexible, global/local subject, a subject who is able to "adapt with ease to changing working and living conditions - the spaces of the future" (p. 188). Duhn emphasised that this ideal subject requires both roots and wings (Beck, 2002, p.19, cited in Duhn, 2006, p. 187). According to Duhn (2006) this means that in contemporary neoliberal governmentalities the desired enterprising subjects, as "author[s] of [their] own economic biography" (p.187), should be mobile and flexible so that they can pursue opportunities as and where they arise. But, it is also desirable for the subjects of State/Nation to have a sense of belonging at the level of community, and some form of identification with a national identity so that they choose to contribute the fruits of their enterprising activities locally, and thus assist in the Nation's success within completive global economies.

Via an analysis of the Te Wharriki vision statement, principles, learning goals and outcomes, Duhn (2006) proposed that within this discursive thread the good or ideal child of Te Whäriki is the "future global subject" (p. 170). The construction of learning and learners identified in the curriculum was seen to constitute the child as a "lifelong learner' who continually recreates his or her self through being a problem solver" (Popkewitz, 2004, p. 189, cited in Duhn, 2006, p. 188). On this analysis Te Whäriki was seen to be a technology of government that affirmed, rather than challenged, existing dominant sociopolitical power relations.

Duhn's (2006) analysis, like Gibbons' (2007b) was not specifically about ece assessment in New Zealand. Yet, both works disturb and complicate the view that contemporary ece practice that is based on Te Whäriki, and which foregrounds openended learning-process outcomes, represents a challenge to the power relations that exist 
within many Western advanced liberal democracies (Duhn, 2006, p. 148; see also Peters, 2006; Rose, 1999).

\subsubsection{Participation and voice as techniques of self government}

Several scholars working with Foucault's ideas have undertaken research that has a specific focus on the educational discourses of participation and voice (Bragg, 2007; Masschelein \& Quaghebeur, 2005; Vandenbroeck \& Bouverne-De Bie, 2006). As with the Foucauldian work reviewed in the previous sections, these studies insert tensions into contemporary educational discourses that valorise practices that are in the service of active and agentic subjects of education, and which tend to promote participatory educational practices as a means of emancipating children "from dominant regimes of power" (Masschelein \& Quaghebeur, 2005, p. 51).

Within what was described as "a new pedagogical paradigm of participation" Masschelein and Quaghebeur (2005, p. 55) conducted an analysis of selected contemporary literature on participation that was published in the European Union. The material for analysis was drawn from "manuals, handbooks, or programmes that show how to participate, what it offers and why it is valuable" (p. 56). In their analysis they focused on what was said about participation as well as the "procedures, instruments and techniques" (p. 51) that were advocated to support participation.

Masschelein and Quaghebeur (2005) worked to identify how children were constructed within the participation literature, and more broadly, what truths about individuals were called upon in the construction of participation. Such analysis assisted the authors "to outline the particular behaviour and the kind of identity that are promoted, and that people are asked to assume, when invited, mobilised or interpellated to participate" (p. 56). They argued that participation functions as "an element in a particular mode of government or power" (p. 51) within which the self is invited to take up an ongoing relationship with the self based on principles of investment and transformation.

Bragg (2007) analysed the notion of voice through a discursive analysis of the Students as Researchers (SARS) project, which was one component of a teaching and learning research programme conducted in the United Kingdom between 2001 and 2003. 
The SARS initiative was focused on foregrounding student voices via an investigation of "issues that mattered to them in their educational experience" (p. 346). The analysis of the SARS project was conducted in the context of an increasing emphasis on the notion of student voice within many levels of education, as well as a largely celebratory and "relatively unquestioning" (Bragg, 2007, p. 344) reception to practices that were seen to enable voice.

Quotations from head teachers, principals and students who had participated in the project were analysed. The quotations were selected in order to "represent significant themes in the data that demanded interpretation, [and] to illustrate an argument that is intended to provoke and foster debate" (Bragg, 2007, p. 347). As in Masschelein and Quaghebeur's (2005) study, the analysis focused on what was said, as well as the particular practices involved in the project. Bragg (2007) argued that the notion of voice within the project operated in a mode of power that was neither coercive, sanctioning nor incentivising; rather, the register was seen to be one of moralisation, establishing "the active and responsible learner as a desirable role model by ascribing those qualities to students" (p. 353). Bragg proposed that participatory initiatives, such as the SARS project, actively shape what is voiced:

Student voice is not unmediated, but guided, facilitated, and supervised through specific techniques that delimit what can be said, and how speakers conceive of themselves — techniques for shaping subjectivities. (Bragg, 2007, p. 349)

\subsection{Contemporary educational discourses of participation and competence as ambiguous}

While Bragg (2007) notes that that the freedom offered by the SARS project "is not a sham" (p. 356), she argues that "it does take place within a specific disciplinary framework" (p. 356). Echoing the observations made by Hultqvist $(1998,2004)$ and Popkewitz (2003), she called for critical engagement with the potential norms and related exclusions that may be constructed by such participatory projects.

A range of commentators working with Foucauldian perspectives have also called for greater critical engagement with participatory pedagogical discourses (Gallagher, 2008; James, 2005; Moss, et al., 2005; Prout, 2003). Moss et al. (2005) take the position 
that it is impossible to be free of power, and Gallagher (2008) argues that Foucauldian ideas about power can provide an analytical lens that can highlight some of the ambiguities of contemporary participatory educational practices.

\subsection{CONCLUSION: Literature Review Parts One and Two}

The material considered in the second part of the review indicates, as was argued in the previous chapter, that from Foucauldian perspectives any given pedagogical discourses and their attendant practices such as observation and assessment can be viewed as technologies of governing. They can be analysed in terms of their practices of power and the self, and considered in terms of their effects, not least of which is the subject of education, primarily, but not exclusively, the child.

By considering Foucauldian analyses of developmental as well as more contemporary educational discourses of competence, participation and agency, this section of the review has shown that whether a pedagogical discourse emphasises (and constructs) a developing child or a competent, agentic and participatory learner, the discourses are taken to be interconnected with - and implicated in - the construction of particular possibilities and norms for subjectivity, as well as knowledge about what constitutes best practice in ece.

The assessment related literature that was reviewed in Part One suggests that contemporary ece assessment in New Zealand exemplifies discourses of participation and competence. Further, this literature suggests that contemporary ece assessment approaches, presented as other than past developmental forms, have on the whole been embraced in a "relatively unquestioning manner" (Bragg, 2007, p. 344), and promoted as being conducive to respectful, authentic and socially just practice. However, the more recent Foucauldian studies that have been considered in the second section of this review suggest that current discourses of participation, competence, agency and interactivity are informed by contemporary advanced or neoliberal governmentalities, which presume (and construct) active, participating, work-in-progress, self responsible and flexible subjects. While these can be considered laudable and desirable forms of self conduct and constitution, the links made with these qualities and neoliberal governmentalities and the 
requirements of a performative society (Gibbons, 2007b) are in my view cause for consideration.

To summarise, the Foucauldian material that has been reviewed unsettles the largely smooth interpretations and narratives about current ece assessment in Aotearoa, which promote learning-process focused, formative and interactive narrative assessments as being indicative of best practice. By undertaking an analysis of contemporary ece assessment that is informed by Foucault's ideas, this thesis can make a timely contribution to ece assessment scholarship in New Zealand, and to early childhood education debates more generally.

In this and the previous chapter I have established the context, rationale and theoretical framings for this thesis. I now turn, in the following Methods chapter, to a discussion about how I undertook a discursive analysis of contemporary ece assessment in New Zealand. 


\subsection{Introduction}

In this chapter I provide an account of how I analysed a range of texts concerned with contemporary ece assessment in New Zealand in order to address my research question: How is contemporary ece assessment constructed in New Zealand, and what is effected, or brought about, by this? The method for analysing the texts was developed with reference to the Foucauldian ideas discussed in the theory and literature review chapters, and also with reference to additional literature with a specific focus on methods. In line with the theoretical standpoints that I take in this thesis concerning assessment (see Chapter 2, particularly pp. 26-27), the selected assessment texts were approached as discourse data (Wetherell, Taylor, \& Yates, 2001a). That is, I understood the texts and the practices they referred to as discursive, as constituting (and being constituted by) various "truth-objects" (Graham, 2006, p. 7), knowledges, discourses and technologies of government.

\subsection{Discourse Data}

\subsubsection{Selection}

Six data items were analysed: a journal article, three book chapters, a master's thesis, and a Kei Tua o te Pae exemplars book. In the initial stages of this study I planned to select a variety of texts about contemporary ece assessment in New Zealand, including narrative assessment examples, in order to analyse assessment, as discourse, in terms of both what is said and done. I wanted to select texts that represented both scholarly and practitioner perspectives, that were presented in a range of contexts to a range of audiences, that reflected writing from the past decade, and texts that were fairly available. I also wanted to include texts that could be seen to have a significant influence and could therefore be 
considered authoritative, such as those written by key players in the development of contemporary assessment approaches.

I endeavoured to meet these selection criteria in order to work with a varied discourse data set. However, I found that the boundary between assessment related texts that reflected scholarly and practitioner perspectives was often blurred. Several of the chosen texts were co-authored by early childhood educators who may have also identified themselves as professional development facilitators. Similarly, the ece scholars and researchers may have also identified themselves as professional development providers. I have labelled two data items as practitioner texts because they take a particular focus on the perspectives of teachers regarding contemporary assessment and involve at least one author who was an ece teacher at the time of writing. (See section 4.2.3 for details).

In gathering specific examples of contemporary ece assessments I planned to draw a sample of assessments from across the whole Kei Tua o te Pae (Ministry of Education, 2004, 2007a, 2009a) series. However, once I began working with the scholarly and practitioner texts, several of which included examples of contemporary narrative assessments, I realised that there was a large amount of rich data to analyse and that a larger sample across the series was unrealistic. I therefore decided to be purposeful and highly selective in my choice of assessment examples from the Kei Tua o te Pae resource. I chose to focus specifically on examples from the exemplar book Children contributing to their own assessment (Ministry of Education, 2004, book 4). I further explain my rationale for focusing on this book in a later section of this chapter.

\subsubsection{Ethical considerations}

Due to the use of data that is available in the public domain I was not required to gain ethical approval for this study through the University protocols. Nonetheless, ethical issues have been of considerable concern, particularly in relation to the treatment and interpretation of writing by other individuals, some of which includes personal commentary on experiences and thoughts about contemporary ece assessment.

In undertaking this study I was aware, and also reminded (cautioned) by an ece academic on one occasion, that I was analysing data that was drawn from identifiable sources, within a small ece community. I was aware that the interpretations I made about the data, 
including the narrative assessment examples which were about and sometimes co-written by children, might not - in fact, probably would not - cohere with the intended representations and meanings of those who wrote the texts.

Returning to my comments made in the Introduction to this thesis, my interest was in analysing the discursive construction and possible effects of assessment as discourse. In taking up a Foucauldian discourse analytic, I was, and am not, interested in trying to trace the intentions of the techniques of assessment to individual intentionalities (Dean, 2010; Foucault, 1980b; Rose, 1999). My focus was to consider what might be effected by the relations of power that are brought into play by the current constructions of ece assessment. To assist this focus and to dis-embed the data from its authorial associations I labelled and numbered the texts, and in my analysis and discussions I use this code to refer to the data items. I describe the data items below. (See Appendix A for reference details of the texts that are being referred to).

\subsubsection{The data items}

Scholarly 1: A co-authored text written by a practitioner whose centre at the time was involved in the Early Childhood Education Learning and Assessment Exemplars project (see Chapter 3, p. 39) and a professional development facilitator. It was published in a New Zealand ece journal directed at a practitioner and researcher audience. It includes five narrative assessment examples with commentary.

Scholarly 2: A chapter in an international collection considering various research projects to do with listening to children regarding their experiences and perspectives on early childhood services. The editors are internationally distinguished early childhood scholars who are associated with childhood studies and post-structural perspectives on early childhood. The selected chapter, written by New Zealand early childhood scholars about narrative assessment in New Zealand includes approximately seven narrative assessment examples/excerpts, with commentary.

Scholarly 3: A chapter taken from a trans-Tasman collection focused on theorising aspects of ece practice. Each chapter is multi-authored by Australian and New Zealand 
ece scholars. The selected chapter is focused on sociocultural assessment and contains a section dedicated to contemporary practices in each country. The section on New Zealand ece assessment includes a series of approximately five narrative assessment excerpts and commentary, based on one child.

Practitioner 1: A chapter in a New Zealand published collection of scholarly papers concerned with Te Whäriki, its influence and potential ten years after the release of the draft curriculum document. It includes several international perspectives. The selected chapter is a multi-authored text, written by several ece scholars and a practitioner. Nine pages of the chapter are dedicated to the diary entries of the practitioner about her teaching team's engagement with contemporary narrative assessment approaches.

Practitioner 2: A master's thesis involving an ethnographic study documenting a teacher and her colleagues move towards contemporary forms of ece assessment in New Zealand. The thesis includes interview excerpts, narrative assessment examples, and extensive commentary.

Exemplars: This is, as noted, the Kei Tua o te Pae book Children contributing to their own assessment. The assessment examples and commentary were the primary focus of analysis. Much of the content in the introductory section replicates or closely maps that found in Scholarly 2 (see above).

\subsection{Developing a method and approach to analysis}

During the research proposal stage of this thesis, I began to develop my theoretical position with regards to assessment. I read a range of work that, broadly speaking, adopted or provided commentary on Foucauldian discourse analytical approaches. I became aware that some scholars are reluctant to outline specific analytical procedures for Foucauldian discourse work. For instance, Arribas-Ayllon and Walkerdine (2008) noted in their contribution to a qualitative research methods collection that in discussions about Foucauldian discourse analysis "it is customary to offer the disclaimer that there 
are no set rules or procedures for conducting Foucauldian-inspired analyses of discourse" (p. 91). Taking this position, they provided a number of "methodological signposts" (p. 98) rather than specific analytical steps, so as to avoid "delimiting a Foucauldian analytic to a set of formal principles" (p. 98). Graham (2006), discussing a discourse analysis undertaken as part of a doctoral study, noted the difficulties that analytical nonspecification can pose for new researchers attempting "to find coherent descriptions of how one might go about discourse analysis using Foucault” (p. 2). But, like ArribasAyllon and Walkerdine (2008), she also cautioned against an overly systematised approach.

As one of those new researchers referred to by Graham (2006), I was, as she had described, having difficulty identifying what to specifically do in order to analyse the selected discourse data. Therefore, I looked at work that focused explicitly on procedural considerations in relation to Foucauldian discourse work (Carabine, 2001; Parker, 1992; Willig, 2008a, 2008b). I drew on this work to map out a series of analytical steps (described later this chapter) based on the broad questions that I had posed for the research. I conducted a trial analysis using the steps on one of the selected texts. I found that these steps offered a way into the analysis, provided an opportunity to develop sensitivity to the material being considered, and helped me to make connections with the specific material and the ideas framing the study. However, I also found-as had been indicated by Arribas-Ayllon and Walkerdine (2008) as well as Graham (2006) that in following this process some of the theoretical insights that are afforded by Foucault's often interconnected and multifaceted ideas were not being prompted. For example, drawing exclusively on these analytical steps helped me to pull apart the text, but it did not help me make sense of what the text, as a discourse sample, was doing. In order to work with the methodological tensions indicated by Graham (2006), I adopted an approach to analysis that involved the use of set analytical moves, as well as more open analytical play (Wetherall, 2001a). In the next section I will detail what this involved.

\subsection{Analytical steps and procedures}

I conceptualised and approached the analysis in two phases in relation to my two-part research question. I will first present the steps I used to work on the texts, briefly explain 
the rationale behind the steps, and then describe the analytical processes that were used in working with the data. The key decisions that were made during the analysis of the discourse data will also be discussed.

Phase one: Discursive constructions: objects, knowledges, discourses

Key question: How is contemporary ece assessment constructed in New Zealand?

Key sub-questions:

- What is said about ece assessment and related elements of the discourse such as children and learning?

Analytical aims:

- To identify the key objects that constitute assessment discourse (Carabine, 2001; Parker, 1992; Willig, 2008a, 2008b).

- To describe how the key objects of the discourse, such as assessment, children, and learning are constructed (Carabine, 2001; Parker, 1992; Willig, 2008a, 2008b).

- To identify the knowledges that are drawn upon in constructing these objects (Carabine, 2001).

- To identify the related discourses that assessment draws upon in its construction (Carabine, 2001; Parker, 1992; Willig, 2008a, 2008b).

\section{Phase two: Effects: positioning, subjectivity}

Key question: What is effected, or brought about, by the construction of contemporary ece assessment in New Zealand?

Key sub questions:

- What truths and norms are constructed by assessment?

- What forms of subjectivity does assessment promote?

\section{Analytical aims:}

To consider the possibilities for action, thinking and experiencing that are mapped by the discursive constructions and truths produced by assessment discourse (Arribas-Ayllon \& 
Walkerdine, 2008; Besley \& Peters, 2007; Carabine, 2001; Parker, 1992; Willig, 2008a, 2008b).

Phase One analytical steps:

\section{1) Identify the objects of the discourse}

Here I sought to identify what things the texts were referring to (Parker, 1992), such as assessment, children, learning, teachers, and the future. This step is based on the idea that rather than referring to pre-existing truths or representing a move towards more accurately describing the reality of, for instance, children and learning, assessment discourse constructs and brings into visibility particular "truth-objects" (Graham, 2006 p. 7) and related ways of seeing and practicing (Foucault, 1980a).

\section{2) Identify how the key objects of the discourse are constructed}

Here I considered the things - objects - that the texts referred to and looked more closely at how these objects were being spoken of (Carabine, 2001). The rationale for this step was connected to that of the previous step. It similarly derives from the view of discourse as forming and constructing objects in particular ways. I sought to be sensitive to the argumentative structure of the texts by attending to the framing of the discursive objects and noticing what was said - and also, what was not being said — in relation to various objects (Carabine, 2001).

\section{3) Identify discourses and knowledges that inform the construction of discursive objects} Initially I conceived of this step as involving discrete parts, with the identification of knowledge and discourses being viewed as two distinct processes. However, as my understanding of the inseparability of knowledge and discourse developed, I approached this as one step. For example, Carabine (2001) suggests that one might think about "discourses... [as] ...historically variable ways of specifying knowledges and truths, whereby knowledges are socially constructed and produced by effects of power and spoken of in terms of 'truths"' (p. 275).

I sought to identify some of the discourses/knowledges that were being used to construct the various discursive objects that I had identified. I found Parker's (1992) 
comments particularly helpful. He argues that "discourses embed, entail, and presuppose other discourses .... [they] draw metaphors and institutional support from each other" (pp. 13-14). I noted for example that narrative assessments were being talked about in a range of ways, and these various ways of speaking evoked a range of other discourses.

\section{Outside the steps}

Parallel to these more explicit analytical steps was a process of intuitively responding to the texts. This involved taking a broad view, zooming-out and getting an overall sense of the discursive material, as well as zooming-in on stylistic features and argumentative framing that seemed significant. For instance, I was surprised by the rhetorical aspects and hyperbolic language and tone in parts of the texts, and the effect they had on me as a reader. Parker (1992) suggests that the discourse analyst might explore the "connotations, allusions and implications which the texts evoke ....through some sort of free association" (p. 7). Willig (2008b) similarly discusses the value of gaining an impression and an overall sense of what a text is doing.

\section{Analytical procedures}

The analysis during both phases was iterative and recursive (Braun \& Clarke 2006; Taylor, 2001b). The work was conducted interactively, particularly after the first and second steps. I applied steps 1 to 3 to all texts, excluding the Kei Tua o te Pae assessment examples. While my focus was initially on addressing the research questions identified for Phase One, I was also to some extent considering my questions as a whole, and noting my ideas about the possible effects of assessment.

In practical terms, I read each item a number of times. I made initial notes about my overall responses to each text using analytic memos (Johnson \& Christensen, 2008), and began to make tentative coding notes on each item itself. Each data item was then segmented into particularly meaningful analytic units (Johnson \& Christensen, 2008). This involved constructing a generously margined word-processed working document for each data item. The working documents contained key information and quotes taken from the items which were then organised under headings relating to key objects, such as children, learning, and other points of interest. 
Table 4.1 Theoretically informed analytical codes

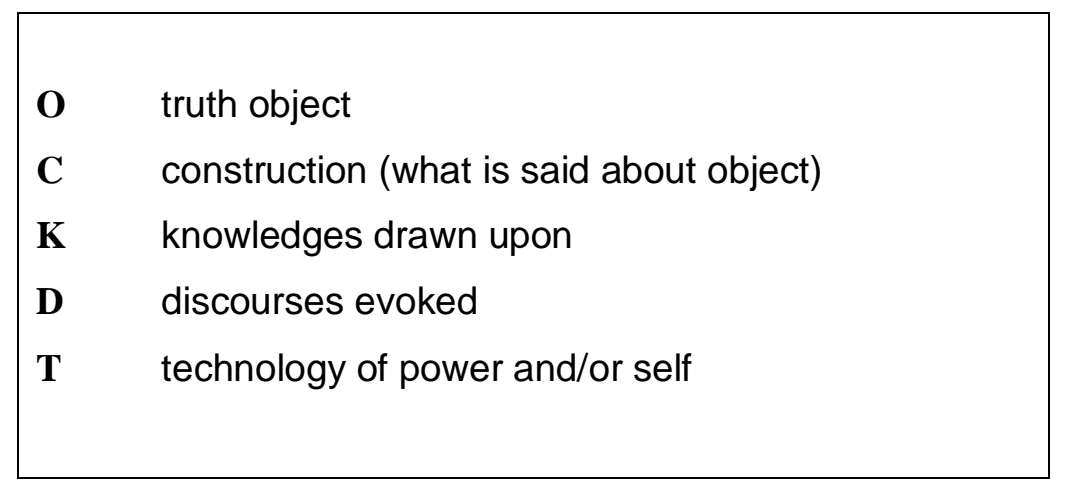

Each working document was then hand coded using a mixture of theoretically informed codes (see Table 4.1) that were developed prior to analysis, and also with reference to emerging inductive codes (Johnson \& Christensen, 2008). The use of inductive codes helped me to detail how the various objects, and assessment as a whole, were being constructed. For example, the code: $L \& M$ stood for language and metaphors and it was used to represent my understanding about the significance of the choice of words in describing a range of discursive objects within the texts. (See Appendix B for details of the working inductive codes that were established during analysis).

After working over the texts several times the inductive coding became more refined, and I began to build a sense of patterns that were present in the construction of assessment (Braun \& Clarke 2006). These patterns informed the initial production of themes regarding the construction of key discursive objects, and assessment overall. Borrowing from Braun and Clarke (2006), I defined a theme as representing "something important about the data in relation to the research question... some level of patterned response or meaning within the data set” (p. 82). Determining initial themes was not simply a matter of identifying the prevalence or recurrence of an idea, but involved my judgement about what was important (Braun \& Clarke 2006).

For Phase One (steps 1-3), I began to collate my analysis of each data item in order to consider the discursive construction of assessment, as it was indicted by the texts overall. However, as I had found during the trial analysis, I found that rather than helping to make sense of how assessment was constructed this process generated a range of siloed and disconnected analyses. I wondered if more extensive writing might help (Braun \& 
Clarke 2006). I tried at this point to write about the construction of assessment based on themes I had developed at that point (see Figure 4.1). But there were too many, and as my supervisor noted, this created a report on analysis that was sliced in too many ways.

\section{Figure 4.1 Early themes in the analysis of assessment discourse}

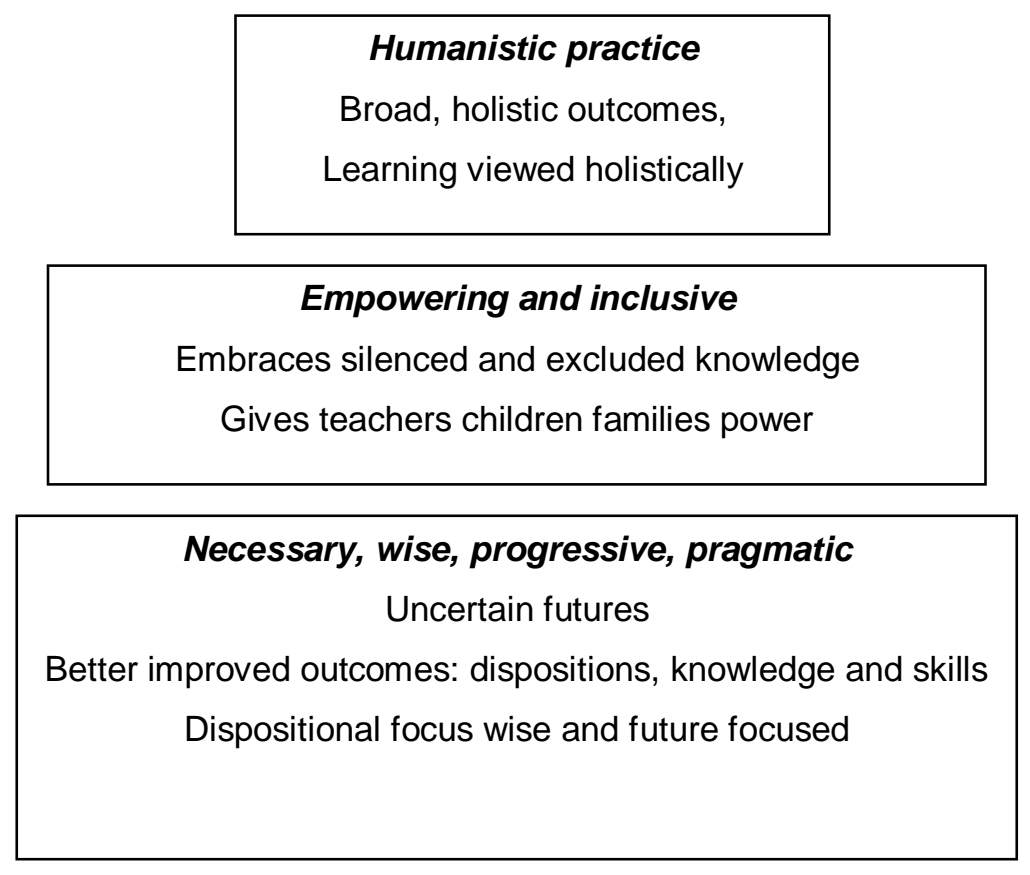

Headings in bold indicate an overall theme. The points below indicate the sub-themes that I attempted to write about.

In order to proceed with the analysis I needed to do a number of things. One was to consciously acknowledge that I was producing, and would subsequently be representing, a selection of analytical findings that were contingent and partial for a range of reasons. First, due to the theoretical and epistemological framings and the influence of my own positions in the study (Taylor, 2001b; Wetherall, 2001a, 2001b), and second, due to the richness of the discourse data, and the impossibility of presenting a full account of my interpretations (Taylor, 2001b).

By doing these things I was able to start to make decisions about which aspects of analysis I would pursue, and what aspects of analysis would not be spoken about in the final reporting (Taylor, 2001b). Moreover, I was able to continue with the analysis in a 
more creative, playful (Wetherall, 2001a) and I think, theoretically sensitive manner. By acknowledging that the analysis I was producing arose from interactions between the theoretical concepts I was working with, the research questions posed, the procedures established, and my responses to the data, I was able to more consciously view thinking - a space where all these elements interacted - as the key analytical tool in this study. Braun and Clarke's (2006) comments were helpful. They challenge the notion that analytic themes are discovered or emerge from data, and instead emphasise that they are constructed: "if themes 'reside' anywhere, they reside in our heads from thinking about our data and creating links as we understand them (Ely et al. 1997, pp. 205-206, cited in Braun \& Clarke, 2006, p. 80).

\section{Figure 4.2 Example of diagramming}

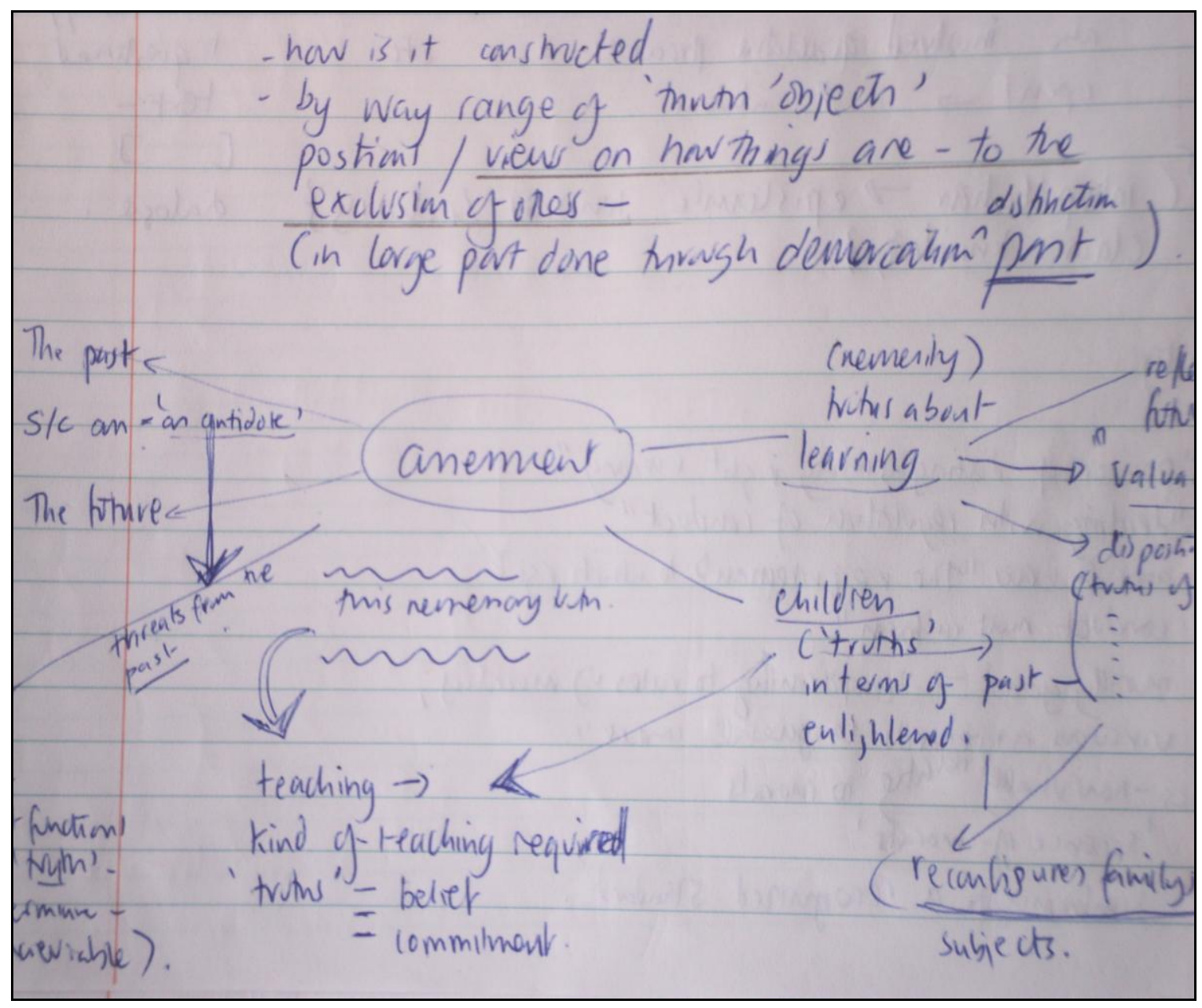


Considerable time was spent drafting and making links between various themes and important features of the data. Parker's (1992) free association, aided by various forms diagramming (Johnson \& Christensen, 2008) was particularly helpful in refining the analysis and working to shape the analysed data in a way that communicated aspects of the analysis that I found to be significant (see Figure 4.2). Further engagement with relevant scholarship informed by Foucault's thinking was also significant (e.g., Mozère, 2006; Simons \& Masschelein, 2006, 2008; Tuschling \& Engemann, 2006).

The idea of discursive strategies, described by Carabine (2001) as the various ways in which a discourse is "deployed....given meaning and force" (p. 288) was helpful at this point also. By describing two key discursive strategies with regards to assessment discourse, I was able to bring together some of the siloed analysis that I referred to earlier in this chapter. The notion of discursive strategies enabled me to think and write about the constructions, knowledges, discourses, as well as the rhetorical and narrative devices that I felt were working together to construct contemporary assessment.

During this refinement process I also tightened the focus for the second phase of analysis. After finding it a considerable challenge to address the first aspect of my research question within the space available, I could see that the questions posed for the second phase were too broad for the parameters of this thesis. In addressing the construction of assessment I found that the child-subject and related ideas such as children's voice and agency were significant within the analysed texts. In light of this finding during Phase One of the analysis I decided to focus particularly on the effects of assessment in terms of the subjectivities promoted for the child-subjects of ece. Accordingly, I focused specifically on the assessment examples in the Kei Tua o te Pae book Children contributing to their own assessment, in addition to the narrative assessment examples in the practitioner and scholarly texts. In the introduction to the Exemplar text it was noted that the assessments were chosen by the Ministry of Education (2004, book 4) to exemplify "how a number of centres in Aotearoa New Zealand are now finding ways to include children's voices in assessment" (p. 2).

At this point the notion of government, and in particular the telos or aims of government (Dean, 2010; Rose, 1999) became important for my research about the possible effects of assessment. I found Foucault's notion of government as "techniques 
and procedures for directing human behavior" (Foucault, 1997b, p. 81) to be a helpful focus for investigating subjectivities as effects of the relations of power at work within assessment discourse.

In approaching the second phase of analysis, I retained my overall question: What is effected, or brought about, by contemporary ece assessment? The sub-questions indicated earlier in this chapter (see p. 66) still informed the work. However, I foregrounded the notion of government in my analysis of the assessment examples and developed a range of analytical questions (detailed below) which were particularly informed by reading the work of Rose (1996, 1999), Dean (2010), and Besley and Peters (2007).

Key question: How are the child-subjects of ece governed, through what techniques of power and the self, and according to what truths and norms?

\section{Key sub-questions}

- What forms of self knowledge are promoted by the various techniques of government that make up assessment?

- According to what ethical principles are the child-subjects of ece assessment invited to constitute themselves?

In order to analyse the narrative assessment examples, I developed a range of additional analytical prompts, including:

- What ways of seeing, practicing and acting are normalised via contemporary assessment practices?

- What truths about the child-subjects of ece assessment do these ways of seeing, practicing and acting presuppose (construct) and promote?

- How is the field of possible actions and experiences being structured by contemporary assessment practices?

- According to what truths do the subjects of ece assessment make sense of their own and others actions, and what forms of conduct do these truths orient subjects towards?

- What forms of subjectivity are therefore invited, encouraged, promoted, and assumed by contemporary assessment practices? 
Additionally, several texts that I had consulted regarding conducting discourse analysis indicated the identification of subject positions as being an important analytical step in considering the effects of discourses (Parker, 1992; Willig, 2008a, 2008b). Subject positions might be thought of as discursive locations or spaces for self knowledge and the direction of conduct that are promoted for the subjects of various knowledges and practices (discourses). As discursive locations, they delimit the parameters for morally authorised or desired ways of being and acting, and for the perception of selves and others (Parker, 1992; Willig, 2008a, 2008b). For instance, Willig (2008b) suggests that "by constructing particular versions of the world, and by positioning subjects within them in particular ways, discourses limit what can be said and done (p. 117).

I had developed a range of prompts based on these ideas in the early stages of my analysis planning. They were still useful as a support for the analytical questions detailed above. I drew on ideas about positioning in my analysis of the assessment examples by thinking about the subject positions that were presumed and promoted in relation to the construction of particular truth-objects. For example, as I considered the related constructions of (a) learning as the ongoing development, application, and strengthening of dispositions for learning, and (b) the construction of children as learners, I asked questions along the lines of:

- What does a child (and teacher or parent) need to do in order to be recognised as an authorised/ desirable subject within this discursive sphere?

- What is expected of a child in relation to the construction of children as learners?

- What are the related subject positions that are promoted for others in their relationships with and responsibilities to children?

During the second phase of analysis I was more familiar with the Foucauldian concepts that informed this study. This meant - as was described earlier in this chapterthat in the analysis of narrative assessment examples, thinking and writing about the texts in response to prompting questions constituted the primary method of analysis. 


\subsection{Limitations}

The knowledge claims and propositions about the construction and effects of ece assessment that I make in this study are limited in a number of ways. As has been noted, the analysis is produced from within a particular epistemic and ontological position, which includes my understanding of Foucault's ideas as well as my personal interest and positioning in relation to ece assessment (see Chapter 1).

The claims I make are also limited due to the selective nature of the data sample and the constraints of space. Had I drawn on assessment examples from a different $\mathrm{Kei}$ Tua o te Pae book different aspects of discursive constructions and the related implications for subjectivity may have been brought into focus. Furthermore, the texts I analysed indicated that there are many discourses and forms of knowledge at work in the construction of assessment and they do not, for instance, indicate a total break from developmental discourses and assumptions. Despite this, as I will show in the following chapter, contemporary ece assessment in New Zealand is frequently framed as a new, post-developmental approach. Duhn's (2006) view that Te Whāriki is a text that sustains, and is sustained by, multiple discourses is very applicable to the assessment texts that I considered. However, it has not always been possible to indicate many of the complex and contradictory discursive trails that are suggested within the texts that were analysed.

I see the use of existing discourse data as being both a strength and limitation of this study. The literature review indicated that there is limited local scholarship applying Foucauldian ideas to various aspects of contemporary ece in New Zealand, and that to date there has not been a study that specifically focuses on contemporary ece assessment as discourse, in a Foucauldian sense. By working with existing discourse data, rather than gathering data via interviews, observations, and specific ece centre documents, I have afforded myself some time to work on theorising aspects of contemporary assessment in relation to some of Foucault's ideas. On the other hand, had the discourse data been collected at an ece centre, this thesis would have provided specific insights into the construction and effects of assessment at a particular site. However, the provocation for the thesis - namely, a concern that ideas related to contemporary narrative, sociocultural ece assessment approaches may be forming a dominant discursive regime - indicated the 
merits of a consideration of discourse data in a range of contexts, from a range of perspectives.

Additionally, the analysis of existing data also adds to what is identified as a limitation, or at least a debated area, regarding the claims Foucauldian discourse analysts can make about the relationship between discursive constructions, subject positions, and subjectivity (Wetherall, Taylor \& Yates 2001b; Willig, 2008b). Willig (2008b) suggests that in working to make links between these elements "we can do no more than to delineate what can be felt, thought and experienced from within various subject positions" (p. 122). She notes that describing what is felt, thought and experienced is another, highly debated, matter. Based on the selected data items I am able to make some conclusions about the norms for subjectivity and self government that are promoted by assessment, although I am mindful not to extend these claims to any definitive statements about the subjectivities for children and others as subjects of ece assessment. This is because I do not see subjectivity as being ultimately determined by the discursive resources that are available within particular relations of power. My comments about subjectivity are speculative: children, teachers and families may be taking up multiple positions within early childhood spaces and beyond.

Finally, by focusing only on contemporary assessment discourse this thesis is also limited because it represents a partial uptake of the analytical possibilities suggested by a Foucauldian engagement with discourse. A more genealogical approach with a focus on the shifting discursive constructions over time in relation to assessment and early childhood education would enable a greater emphasis on the historicity of the discursive constructions being investigated (Arribas-Ayllon \& Walkerdine, 2008).

\subsection{Evaluating this thesis}

There are a range of ideas and debates about how to address validity or trustworthiness in relation to qualitative research (e.g., Johnson \& Christensen, 2008) and discourse analytical approaches specifically (Taylor, 2001a, 2001b; Wetherall, 2001a). In taking up what can be broadly termed a post-structural position, I understand the knowledge that this study produces as being partial, contingent, and "perspectival" (Dean, 2010, p. 17; Wetherall, 2001a). Therefore notions of validity or trustworthiness in qualitative research 
that relate to the minimisation of, for example, the problem of researcher bias are not relevant to this thesis (e.g., Johnson \& Christensen, 2008, pp. 275-276), because they arise from positivist and post-positivist discourses (Taylor, 2001a, 2001b).

This is not to say that I see the work as being outside of evaluation. Researcher reflexivity, including in relation to the provision of a detailed account of analytical procedures and decisions, is taken to play a key role in supporting the evaluation of discourse analytic research (Taylor, 2001a, 2001b). In this chapter I have provided a detailed explanation of the methods of analysis and their rationale. In earlier chapters I have indicated the epistemic and ontological positions taken in this thesis, and I have clearly positioned myself, my interests, and explained my actions during the research process (Taylor, 2001b; Wetherall, 2001a). I have conducted and presented the work reflexively, with a recognition that the analysis presented is not neutral, but is itself "implicated in the work of reality-construction" (Atkinson, 1990, p. 6, cited in Taylor, 2001a, p. 319). I am therefore enabling readers to make their own judgments about the legitimacy and credibility of the work (Taylor, 2001b). Furthermore, I suggest, following Wetherall (2001a) that this research might also be evaluated according its connection with related scholarship, and also with reference to the extent to which it generates “novel perspectives" about ece assessment (p. 395).

\subsection{Conclusion}

Having outlined and discussed how — with what processes and rationales - I undertook a discursive analysis of current ece assessment in New Zealand, I turn in the following two chapters to a presentation and discussion of key aspects of my analysis. 


\section{Chapter 5: ANALYSIS \& DISCUSSION I}

\subsection{Introduction}

In this chapter I present my analysis of ece assessment with a primary focus on addressing the first aspect of my research question: How is contemporary ece assessment in New Zealand constructed? However - as befits Foucault's proposal that discursive truths and effects are in circular relation - this chapter does involve some comment on the regulatory and governing effects of ece assessment. This is because in analysing the selected assessment texts I found that what is a truth effect of assessment discourse, such as a teacher view or vision of children as competent learners, is simultaneously a technology of government, structuring and inviting particular ways of seeing and practicing in relation to children. Furthermore, while in Chapter 6 I build on the analysis and arguments presented here, focusing especially on the forms of subjectivity that are promoted and normalised for the child-subjects of ece, this does not occur in a strictly linear manner. Accordingly, these two chapters might be thought of, at least in part, as companion chapters.

Overall, I find that the various knowledges, discourses and discursive strategies that are at work in and across the analysed texts work to charge contemporary ece assessment approaches in New Zealand with a strong positive moral valence. In my analysis, formative, narrative, dispositionally focused, sociocultural assessment is constructed as a desirable, progressive, empowering, and necessary practice.

In presenting my analysis I first introduce two discursive strategies, which I see as playing a key role in constructing contemporary ece assessment in New Zealand as morally desirable and representative of "'right', 'best' and 'ethical"” practice (MacNaughton, 2005, p. 2). I then consider the discursive construction of key 
truth-objects within assessment discourse: learning, children, and the future, and I discuss how I see these truth-objects contributing to ece assessment's morally valorised status. Finally, in the closing section of this chapter, I will suggest that contemporary ece assessment, as discourse, lashes together a range of knowledges and discourses according to a superpragmatic way of thinking about the government of children (Hultqvist, 2004). I will argue that assessment draws together a variety of often disparate discourses to support the overall aim of assessment: the construction of learners who are tied to the ways of seeing and acting that are promoted by the dominant construction of learning within assessment discourse. This last section of the chapter serves as a bridge between this and the following analysis chapter.

\subsection{Discursive strategies}

\subsubsection{Contemporary ece assessment as other than past approaches}

Two key discursive strategies work in tandem to construct contemporary ece assessment in New Zealand as a morally desirable practice (see Carabine, 2001, Chapter 4, p. 72). One of these strategies is the construction of contemporary assessment in opposition to and as other than prior developmentally framed practices. There is a clear demarcation between past and present ece assessment approaches in all of the analysed texts. This finding is consistent with the review of primarily local assessment literature undertaken in Chapter 3, where it was noted that contemporary formative assessment approaches are presented as being other than and turning from modern, positivist, developmental psychologically informed child observations.

The oppositional construction of contemporary ece assessment is a strategy that is at work extensively across the texts. There are, for instance, frequent references to assessment in the context of developmentally appropriate practice (DAP) as being focused on pre-determined and fixed learning outcomes and aimed at measuring children's progress through "well-defined and demarcated ages and stages of development" (Scholarly 3, p. 54; Practitioner 1, 2). There is much talk of the universally envisaged path for learning (developmental) progress as being assessed via standardised (Practitioner 2; Scholarly 3) and normalising (Scholarly 2) observations. Past DAP informed assessment is spoken about as being rigid, a "technical task" (Scholarly 3, p. 
64) involving tools such as "the rather clinical and often decontextualised running records or anecdotal observations" (Practitioner 1, p. 193).

The learning outcomes of interest within a developmental framework are spoken about as being narrow, "externally conceived, predetermined" (Scholarly 3, p. 66; Scholarly 2; Practitioner 2) and focused on learning endpoints such as the mastery of a skill and resulting in the reduction of learning into "small measurable "chunks" (Scholarly 3, p. 54). Moreover, focusing on narrow learning endpoints such as the acquisition of knowledge, skills or a particular developmental level is seen to serve limited purposes other that to meet external accountability requirements (Practitioner 1, 2; Scholarly 1, 2, 3).

In contrast to these characterisations of previous developmentally framed assessments as being narrow, confining and decontextualised, contemporary narrative based ece assessment approaches in New Zealand are spoken of very positively. They tend to be characterised as empowering and as being subjectively animated by perspectival knowledge and aspirations, reflecting a reclaimation and celebration of the previously silenced "personal voice" (Scholarly 1, p. 10). They are spoken about as being informed by "a holistic conception of education - 'education in its broadest sense" (Scholarly 2, p. 129), and an understanding of "the uncertainty, diversity, complexity and ambiguity of learning" (Scholarly 3, p. 66).

Narrative assessments or "telling a story" (Practitioner 1, p. 193) are also spoken about as an assessment tool that is "less clinical" (Scholarly 1, p. 9) than earlier tools and able to reflect the complex, "active, dynamic...fluid" (Scholarly 3, p. 56), contextual, and ongoing nature of learning as a process of "participation and reciprocal relationships between people, places, and things" (Practitioner 1, p. 188; Practitioner 2; Scholarly 2, 3). Accordingly contemporary assessment is seen to be able to support "diverse learning pathways"(Ministry of Education, 2004, book 1, p. 3, cited in Scholarly 3, p. 53). Furthermore, via the interpretive qualities of the storied form, narrative assessments are seen to be able to illuminate the humanity all of those involved, because both the narrator and protagonist, such as the teacher and child, can be seen as "human beings" (Scholarly 3, p. 63) with "feelings" (Scholarly 1, p. 9). Narrative assessment is also spoken about as being able to meet accountability requirements. But it is emphasised that these can be met 
by attending to assessment as a formative, purposeful, future oriented activity that aims to engage children in ongoing learning (Practitioner 2; Scholarly 3).

This oppositional construction of contemporary ece assessment reflects a dividing, or binaristic, logic. To put it basely, the frequent oppositional construction of ece assessment presents past approaches as unenlightened (wrong, ignorant, unjust, inhumane, etc.) and the present as enlightened (right, just, respectful, etc.). Along with this dividing logic, past and present assessment practices are associated with widely valorised or negatively characterised discourses in education. This association with other discourses sometimes occurs explicitly, but also through the use of what I term discourse triggering words and phrases. I use this term to refer to the ways that discourses, evoke, embed, connect with and gain support from one another (see Parker, 1992, Chapter 4, pp. 67-68). The use of terms such as broad, holistic and narrow in the discourse examples above trigger, imply, and connect with other related educational discourses. In this case these words favorably position contemporary ece assessment by suggesting liberal, progressive and humanistic educational discourses that emphasise education as an intrinsic good, rather than serving extrinsic and primarily vocational and instrumental purposes (e.g., Jones et al., 1995).

The discourse samples in this section indicate that the construction of assessment as desirable is achieved in large part through the ongoing oppositional construction of past and present approaches across the texts. An association with morally desirable educational discourses also aids this construction. Through these discursive strategies, I contend that current ece assessment in New Zealand comes to occupy the space of desirable, enlightened, present and future, and past developmental assessments come to occupy the space of undesirable, unenlightened other. Indeed, in Scholarly 3 developmentally based assessment is referred to as "a much-loved old garment... [that] is long past its best, and ought to have been discarded long ago" (Broadfoot 2001, p. 109, cited p. 54). Whereas contemporary "innovative" (p. 67) ece assessment practices such as those exemplified in Kei Tua o te Pae are described as reflecting "twenty-first century views of knowledge and ways of knowing" (p. 51). 


\subsubsection{Contemporary ece assessment as a secular salvation practice}

Secular salvation narratives are also at work within this oppositional construction of contemporary ece assessment (Hultqvist, 2004; Pena, 2006; Popkewitz, 2003, 2004). I view ece assessment, by its selective critiquing of aspects of Enlightenment and modernist thinking as working to construct current ece assessment as a salvation practice (Popkewitz, 2003, p. 47). That is, a practice that can realise or support the achievement of a humanistic state of salvation, "a secular, earthly paradise" (Popkewitz, 2004, p. 192), a "sunny uplands of liberty and human rights" (Rose, 1999, p. 10).

Many of the things said about the past and present approaches to ece assessment in the oppostional examples above can be read as critiques of a dominant strand of modernist thinking, a strand that has been termed by Toulmin (1990, cited in Dahlberg \& Moss, 2005, p. 53) as scientific modernity. The statements made in the discourse data which emphaise current ece assessment as new and post-developmental link with criticisms of child development as a modern discipline that is part of, and affirms, the broader project of modernity (see Cannella, 1997, Chapter 3, p. 52). The statements evoke critiques of scientific modernity's valuing of "order and universal forms" (Dahlberg \& Moss, 2005, p. 54), its emphasis on objective, neutral reason as a key to the progress of humanity, and its related assumption of a universal, independent, goal setting, and rational subject (Dahlberg \& Moss, 2005; Dahlberg, et al., 2007).

By speaking about contemporary assessment approaches as valuing and recognising voice, subjectivity, contextuality and complexity, ece assessment also calls upon several other discourses. These ways of speaking about current assessment evoke what Toulmin (1990, cited in Dahlberg \& Moss, 2005, p. 53) identifies as an earlier Renaissance humanistic strand of modernist thinking, which is seen to have "celebrated singularity and difference, accepted uncertainty and [the] contingency of existence and adopted a sceptical tone" (Dahlberg \& Moss, 2005, p. 53). Simultaneously, the ways that contemporary assessment is spoken about link with some aspects of postmodern discourses in terms of the valuing of complexity, plurality, subjectivity and contextuality (Dahlberg \& Moss, 2005; Dahlberg, et al., 2007).

Yet despite these discursive associations with both postmodern and humanistic discourses - through the persistent juxtaposition of the positively characterised 
contemporary ece assessment approaches with those of the past - the current assessment discourse maintains and draws upon a central Enlightenment and modernist theme: the ongoing progress and improvement in the state of humanity. In particular the assessment discourse draws on the Enlightenment aspirations for the achievement of a humanistic heavens on earth (see Hultqvist, 2004, p. 159), a state of salvation for all humanity that might be achieved by slowing leaving "ignorance and prejudices behind... [and moving towards] a society where equality between human beings prevails irrespective of descent, race and gender" (Liedman, 1997, cited in Dahlberg et al.,2007, p. 20). For instance, in the discourse examples presented in the previous section I find that contemporary assessment is spoken abut in a way that points to an enlightened state where all children, as well as all families and teachers are respected as human beings. That is, as unique individuals whose learning potential is liberated from the narrow, universalising - and hence unjust - confines of past conceptions and constructs of learning.

The construction of contemporary ece assessment in New Zealand as a salvation practice is also achieved significantly through the frequent use of language and metaphors of transformation and enlightenment (e.g., new, shifted, transformative, deeper-level, vision, new experience, etc.; see Practioner 1, 2; Scholarly 1, 3). A number of the texts read in part like testimonials, with the writers reporting — testifying to - the goods that can be achieved when a teacher achieves a transformed "assessment consciousness" (Practitioner 1, p. 189, emphasis added, see also Practitioner 2, Scholarly 1). These texts construct images of learning communities that are enlivened and transformed by a recognition, appreciation and harnessing of children's and adults "intrinsic motivation" (Practitioner 1, p. 192, emphasis added); by perceptions of competence and capability regarding selves and others, and by strong, collaborative relationships that are focused on supporting deep learning (Practitioner 1; Scholarly 1). They speak about vitalised, passionate, emotionally engaged, motivated teachers who are transformed by the "power of narrative" (Practitioner 1, p. 193) and who experience a "sense of enthusiasm and joy about assessment and documentation" (Scholarly 1, p. 12, emphasis added). They depict teachers who are able to have an "up-close and personal relationship with the learner" via the use of narrative assessments (Scholarly 1, p. 12), and can who experience genuine pleasure and excitement in their relationships that are 
informed by their newfound respect and vision of children as learners and their knowledge of "the child at a much deeper level" (Practitioner 1, p. 198; Scholarly 1).

Contemporary ece assessment's status as a salvation practice is further reinforced by the use of salvation narratives within discussions about teacher thinking and their journeys of change towards what are constructed as new, enlightened and morally desirable assessment practices (Practitioner 1, 2; Scholarly 1). This is particularly evident in the Practitioner 2 text. This text largely reads as a saga of salvation that documents the journey, the challenges and the struggles that a teaching team has in achieving a shift towards new practices. In this text and others (Practitioner 1, 2; Scholarly 1) the key site of struggle for salvation is in teachers' own souls: their "intentions, values and beliefs" (Practitioner 2, p. 27).

In Practitioner 2 the extent to which the goods pointed to by assessment discourse can be realised are largely hinged upon whether teachers can come "to terms with change" (p. 26), be "committed to change" (p. 29) and adopt "new ways" (p. vii) in their thinking and practice of assessment. This is presented as involving the need to work on their "teacher identity" (p. 29) and "who you are as a teacher" (p. 68). This need is particularly pressing if teachers have well established, "old familiar [assessment] habits" (p. 88). A key challenge to achieving a transformed assessment vision that is presented in this text is the entrenchment (e.g., p. 88; see also Davis, 2006, Chapter 3, p. 43) of "DAP, criterion-referenced and summative assessment" (p. 88) approaches. Texts such as Kei tua o te Pae are presented as guiding texts, to assist teachers, pointing to the new ways, and professional development facilitators are positioned as guiding figures who, with correct vision, can support and "enable teachers to critically reflect on their practice and identify for themselves instances of reversion to the familiar" (p. 94).

The notion of right beliefs and the need to work on the self as teacher in order to facilitate the goods that assessment as a salvation practice can enable is evident in other texts too. For instance, in discussing the changes that are prompted by contemporary assessment approaches it is noted that this may involve "a change in belief or attitudes about children's competence and about the involvement of families in assessment" (Practitioner 1, p. 189). While elsewhere, the need (if one is to be a good teacher) to commit to the significance of supporting learning dispositions is clear: 
The Learning Stories framework presupposes that developing these [Te Whariki related] dispositions is at the heart of 'wise' practice... a position that teachers intending to use Learning Stories need to agree with. (Scholarly 1, p. 11)

These discourse examples suggest that assessment is constructed as a salvation practice that can support a humanistic heavens on earth in the form of learning communities that are populated by respected, motivated and joyful learners. However, to achieve such an enlightened state, teachers, as salvation agents, need to be vigilant. They need to ensure that they do not slip back into old, undesirable ways of thinking and being, and thus compromise the achievement of contemporary ece assessment's goods. A range of techniques of power and the self such as personal reflection, team discussion, and professional guidance seem to be important aids in achieving the correct form of postdevelopmental assessment vision (Practitioner 2). (See also Practitioner 1, and the discussion of a Professional Development programme focused on narrative assessment approaches. This programme can be read as a scheme that rewards teachers who adopt appropriate assessment related subject positions; see also Scholarly 1, Scholarly 3, pp. 58, $64)$.

\subsection{Key discursive truth-objects}

The twin discursive strategies that I have suggested construct contemporary ece assessment in New Zealand as a desirable, morally valorised, secular salvation practice are also at work in the construction of key discursive truth-objects within the discourse, a consideration of which I turn to now.

\subsubsection{Learning: the ongoing process of being and becoming a learner}

There are traces of various discourses of learning within the texts that were analysed, including the critiqued developmentally informed constructions. However the dominant construction is of learning as the ongoing process of being and becoming a learner. This construction of learning plays a vital role in the overall position of current assessment methods as morally desirable. Many of the things said about learning in relation to this 
construction also strongly contribute to the construction of ece assessment a salvation practice.

Much of what is said about the vision of learning that underpins ece assessment is suggestive of a secular humanistic state of salvation that is particularly underpinned by values of diversity and social justice. For example, the notion of learning as the ongoing process of developing increasingly competent participation repertoires that emerge in specific social and cultural contexts is emphasised across the texts. Learning is spoken about as a situated, ongoing, process of participation, interactions and engagement in reciprocal relationships with people, places and things (Practitioner 1, 2; Scholarly 2, 3). In one text, for instance, it is noted that a sociocultural perspective views learning as an "active and dynamic process of changing participation in valued community activities that lead to this accomplishment" (Scholarly 3, p. 56). It is emphasised that learning as participation enables engagement in community activities in which participants have "a significant personal investment" (Greeno et al., 1996, p. 26, cited in Scholarly 2, p. 138), and that dispositional assessments focus on learning in the context of "personally significant experiences and relationships" (Scholarly 3, p. 55). Furthermore, contemporary assessment, in taking up a narrative format is spoken about with reference to the universality of 'the story': "regardless of...[their]...cultural or other group affiliations" all people share the common experience of leading "storied lives" (Practitioner 1, p. 193).

Statements such as these particularly evoke discourses of education for social justice (see Chapter 3, pp. 45-46). By speaking about community and personally valued activities and emphasising that dispositions for learning can develop in a range of contexts there is a sense that narrative, sociocultural assessment-by focusing on and valuing all interactions as learning - represents a solution to the often critiqued modern Western universalist child development discourses. Where learning is constructed flexibly, as participation, there is the sense that all children, all families and all activities, forms of participation and interaction can potentially provide learning possibilities and opportunities (Practitioner 1, Scholarly 1, 3; see also Tuschling \& Engemann, 2006).

Such a construction of learning seems to shatter what is widely described as the limiting developmental or DAP based constructions of learning that were (and are) seen 
to silence the voices and knowledges of those who do not have Western middle-class cultural capital (see Chapter 3, p. 32). This flexible construction of learning would seem to enable all members of an ece community to value their own activities and practices as learning, to determine how their actions and social practices will be narrated as learning, and, furthermore, to be empowered individuals-in-communities who can direct and shape their own learning pathways according to what they define as "valued learning" (Practitioner 1, p. 192).

However, despite such references to discourses of social justice and connections with humanistic and postmodern discourses and their valuing of difference and diversity, a consideration of the things that are said about what it means to develop and progress as a learner problematises this construction of assessment as a practice that is underpinned by such values. It seems to me that it is a very particular learner and form of learning that assessment discourse both presumes and works to construct as truth (Dean, 2010).

For instance, it is noted in one text that while progress in learning is not conceptualised as the achievement of pre-determined learning outcomes, contemporary ece assessment in New Zealand still maintains an aspiration to support learning progress, and it is still informed by ideas about what it means to be "a 'better' learner" (Scholarly 2, p. 135). Learning progress is to do with the learner becoming an increasingly competent participant, developing and strengthening their inclination and ability to draw on various participation repertoires or dispositions and to apply these in a range of settings and activities, with increasing flexibility and complexity (Practitioner 2; Scholarly 2). In addition to the key dispositions for learning that are described in relation to Te Whāriki (see Table 3.1), a number of other dispositions or learning attitudes (Scholarly 3) are referred to. These include "motivation; a capacity for respect and tolerance; an ability to collaborate with others; an inclination for risk-taking, inquiry and problem-solving" (Scholarly 3, p. 55) as well as dispositions of "responsibility or control and critique" (Scholarly 2, p. 147). The examples of these latter dispostitions of critique that are given in the Scholarly 2 text are to do with (a) a child's observation and comment about the unfairness of the inconsistent rules for letter formation during hand writing lessons, and (b) a child suggesting an alternative ending to a story that was being read with his teacher. 
Progress in learning is also spoken about in terms of a transference of power, a shift in the balance of power towards the child as learner (Practitioner 1; Scholarly 2). In these treatments the progressing, competent, confident learner is spoken about as having an increased inclination and ability to "steer their own course, to set their own goals, to assess their own achievements, and to take some of the responsibility for learning" (Scholarly 2, p. 140). They are described as becoming "more adept at participating in distributed systems, increasingly able to recognise, respect, manage, develop and transform networks of support" (Scholarly 2, p. 138). Taken together, the Scholarly and Practitioner texts work to construct the progressing learner as a subject who is increasingly motivated, responsible for and engaged in their ongoing learning.

In view of this conceptualisation of the learner and learning progress, it becomes unclear on what basis contemporary ece has a status as a practice that is underpinned by values of plurality and diversity. These discourse samples suggest that ece assessment envisages the progressing learner as a particular type of agent with particular capacities (Dean, 2010). A DAP based emphasis on the developing child who in an optimal playbased environment can develop normally may be less emphasised in these constructions of learning (see Chapter 3, p. 52). Nonetheless, a universality of desired outcomes for children seems to be work in contemporary assessment discourse. Within a DAP context the aspiration was for optimal, normal development via universally conceived pathways, whereas in current ece assessment discourse the emphasis is on diverse learning pathways towards one desired outcome. The excerpts above suggest that this singular and universally applicable outcome is the establishment of the child-subject as a self directing, self motivating, and goal setting agent. A consideration of discussions about images and visions of the child in the discourse data further supports this analytical claim.

\subsubsection{The child as a competent, confident learner with voice}

The construction of assessment as a morally desirable practice rests on the establishment of interrelated truths about learning and children, both of which are, in my analysis, very particular constructions. In the assessment texts children are often spoken about as being empowered by contemporary assessment practices. This status of being empowered rests 
on the establishment of children as competent, confident learners as an authoritative truth or a morally desirable way of perceiving children. The idea of the image or view of the child is present in most of the texts considered and the related notion of constructs of childhood has been circulating in ece discourses more broadly for some time (e.g., Dalhberg et al., 1999, 2007; Practitioner 2; Scholarly 1, 2, 3). However, it seems that despite this the child as competent learner counts as a true proposition within the discourse (Foucault, 1980a).

For instance, in Scholarly 2, a very circuitous text, it is proposed that the purpose of assessment in the context of Te Whäriki is "to notice, recognise and respond to competent and confident learners and communicators" (pp. 129-130). It is emphasised that the child of Te Wharriki inspired assessment is taken to be competent and confident in the present, and that this is the focus for the future too. In this text it is also argued that where "the "educational agenda" (e.g., pp.130, 132) starts with the view of the child as competent, and is not focused on pre-defined, pre-set educational agendas, then "really listening to children" (pp. 129, 132, emphasis added), hearing their voices, and going beyond listening by letting what is heard "make a difference" might be possible (p. 143). Furthermore, it is stated that "the teacher who listens carefully to children's voices will have a particular image of children and of learners" (p. 133). Namely, the "view of the person" (p. 139) articulated by Te Whäriki: the child as a competent, confident learner and communicator.

Such statements have disciplinary and normalising effects. They work to regulate what is acceptable for teachers to see, think and say about children. Other texts perform this regulatory work too. For instance, traditional observational techniques are spoken about as tending to "focus on the child alone, as if he/she were an object operating in a contextual vacuum" (Scholarly 1, p. 12, emphasis added). The related normative child development constructs are described as promoting a view of the child as powerless and needy (Scholarly 1,3). On the other hand, contemporary narrative assessments, via multi authored accounts are spoken of as enabling multiple perspectives to be seen and heard, including the voice of the child who is a competent learner and social actor with a right to be heard (Scholarly 2, pp. 142-143). 
As with the ways of speaking about assessment in general, and learning in particular, these sorts of things that are said about children evoke - and in the case of Scholarly 2 explicitly link with-discourses of both children's rights and social justice (see Chapter 3, pp. 43-46). This discursive linking works to position a very specific way of thinking about, seeing and practicing with children as being "in the true" (Foucault, 1972, p. 224). The use of the term the child's voice in several of the texts particularly exemplifies this positioning (Scholarly 2, Practitioner, 2). Interestingly there is no definition of voice given in the texts considered. Voice seems to function as a type of ontological shorthand, standing for the truth of the competent, agentic, unique, perspective-having learner. It seems that voice is taken to be a self evident, nondiscursive correlate of the truth of children as learners and of learning as the ongoing action of strengthening this truth. This analytical point connects with White's (2009) view that the child's voice within New Zealand's authoritative assessment discourse is assumed to be, and treated as, an unproblematic and uncontentious "retrievable phenomenon" (p. 3).

As a salvation practice, contemporary ece assessment in New Zealand can be read as indicating progress and improvement in supporting children's rights and liberty. These rights are to be met via a recognition and enablement of children's agency, competence and their "essential subjective will" (Rose, 1999, p. 1). According to assessment discourse it seems that this will is intrinsically motivated towards behaving as a learner. But, as I will continue to argue in the next chapter, the competent, confident learner with voice is not prior to practices of power (Foucault, 1980b). The child's voice, and the subjective will and perspective that is expressed, heard, recognised and registered is articulated within particular discursive economies (Foucault, 1980a). Really listening to

children, as it is presented within ece assessment discourse, assumes that children have an essential learning desire and an innate inclination towards conducting themselves as learners (Fendler, 1998, 2001; see also Duhn, 2006, pp.192-193).

\subsubsection{The future as changing and uncertain}

The desirability, and indeed the necessity of contemporary ece assessment approaches in New Zealand early childhood spaces is also constructed with explicit and implied 
references to discourses of globalisation, knowledge economies and their concomitant educational discourses of lifelong learning (Scholarly 3, p. 55; see also Duhn, 2006; Maharey, 2006, Edwards, 2004). In several texts the future is spoken about as unknown, but certainly characterised by change and uncertainty: "tomorrow's world is much less certain than that of the past" (Scholarly 3, p. 53); "we have no idea what environments and contexts the current generation of children will meet in the future..." (Scholarly 2, p. 139); "we can no longer rely on knowledge and skills to remain constant over a lifetime" (Scholarly 1, p. 11).

A focus on supporting learning dispositions and positive learning inclinations and attitudes, aiming for the establishment of children's identities as learners and supporting them to "to feel comfortable as learners for the rest of their lives" (Scholarly 1, p. 11) is positioned as a responsible response to the certainty of change: "The type of knowledge - and therefore assessment — needed for the complexity of tomorrow's world is much less certain and more amorphous than that of the past" (Scholarly 3, p. 53). The need to focus on learning to learn in order to prepare children for the certainty of changing futures is supported with reference to the perspectives of those in education, business as well as teachers and parents (Scholarly 3). In Scholarly 3 it is stated that:

Now it is attitudes and dispositions that many in both business and education see as the important prerequisites for effective participation in a diverse and changing world. Ask any group of parents or teachers what attributes the children of today will need as adults to live socially responsible and fulfilling lives and the answers will be similar. They are likely to include: motivation, a capacity for respect and tolerance; an ability to collaborate with others; an inclination for risk-taking, inquiry and problem solving. (Scholarly 3, p. 55)

By focusing on learning attitudes contemporary-innovative-ece assessment can work to ensure that children will be fit for the future. Or - to draw on related contemporary educational discourses that speak of the education system in New Zealand as a whole - it can ensure that children are "set up for lifelong learning" (Maharey, 2006) and supported to become "creative, energetic and enterprising" lifelong learners and active citizens in 
the twenty first century (Ministry of Education, 2007b, p. 8; see also Ministry of Education 2010).

In these future-oriented treatments the state of salvation that contemporary ece assessment can realise becomes quite concrete. The enlightened state or future space of liberty and human rights that is evoked via the emphasis on fast and endlessly changing futures is a learning society (e.g., Simons \& Masschelein, 2006), or in New Zealand terminology, a knowledge society (e.g., Duhn, 2006; Gilbert, 2005; Maharey, 2006). Learning societies are to be populated by motivated, flexible individuals and communities who are lifelong learners, active and engaged in pursing and constructing their own ongoing learning opportunities (e.g., Edwards, 2004; Peters, 2006; Simons \& Masschelein, 2006) in competitive knowledge economies (e.g., Hope \& Stephenson, 2005), where the knowledge that is required to successfully participate and contribute keeps changing (Scholarly 3). As Duhn (2006, see Chapter 3, pp. 55-56) has noted, Te Whāriki explicitly positions children as lifelong learners. She argues that this positioning reflects aspirations for the construction of ideal, future global subjects within the twin discourses of neoliberalism(s) and globalisation. Ece assessment practices that focus on constructing flexible, ongoing learners and communities of learners are clearly implicated in the production of subjects for future learning/ knowledge societies.

The status of ece assessment as practice that sustains and supports pluralism, multiple knowledges, perspectives, and therefore by extension multiple visions of the good life (Mouffe, 2000) is ambiguous in these future-looking treatments. The links between discourses of lifelong learning, the learning society and advanced liberal rationalities of government have been made (e.g., Duhn, 2006; Peters, 2006; Simons, 2006; Simons \& Masschelein, 2006). Indeed, the subjects constituted within such discourses appear to be one and the same: both promote an ideal subject who governs and directs themselves according entrepreneurial and enterprise values, adopting an ethos of investment to their own self-constitution and government, seeking opportunities to increase their human capital (their ability and desire to perform) by moving in and out of networks as and when opportunities arise (Duhn, 2006; Edwards, 2004; Masschelein \& Quaghebeur, 2005; Peters, 2001, 2006; Simons, 2006; Simons \& Masschelein, 2006; Tuschling \& Engemann, 2006). Within such regimes of government it is unclear where- 
beyond the rhetoric of endless life-choices, pathways and (learning) opportunitiespluralism might be cited (Rose, 1999; Tuschling \& Engemann, 2006).

\subsection{Contemporary ece assessment: a superpragmatic amalgam of knowledge and discourses}

Contemporary ece assessment is constructed with reference to a range of discourses, many of which are contradictory, disparate and in tension. This has been indicated by the analysis presented thus far in this chapter, but there is more to say about this feature of assessment's construction. As I worked with the texts I was intrigued by the heterogeneous mix of knowledges and discourses that were drawn upon to construct contemporary ece assessment as a morally desirable practice. I was particularly puzzled by the pulling together of discursive references that emphasised the objective, universally knowable world, and those which valorised and emphasised subjective experience, specificity, and plurality.

For instance, in one text the Learning Stories assessment approach is described as being founded on "a robust lineage of both theory and research" (Scholarly 1, p. 8). This assessment approached is also described as being underpinned by a focus on, and validation of, the "personal voice" (Scholarly 1, p. 10). Thus, in speaking about current ece assessment, scientific modernist/positivist discourses as well as interpretive paradigms are being simultaneously evoked. Similarly, a dispositional focus for ece assessment outcomes is discussed with reference to an insufficient research base to warrant a focus on knowledge and skills as primary learning outcomes in ece (Practitioner 2). A focus on dispositions as outcomes is also justified with reference to an increased awareness of the importance of affective aspects of learning that has been brought about by the insights from research about motivation (Scholarly 1, p. 11; Scholarly 2, p. 140).

I came to see the multiple discursive elements that make up ece assessment as being lashed together within assessment discourse according to a superpragmatic (Hultqvist, 2004) rationality of government (Dean, 2010; Rose, 1999). For Hultqvist (2004) superpragmatism refers to a form of reasoning about government where "anything might be related to anything as long as it increases resources and wealth" (p. 173). He 
uses the term to particularly refer to reasoning about the government of children through various discourses and forms of knowledge where "anything that can be used to facilitate and mobilize the child's competencies and capacities is brought to use" (pp. 171-172). In the context of this analysis of ece assessment I use to superpragmatism to refer to a rationality of governing where anything might be related to anything as long as it optimises the desired outcomes and increases wealth or recourses.

The connective thread within the varied discourses and knowledges that make up ece assessment is that they are all brought to work to support an overall aim of contemporary ece assessment. This is, in my analysis, the tying of the subjects of ece, particularly children, to the identity of themselves as learners and to the repertoire of actions, ways of seeing and interpreting experience that are dominantly constructed as learning within the discourse (Foucault, 1982; see also Mozère, 2006). The wealth or resource that is being optimised by contemporary assessment is children's identification, desire and capacity to be and to act as learners (Duhn, 2006; Fendler, 1998, 2001). This resource is cited within — or rather, constructs in particular ways — children's psychological interiors, their souls. (Foucault, 1995; Rose, 1996).

\section{5 Conclusion}

In this chapter I have presented and discussed my discourse analysis of contemporary ece assessment in New Zealand, with a particular focus on addressing its construction. I have argued that contemporary assessment is constructed as a morally desirable practice. I have discussed some of the key elements that constitute ece assessment: truth-objects, various forms of knowledge and discourse, and suggested that these elements are given force or mobilised via two interconnected discursive strategies.

I have worked to show that these strategies and their related discursive associations and evocations work to form a mutually reinforcing system, a discursive loop. Within this loop, this regime of truth, contemporary ece assessment practice and the ideas that it is based upon are in the true (Foucault, 1972), and taken to be indicative of “"right', 'best' and 'ethical"' practice (MacNaughton, 2005, p. 2). I have proposed that a large part of the morally valorised position for contemporary ece assessment is to do with the extensive discursive associations that work to construct ece assessment as a practice 
that is supportive of and based on values of pluralism, diversity, social justice and children's rights. However, by analysing several key discursive truth-objects: the child, learning and the future I have argued that the basis for current assessment's status as a practice supported by such values, and as a practice that turns from or rejects the normalising functions of past ece assessment approaches, is unclear. By considering what is said about these three truth-objects I have argued that ece assessment in Aotearoa is underpinned by universalising assumptions about — and aspirations for - the subjects of ece. I have also suggested that the heavens on earth, the future learning society that these subjects are being prepared for is based on advanced liberal assumptions about how to achieve, as Rose (1999) has put it, the good of "the collective body" (p. 6).

My analysis of ece assessment resonates with Duhn's (2006, see Chapter 3, pp. 55-56) analysis of Te Whāriki as a technology of government. My finding that ece assessment envisages leaning progress as being to do with the enhancement of children's self-steering capacities and learning desires suggests that current ece assessment approaches, as with the curriculum they support to enact, at least in part, work to establish and are established by visions of the ideal, self responsible, opportunity seeking subject of neoliberal governmentalities.

Having identified and considered key aspects of current ece assessment's construction, I turn in the next chapter to a focus on the implications of assessment for the subjectivities of the child-subjects of ece. I build on the argument and analysis presented in this chapter via specific attention to the techniques of ece assessment. In doing so I elaborate on my argument that ece assessment works to install a highly normalising regime of government. 


\section{Chapter 6: ANALYSIS \& DISCUSSION II}

The end of good government is the correct disposition of things — even when these things have to be invented so as to be well governed. (Rabinow, 1984, p. 21).

\subsection{Introduction}

In this chapter I specifically address the second part of my research question: What is effected, or brought about, by the construction of contemporary ece assessment in New Zealand? I focus on the effects of assessment in terms of the forms of subjectivity that are promoted for children. In the previous chapter I argued that the child and learning were interconnected and key discursive truth-objects. I also suggested that the overall aim of contemporary ece assessment discourse was to produce the child-subject as a competent, confident learner. In this chapter I look at the techniques of government that simultaneously serve and work to construct this desired child-subject as learner. My analytical lens is particularly focused by Foucault's notion of government as the conduct of conduct, as "techniques and procedures for directing human behaviour" (Foucault, 1997b, p. 81).

The analysis presented in this chapter builds on that presented in the previous chapter, but it draws especially on the discourse data provided by the narrative assessment examples presented in the Scholarly texts and the Exemplar text, including the commentary to these exemplars written by the Ministry of Education (see Chapter 4, p. 63 for data set details). My focus is on discussing the key techniques that govern and construct the child as a particular type of subject. However, I have found that ece assessment governs and directs the conduct of all the subjects involved in assessment and that the government of various subjects is interconnected. In the previous chapter I 
pointed to the regulatory effects of assessment for teachers in terms of the governing of their beliefs, vision and practice. Here too, I will make passing reference to the government of teachers and whānau where there is relevant data. However, space does not allow a fuller discussion of how governing works in various ways for the multiple subjects of ece.

In presenting my analysis I first consider the dominant construction of learning that was presented Chapter 5, and focus on its function as a normalising technique of government. This discussion leads to a consideration of narrative assessments and the related technologies of the child's voice and children's learning portfolios or profiles. I continue the denaturalisation and problematisation work that was begun in the previous chapter through this analysis and discussion about the key technologies of power and the self that are at work in ece assessment discourse.

\subsection{Learning and narrative assessment as technologies of government}

As a technical and discursive activity government involves the application of a range of techniques that — in addition to shaping conduct — are integral to making up both the spaces to be governed as well a knowledge of the entities or elements that are to be governed (Dean, 2010; Rose, 1999). Rose (1999) argues that "in any concrete situation, it appears as if practices of governing are determined by the nature of those who they govern: their character, passions, motivations, wills and interests. But the reverse is the case" (p. 40). I take this position in my analysis of ece assessment in New Zealand. That is, I argue that the practices of government that make up assessment are presented as reflecting and being determined by the truth of children in ece-such as the truth of their identity as learners, and their related desire to direct and reflect on their actions as learning. However, like Rose (1999), I propose that it is the practices of ece assessment that inscribe these particular truths, motivations and wills onto the interiors of children. As I stated in Chapter 2, I view assessment as a productive technology that works to construct particular subjects of government. 


\subsubsection{Learning as a normalising technology}

Dean (2010) notes that government, as the conduct of conduct, is an "intensely moral activity" (p. 19). It involves the direction of selves and others with reference to "particular sets of norms" (Dean, 2010, p. 18) for conduct. These sets of norms can provide an evaluative framework according to which behaviour can be judged, worked on and shaped accordingly. Similarly, Rose (1996) refers to Foucault's understanding of ethics as the "means by which individuals come to construe, decipher, act upon themselves in relation to the true and false, the permitted and the forbidden, the desirable and the undesirable" (p. 153).

The analysis of contemporary ece assessment's construction that was presented in Chapter 5 indicated that the notion of the norm and normative judgments were clearly designated and associated with undesirable and unenlightened past forms of developmental assessments. Nonetheless, I see the norm "what ...[is] normal or not, correct or not, in terms of what one must do or not do" (Foucault, 2000, p. 59), as now being active and animated by the discursive constructions of the child as competent, confident learner and learning as the ongoing action and development of learning dispositions or participation repertoires. The previous chapter indicated that due to contemporary ece assessment's oppositional construction, these discursive truth-objects are not framed or presented as normative concepts within current assessment discourse. However, in my analysis these interrelated constructs provide a normative framework of understanding that expresses a very specific position about "what constitutes [the] good, virtuous, appropriate, responsible conduct of individuals and collectives" (Dean, 2010, p. 19).

For instance, terms in the discourse data such as learning opportunities, learning possibilities, learning experiences and learning pathways function as normative moral injunctions. They encourage those to whom the terms are applied-most notably children - to mobilise their affects and passions (Rose, 1996) according to a perception of events as learning opportunities (Tuschling \& Engemann, 2006), and to conduct themselves accordingly. That is, to act as learners - where learning is a performance of behaviors related to learning dispositions - and to engage themselves in "a cumulative sequence of ever-increasing engagement to learning" (Practitioner 2, p. 5). 
The dominant construction of learning as the ongoing action and development of learning dispositions positions all subjects of ece as learners. As I argued in the previous chapter, the connections with discourses of postmodernism, humanistic modernity, and concepts of plurality and difference suggest that ece assessment can bring about spaces that encourage multiple subject positions and possibilities for subjectivity. However, I have not found indications in the discourse data - either in the form of the Scholarly and Practitioner texts that were discussed in the previous chapter, or in the assessment examples that will be considered in this chapter-that this is the case.

For example, in a narrative assessment written by a teacher at an ece centre, a baby who has been moving around a room by pulling himself along on the floor is described as having "his own personal agenda" and being "self-motivated to be 'on the move,” (Scholarly 1, p. 9). Elsewhere, a toddler who wants to take off her own jersey/jumper and who states "no" in response to her teacher beginning to take the jumper off, is described in an assessment by that teacher as having "gutsy persistence" and, according to the authors of the text, demonstrating an "emerging ability to be responsible for her own well-being” (Scholarly 1, p. 12).

In assessments such as those indicated above, the performative aspects of learning as the ongoing action and development of learning dispositions is very evident. I found this to be the case in most of the assessments within my data sample. The learner-inaction is in the foreground. By this I mean that the forms of intentionality that relate to notions of progress in learning (see Chapter 5, pp. 87-88) such as setting goals, being motivated, and being engaged and responsible for learning are applied (inscribed) to the actions of children. They also provide key concepts for the construction of many of the learning narratives, as well as the commentary in the assessments in the Scholarly and Exemplar texts.

Because of this focus on the learner-in-the-action-developing-learning dispositions - and the ascribing of intentionalities related to this construct - a normalising framework of desirable forms of conduct is brought into play. As a construct, the notion of learning as the development of participation repertories provides a focusing lens through which the child-subjects of ece can be seen, become knowable, and hence governable, as learners. Furthermore, when this construct of learning is mobilised in 
narrative assessments it creates a boundless space for the government of selves and others. Learning in this construction is continuous and, seemingly, synonymous with all forms of social life (Hultqvist, 2001; Edwards, 2004; see also Drummond, 2003, Chapter 1, p. 4). Anywhere and everything is potentially a learning opportunity (Tuschling \& Engemann, 2006).

\subsubsection{Narrative assessments as inscription devices}

Narrative assessments function as flexible technologies of government. They work at once as techniques of power and techniques of the self. The brief assessment examples presented earlier indicate that children, as learners, are spoken about in particular ways: as goal setters, as having personal agendas, as being self motivated and persistent, and as becoming responsible for their well-being. This coheres with the construction of the progressing learner that I identified in the previous chapter. In other assessments that were analysed, children are constructed as self assessors and documenters, and they are spoken about, for instance, as being determined, as having talents and "growing passions" (Scholarly 1, p. 10), as showing "great perseverance when presented with a problem... [and as showing] incredible persistence and curiosity" (Scholarly 3, p. 65). By speaking about children in these very specific ways narrative assessments function as inscription devices that work to map particular norms for subjectivity onto the souls of children (Popkewitz, 2003). I now provide several more extended analytical examples to elaborate on these claims about narrative assessments as technologies of government.

Louie going out the door (Exemplars, p.10) is a narrative about a baby who does not yet crawl but who moves himself through toys and other obstacles in order to get outside. The assessment is written with an emphasis on dispositional learning and notions

of progress in learning as being to do with strengthening ones learning desire and control. Thus, in a short term review of the learning narrative a teacher describes the event as an instance of "great determination... [where] ... he knew what he wanted and went for it, moving whatever got in his way!"(p. 10). In the commentary to the assessment exemplar Louis is described as setting and "carrying out his self-set goal: getting outside onto the veranda and pulling himself up in the trellis" (p. 10). It is noted that "for Louie, access to the outdoors was an important opportunity for his learning" (p. 10). Furthermore, it is 
suggested in the Ministry of Education commentary to the assessment that the teacher's comment in the narrative that Louie "smiled with great delight about being outside" indicates that the narrator recognises the way in which Louis communicates that he has achieved his self set goal. This assessment is also described in the commentary as providing "baseline data for documenting development and change in how Louis sets himself goals and indicates that he has assessed his own achievement” (p. 10).

What is striking about this and a number of other assessments is the assigning of particular intentionalities and motivations to the child-subjects of ece assessment. Children's subjective experiences, including their affective expressions such as smiling or chuckling, are narrated according to the constructions of learning and notions of learning progress that are emphasised within contemporary ece assessment discourse. For me, Foucault's (1980a, 1980b; 1982; Mozère, 2006) proposal that subjectivity is discursively produced, and involves a tying of subjects to particular forms of identity and self knowledge became palpable as I worked with specific narrative assessments.

The emphasis on children as learners-in-action dominated most (but not all of) the narratives that I analysed. The learner-who is purportedly animated by a subjectivity that accords with the norms for desire and intentions that are constructed by contemporary assessment - is foregrounded. Louie, for instance, is not spoken about as smiling because he might have enjoyed a feeling of togetherness (Alcock, 2008). Elsewhere, Jak asks his teacher about what he could make with some blocks, and they subsequently work together on a construction, making reference to a number of images on the wall of the ece centre as they build. In the commentary to the assessment this activity is spoken about as showing how Jak was assisted to develop an awareness of the strategies he can use to "share responsibility for ...[his] learning and the assessment of its success" (Exemplars, p. 17). The possibility that Jak, and all of his actions, may have been informed by the desire to be with his teacher (Brennan, 2007) does not register. Elsewhere (Exemplars, p. 8), comments of an aesthetic nature - for example about the use of design, colour and space-were notably absent in a story about a screen printing episode which included several photographs of the prints. Instead, the narrative centred on the child's problem solving and good ideas during the process of screen printing. 
My intention, in proposing other possible elements for inclusion in assessments, is not to argue that these silent or omitted documentation possibilities should be documented. Rather, I wish to illustrate that an emphasis on the child-learner as a responsible, motivated and problem solving subject involves the cutting of experience in particular ways. This cutting works to enable particular sight lines and ways of experiencing and it disables, blurs or marginalises others (Rose, 1999). Within the discursive space carved by ece assessment, events and actions are made sense of in particular ways: A child smiles because, as was noted above in Louie going out the door, they have achieved their self set goal, or because they have taken responsibility for a problem, and "done their teaching for the day" (Scholarly 2, pp. 135-136).

This analytical point is supported by White's (2009; see Chapter 3, p. 48) study of ece assessment. Although White's study was framed with a Bakhtinian perspective, the finding that current authoritative assessment discourse dominated centre assessment practice and marginalised other genres and ways of approaching the act of assessment supports my analysis. I argue that the dominant constructions of learning and the child within the discourse enable and promote certain ways of seeing and thus render others marginal and imperceivable. Similarly, White (2009) found that alternative assessment genres such as those she termed intimacy and freeform (see White, 2009, pp. 137-149), which involved noticing embodied, aesthetic, and emotional aspects of toddlers' communication were dismissed — and at times actively omitted — within the official dispositional and learning interest focused centre assessment discourse. Indeed, these alternative genres were likened by one teacher to "dust under the carpet" (White, 2009, p. 156).

The cutting of experience according to particular norms also constructs certain locations for taking up authorised, desirable subject positions, and as is the way with norms, it also constructs other unauthorised or less desirable positions (Parker, 1992; Willig, 2008a, 2008b). This cutting enables particular spaces for the development of subjectivity. In learning narratives such as those described above, attention to people, places and things seems to be subordinated to the attention on the performing learner. It seems that speaking about people, places and things is relevant to the extent that this provides information about the performance of the learner, indicating their ability to 
competently activate participation repertoires in particular contexts in order to engage with learning opportunities and to pursue their goals. Or as is described in Scholarly 2, indicating their increasing ability to participate "in distributed systems...[becoming] increasingly able to recognise, respect, manage, develop and transform networks of support" (p. 138). Through narrative assessments that centre on their actions as self responsible learners it seems that children are being inscribed and tied to an identity as learners and to an identification and perception of their experiences as learning experiences, and they are being regulated by the related moral expectation to engage with and optimise such experiences.

Parents and whānau are also involved in the inscription of children's actions and experiences according to the norms of the child as learner. They are encouraged to speak about and perceive their children in particular ways through the invitation to contribute to, respond to, and to write narrative assessments about the child's life inside and outside the centre. For example, in an assessment about a toddler Greta playing with musical instruments a teacher addresses the child's mother: "Ruth, given the confidence and competence of Greta's musical performance you'll already be aware of her talent! What are we going to do about it?" (Scholarly 1, pp. 9-10).

In the text presenting this and other narrative assessment examples a shift towards a storied approach to assessment is described as involving a shift in teacher-parent relationships, towards an approach where parents are considered "partners in the search for learning opportunities that have real meaning for the child” (Scholarly 1, p. 10). In this and other narrative assessments I see the child being positioned as a learner whose capacity to perform as a learner must be enhanced. Simultaneously the parent is addressed and invited to take up a position in relation to their child as an opportunity scout and a (learning) experience broker and optimiser, a subject who should aim to enhance their child's key resource: their desire and capacity to be and to act as a learner. Thus, narrative assessments work to discipline the conduct of parents and whānau in their relations with children, and to involve them in the inscription of children's interiors with reference to the norms of children as ongoing learners. 


\subsubsection{The child's voice and learning portfolios as technologies of the self}

As technologies of the self, the child's voice and portfolios work to install particular forms of self knowledge and they encourage children to work on and govern themselves in particular ways. They provide models and procedures through which children can achieve the overall aim of ece assessment: the subjective experience, knowledge and conduct of the-self-as-learner who engages in the ongoing performance and development of learning dispositions.

The voice of the child, as I noted in the previous chapter is not defined within the texts that I analysed. It is treated as an un-contentious (see White, 2009) and nondiscursive construct. It seems to stand for the voice literally — what a child says - but also, more broadly, it seems to signify a child's contribution or their perspectives on what they are motivated by and what matters to them. The child's perspective or voice, may also, it is noted in Scholarly 2, be communicated by "gestures, sounds and facial expressions" (p. 145).

The definitions of voice and agency adopted by Smith (2007, p. 4, see Chapter 3, pp. 44-45) exemplify a view of voice as a non-discursive phenomenon. The child's voice is defined by Smith as "that cluster of intentions, hopes, grievances, and expectations that children guard as their own" and agency is defined as "how children express their voice". However, in my analysis of assessment examples I found that what is heard -including in the interpretation of children's facial expressions and sounds (e.g., smiling, chuckling) — and the perspectives of the child that are sought, is mediated according to the discursive truth of the child as learner.

For instance, in a series of assessment excerpts chosen to illustrate listening to children's voices, a child Dylan has made a figurine of a favourite cartoon character with his teacher (Scholarly 2). He responds to his mother's query about what he would like to do next by saying that he would like to make another one, this time of the cartoon character Shrek. He adds, in response to further queries, that he could get pictures of this character from The Warehouse (a department store). He also says that he would like to take more photos of his teacher helping him to make the next figure. Later in the assessments the teacher addresses Dylan who did take further photos: "Thank you for helping me Dylan. You have just documented your own learning" (Scholarly 2, p. 142). 
Elsewhere (Exemplars, p. 21), an assessment that leaves the what next component of the assessment unspecified so that the teacher can discuss learning possibilities with the child is included as an example of assessments that include children's voices and invite their contributions.

Recalling Bragg's (2007, see Chapter 3, p. 58) position, the voice of the child as it is exemplified in the texts I analysed is expressed within a particular discursive system, and according to the truths and norms that have high currency in this system. The assessment examples provided above suggest that the child's voice functions as a form of confessional practice, and thus it is integral to the government of selves and others (Foucault, 1997b, 1997d). Through the concept of voice, children are invited and encouraged to express their intentions, to speak about what they have done, what they intend to do, and what they will need to do it. They are, in conjunction with their confessors - teachers, parents, whānau - encouraged to make themselves up as subjects according to the ethical principles (Besley \& Peters, 2007) that are related to being a learner as it is constructed in ece assessment discourse. Moreover, the learner that ece assessment works to constitute - the self responsible, optimising, and goal setting subject - maps closely onto the desired subject of advanced or neoliberal governmentalities (e.g., Bragg, 2007; Rose, 1996, 1999).

Children's learning or assessment portfolios also work to install forms of self government according to these normative principles for self constitution and conduct. Children's portfolios incorporate the child's voice, the voice or perspective of others, as well as various forms of documentation such as photos. The ongoing and cyclic forms of engagement with assessment portfolios that are promoted for children play a key role in promoting children's self government according to the norms indicated above. Children are invited to read and revisit past assessments that have been collected in their learning portfolio, to look at and reflect on past learning performances with teachers and parents. They are encouraged to respond to prompts about their intentions and plans for action in relation to past performance, and to be involved in the documentation of some of this subsequent learning activity.

Dean (2010), as well as others (e.g., Fendler, 2010; Willig, 2008b), emphasises that discourses and techniques of government do not determine subjectivities, but rather 
"elicit, promote, facilitate, foster and attribute various capacities, qualities and statuses to particular agents" (pp. 43-44). Dean suggests that the aims of government, which are enacted via technical means, can be deemed successful to the extent that the subjects of government "come to experience themselves through such capacities ...qualities... and statuses" (p. 44). I argued in the previous chapter-and continue to here- that a key aim of assessment is the ongoing enhancement and optimisation of children's capacity and desire to be and to act as learners. In the assessments that I analysed there were a number of instances where the techniques of voice and the compilation of learning performances in portfolios were, it seemed, effectively installing the forms of subjectivity that assessment as a technology of government aims for. Some children seemed to be subjectifying themselves - making themselves into subjects (Masschelein \& Quaghebeur, 2005) — according to the desired norms of the child as a self directing, reflexive, performance opportunity seeking learner.

For instance, Dylan (Scholarly 2) in suggesting that he will document the actions that he plans to undertake seems to be taking up the position of learner and conducting himself according to the expectations and norms for conduct that accompany this: to plan, to set goals, and to document (learning) actions. In another assessment Laughlan calls to a teacher while hoola-hooping: "write about my moves..." (Scholarly 2, p. 144). He proceeds to tell the teacher about what he does to keep the hoola-hoop turning. The assessment contains his call to the teacher, his moves as he explains them, as well as photos of his actions. Laughlan appears to be relating to his actions with an understanding of them as learning performance: something that can command an audience and that can be documented for future consideration.

Elsewhere a series of narratives outline how Alex revisits her portfolio with her teacher and uses it as a prompt for further action: copying some of the writing in the folio and undertaking further block constructions in response to photos of an earlier building in another assessment (Exemplars, pp. 14-15; Scholarly 2, pp. 146-147). In the Scholarly 2 text, alongside mention of Alex is a story about Alice, who also engages with her portfolio in a highly reflexive manner. Alice, for instance, having looked through her portfolio with her teacher comments: "I need some more photographs of me, don't I? (Scholarly 2, p. 146). 
The discursive construction of the subject is particularly palpable here. There is a nauseating sense of simulacra in this series of narratives, of performance upon performance being captured and reflected upon, and the making up of the subject of ece via these representations. Both Alice and Alex's comments and actions are made in response to reading their portfolios which tell stories and include photos about their prior actions. Their subsequent comments and actions are recorded and included in their portfolio's with accompanying photos (of them looking at the folios). In the case of Alex, there is another story about the documented events written by another teacher about Alex and her teacher looking at the folios. This story writes about Alex copying of some of the text in one of the narratives in her portfolio, and it includes the comment by this second narrating teacher: "as I watched and photographed, I felt very excited. Alex had initiated the whole exercise and she was actively pursuing the opportunity to write" (Exemplars p. 15).

The norms for conduct and subjectivity of the self-as-learner-in-action were, it seemed, somewhat inescapable in this series. Alex, and to a lesser extent Alice, was subjected to representations of herself-as-a-learner over time and from multiple points at the one time. Such representations could be seen to be play a role in dominating the way that the field of possible actions is structured (Foucault, 1982). It felt to me that it might be a challenge in such instances for children such as Alex, Alice, Laughlan, and Dylan to know and conduct themselves as other than learning subjects as this is dominantly constructed in ece assessment discourse.

\subsection{Conclusion}

In this second analysis and discussion Chapter I have elaborated on the arguments and analysis that was presented in Chapter 5. I have drawn particularly on the discourse data provided by narrative assessment examples in order to address the question of the discursive effects of contemporary ece assessment in New Zealand. I focused my analysis primarily on a consideration of the subjectivities that are promoted for the child-subjects of ece assessment.

My analysis suggests that the forms of subjectivity that are presumed and promoted by ece assessment link with those forms of entrepreneurial self government that 
are desired (and assumed) within neoliberal governmentalities (e.g., Rose, 1996; Peters, 2001; Simons, 2006). The subject of ece that I have found to be presumed and promoted might be described as an "active individual that seeks to augment its attributes" (Tuschling \& Engemann, 2006, p. 459), a self reflexive subject who, at times in conjunction with others, seeks to document, and to actively pursue further opportunities to optimise their learning-self performance.

My analysis also suggests that the various techniques of government that make up narrative assessment can potentially activate a form of totalising panopticism. Foucault $(1995,2000)$ speaks of panopticism as a mode of power that works through continuous surveillance and examination, and which is focused on ascertaining whether conduct is adhering to particular norms. I see narrative assessments as bringing into play a continuous examination, where all involved are invited to perceive, narrate and conduct themselves according to the norms of learning as ongoing, continuous performance, and development of learning dispositions.

I have argued in this chapter, and the previous, that an overall aim of contemporary ece assessment in New Zealand is for children to develop a knowledge of themselves as learners and to develop forms of subjectivity and self government that cohere with the morally desirable ways of conducting oneself that are established by contemporary ece assessment discourse. According to my analysis the aim of ece assessment might then also be described as to construct children as panopticians of the self. In such a state, children as the primary subjects of ece, are encouraged to govern themselves as learners continuously_-supervising, documenting, examining and enhancing their learning performances and pursing ongoing opportunities - in an ideal state of subjectification where self government is conducting according to the overall principle and technique of "permanent self performance" (Tuschling \& Engemann, 2006, p. 459). 


\section{Chapter 7: CONCLUSION}

\subsection{Introduction}

In this concluding chapter I first revisit the context and aims of this study. I briefly discuss what I think taking up a Foucauldian analysis has enabled me to do in this thesis. I then turn to a consideration of the analytical claims and arguments made in the previous two chapters. A broad summary of the main findings of these two chapters is provided, and I work to synthesise particularly important aspects of the analysis. I extrapolate on two lines of argument that were presented in the analysis and discussion chapters in order to bring together aspects of the analysis that I find particularly significant, and also in order to foster debate. I make some additional comments about the limitations of this thesis and indicate possibilities for further research. My closing comments include some reflections on my own experiences of conducting ece assessments, in light of the findings of this study.

\subsection{Starting points for the thesis}

I began this thesis by outlining what seemed to be the widespread view of contemporary ece assessment in New Zealand as an empowering and authentic practice. I indicated that narrative, formative, sociocultural and dispositionally framed assessments are widely endorsed in a range of contexts: scholarly, ministerial, evaluative, and practitioner. Drawing on my own experience I noted that contemporary ece assessment was positioned as being an integral component of early childhood work, forming part of the "golden triangle" (White, 2009, p. 4 ) of quality ece provision in Aotearoa. I also described my unease with contemporary ece practices, which was due to ambivalence about positioning myself as a good teacher within dominant ece assessment discourse. I described some of 
the difficulties I had with making the types of statements that were recognised as true propositions within the discourse (Foucault, 1980a). I indicated why I came to see a Foucauldian perspective as being relevant to my questions and concerns.

\subsection{The enablements of a Foucauldian analytic}

I took up a Foucauldian perspective in order to critically analyse contemporary ece assessment in New Zealand. I wanted to destabilise and denaturalise what seemed to be the dominant, empowerment infused ece assessment discourse and to contribute to local debates in early childhood scholarship, which I found to be limited in the case of current ece assessment.

I posed a two-part question to guide the analysis: How is contemporary ece assessment constructed in New Zealand, and what is effected, or brought about, by this construction? In order to pursue this critical analysis I focused particularly on Foucault's notions of discourse and government. To address the research questions I developed a method of analysis that drew on a variety of Foucauldian scholarship, some of which focused on analytical procedures. By working with both procedurally specified and open, associative analytical modes I was able to position myself during the analysis as a subject addressed by assessment discourse. I was therefore able to experience the evocative and strategic effects of contemporary ece assessment discourse.

By approaching contemporary ece assessment in Aotearoa as a discursive construction I have been able to ask: on what grounds - according to what truths about learning, children and the future - does assessment have a status as an empowering and desirable practice? Furthermore, by viewing the subjects of ece assessment as discursive truth and power effects, I have been able to consider the truths and mentalities of government that may be at work at in the constitution of these subjects. This has enabled me, at least in part, to re-position the key objects of assessment — the child and learning - outside of their valorised location, in the true, within dominant ece assessment discourse (Foucault, 1972). An important part of the re-positioning and destabilising work has been the consideration of ece assessment as a technology of government that connects with the profoundly economic rationalities that are dominant in New Zealand 
and other advanced liberal democratic governments (e.g., Codd, 2005a; O’Neill, 2005; Simons, 2006; Tuschling \& Engemann, 2006).

\subsection{Key findings of the thesis: summary, synthesis and some extrapolations}

Contemporary ece assessment in New Zealand is constructed as a morally valorised practice that is animated by, and in support of, values and principles such as social

justice, human, and specifically, children's rights, diversity and plurality. Contemporary assessment also works to implement a normalising regime of government.

Ece assessment, as discourse, is made up of a variety of interconnected truthobjects, knowledge/discourses and techniques of power and the self. The truth-objects and related discourses that make up ece assessment are "given meaning and force" (Carabine, 2001, p. 288) via two interconnected discursive strategies. These are (1) the oppositional construction of contemporary assessment in relation to past undesirable forms, and (2) the construction of ece assessment as a secular, humanistic salvation practice. These strategies work in tandem to position contemporary ece assessment as a desirable, progressive, inclusive, empowering and socially just practice.

Additionally, three key-truth objects are constructed by assessment, and they work to position current practices as being morally justified and necessary. These truthobjects are (1) learning as the ongoing process of being and becoming a learner, (2) children as competent, confident learners, and (3) the future as changing and uncertain. The construction of these objects represents specific assumptions about who the subjects of ece are, who they should be, and what forms of society they should inhabit.

The dominant and normative constructs of the child as a competent, confident learner and learning as an ongoing performance of learning animate various technologies of government. These techniques include the writing and compiling of narrative assessments in learning portfolios with accompanying photos, the documentation and enlisting of the child's voice in narrative assessments, and the revisiting and reflexive engagement with the learning (performances) captured in these portfolios. 
Figure 7.1 A model of the construction of contemporary ece assessment in New

\section{Zealand}

\section{ECE ASSESSMENT AS MORALL Y DESIRABLE PRACTICE}

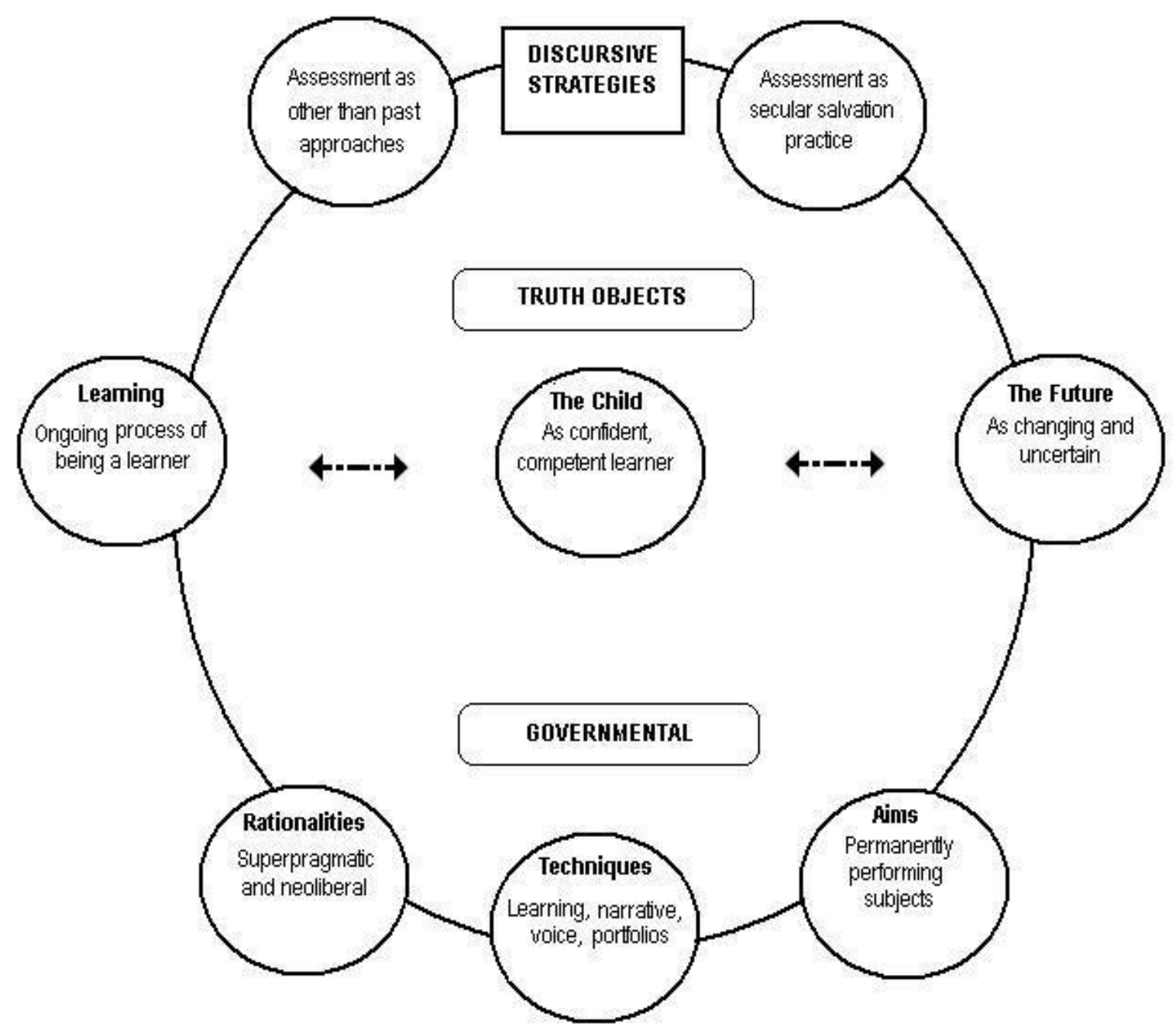

All depicted elements work together to form a mutually reinforcing and normalising discursive loop or regime of truth

Once they are mobilised in narrative assessments the normative constructions of children and learning have significant regulatory effects, and not just for children. They work 
to structure the vision of those conducting assessments - teachers, parents, whānau, and children themselves - towards a view of experience and interactions with people, places and things as learning opportunities. That is, opportunities that should be desired, taken up, and used to support the ongoing development (optimisation) of the capacity and desire to perform the self-as-learner. The ideal developing learner as self responsible, motivated, learning opportunity seeking, and goal setting agent provides the dominant interpretive logic in the making of narrative assessments. This logic shapes and guides possibilities for reflecting on past, present and future actions. All actions are-or should be-learning actions (Tuschling \& Engemann, 2006). This dominant interpretive logic means that other interpretive schemes for the construction of narratives about early childhood spaces and the actions of those within them are for the most part imperceivable.

The norms for self constitution, self knowledge and self government that are constructed by ece assessment for the child-as-learner map closely onto the forms of subjectivity and self government that have been analysed as being integral to advanced liberal rationalities of government. The desired progressing learner of ece assessment seems much like the self responsible, self steering, entrepreneurial subject of advanced or neoliberal governmentalities (e.g., Besley \& Peters, 2007; Bragg, 2007; Rose, 1996, 1999). As a technology of government that is animated, at least in part, by neoliberal governmentalities ece assessment promotes and assumes the desirability of economic and entrepreneurial attitudes to all forms of interaction and relations (Simons \& Masschelein, 2006).

\subsubsection{Extrapolation \# 1. Contemporary ece assessment: constitutive of particular norms for living}

In the introduction to this thesis I noted that Drummond (2003) an assessment scholar from the United Kingdom described New Zealand's ece narrative assessments as approaching learning "as a moving event, dynamic and changeful, practically synonymous with living" (p. 186). In light of my analysis of ece of assessment in New Zealand, I wish to reformulate this comment. Ece assessment, animated by a dominant 
and boundless construction of learning as the ongoing process of being and becoming a learner in a myriad of possible interactions with people, places and things is a practice that is constitutive of particular norms for living. Therefore it is also a practice that is constitutive of particular norms for subjectivity and the government of selves and others.

As I argued in Chapter 5, the sunny uplands, the universal and humanistic state of salvation that ece assessment seeks to achieve is a learning society, or in the terminology of New Zealand educational discourses, a knowledge society (e.g., Hope \& Stephenson, 2006; Maharey, 2006, Peters, 2006). The notion of future (and ideally present) learning societies populated by lifelong learners is seen from governmentality perspectives to be an important intellectual technology of government (e.g., Peters, 2006; Edwards, 2004). It has been argued that discourses of lifelong learning and learning societies are integral to the reordering/ reconstruction of the social and economic domains within advanced liberal, post-welfare jurisdictions. In particular, these discourses are seen to be integral to the establishment of an extensive domain of government where the learning, social, and economic orders are one and the same. In a related way the discourses of lifelong learning and learning societies are seen to be integral to the reconstitution of the subjects of government according to neoliberal governmentalities (Peters, 2001, 2006; Edwards, 2004; Simons, 2006; Simons \& Masschelein, 2006, 2008; Tuschling \& Engemann, 2006).

Ece assessment in New Zealand is constructed with reference to discourses of lifelong learning. It can be read as a practice that involves the establishment of new norms for conduct and, therefore, related forms of exclusion. Popkewitz' (2003, see Chapter 3, p. 54) comments illustrate this point. He argues that lifelong learning is not just a phrase "but an amalgamation of practices that order, classify, and normalize that qualify and disqualify individuals to act and participate" (p. 55). Edwards (2004) takes a similar position. He suggests that the learning society is to be populated by active citizens who conduct themselves according to the norms of innovation, flexibility, and mobility. He proposes that within learning societies such norms for self government can be seen to function as "ontological conditions for successful societal participation" (p. 76).

Simons (2006), considering the subjects of lifelong learning, proposes that the ideal subject should take up an "attitude of investment" (p. 537) towards themselves, and conduct themselves with an entrepreneurial ethos, motivated by a desire to develop their 
human capital in an ongoing way through series of strategic choices. Furthermore, the establishments of such norms (truths) for conduct are seen by Tuschling and Engemann (2006) to be key to the establishment of a flexibilised work force in "post-Fordist organizations...where lifelong learning takes the place of lifelong employment" (p. 457; see also Peters, 2001). Tuschling and Engemann (2006) challenge the endless choices in ways of life that are evoked by discourses of lifelong learning. For example, they suggest that learning to learn might be understood as "both an offer and an order to develop motivation and ability to do so" (p. 466). Edwards (2004) adds further ambivalence to readings of lifelong learning as, in the case of contemporary ece assessment discourse, a humanistic, secular salvation practice that is supportive of social justice and equality for all. He proposes that discourses of lifelong learning involve an element of Darwinian logic: "adapt through innovations, flexibility and mobility, or..." (p. 77).

\subsubsection{Extrapolation \# 2. Contemporary ece assessment: governing permanently performing selves-as-learners}

In my analysis the child-subject of current ece assessment in New Zealand is no less disciplined or normalised than the child-subject of developmental observations. Rather, the child today is differently and perhaps more efficiently governed (Fendler, 2001; Foucault, 1980a, 1980b). Current assessment approaches still work to optimally develop the child as resource (e.g., Rose, 1996; Hultqvist, 2004). In previous developmentally framed assessment approaches it seems that the aim was to optimise children's development according to universal and predefined stages. In New Zealand's contemporary ece assessment methods, optimal development is to be achieved primarily through the child's government of self and the development (in conjunction with others) of their key resource. This resource is their desire and capacity to be and to act as learners, where learning is dominantly constructed as the ongoing performance of behaviors related to learning dispositions.

The efficiency of this form of government lies in the establishment of the correct disposition and orientation to all events as learning opportunities within the childsubject's soul, and also, through the promotion of panoptical relations with the self 
(Foucault, 1995; Rabinow, 1982). The correctly disciplined child-subject as learner will self monitor, evaluate and modify their conduct according to the norms of learning that are established by current ece assessment discourse. The well disciplined child-subject is one who conducts themselves according to the norms of self responsibility, self motivation, self optimisation and performance. In these norms, children's souls are being inscribed with fundamentally economic and entrepreneurial principles, which are also foundational principles of government within advanced liberal governmentalites (e.g., Peters, 2001; Rose, 1996, 1999; Simons \& Masschelein, 2006).

Assessment as a governmental technique disciplines and governs children, teachers and whānau in particular ways. By focusing on the optimisation of what might be termed the new universal capital of learning desire and capacity, all subjects of ece are empowered as partners to work on, develop and enhance this resource. Or, to put it another way, current ece assessment in New Zealand promotes "specific practice[s] of freedom as obedience to particular norms" (Simons \& Masschelein, 2006, p. 424).

My analysis of ece assessment as implementing a normalising regime of government that is aimed at constituting self governing, performative, learning-ready and desiring subjects links with aspects of other Foucauldian analyses of contemporary educational discourses, such as those discussed in the literature review (Bragg, 2007; Duhn, 2006, Gibbons, 2007b; Hultqvist, 1998, 2004; Masschelein \& Quaghebeur, 2005; Popkewitz, 2003). These studies suggest that moves towards pedagogical practices based on principles of competence, activity, interactivity, capability and learning processes do not, in a Foucauldian sense, indicate a departure from the government of children (and others involved in ece). Rather, these studies, as does this thesis, suggest that the subjects of such contemporary educational discourses are being governed and governing themselves according to new norms. In light of this analytical claim, the links between current ece assessment and the values of plurality, diversity and social justice seemed to be limited, and at least partly rhetorical. 


\subsection{Limitations}

In Chapter 4, Methods, I outlined what I saw as being key limitations of this study, but a number of additional comments are needed here. The analytical claims and arguments presented here are based on a limited discourse data set. Furthermore, I emphasise that the discussion in the previous two sections of this chapter should be understood as being particularly speculative, and presented in order to foster debate.

However, there are some indications that the discourse data that I have analysed is indicative of the discursive make up of the broader dominant ece assessment discourse in New Zealand. Several of the texts in the data set are written by authors who have been integrally involved in the development of contemporary assessment approaches in New Zealand, including as authors of the Kei Tua o te Pae resource. Some of these authors have written widely about contemporary ece assessment in New Zealand. Therefore it is likely that the arguments and concepts presented in the analysed texts will be circulating in other similar texts that were not included in the data set. Furthermore, several of the texts in the data set are currently course readings in the Victoria University ece teaching degree, and therefore can be seen to be actively establishing and contributing to the authorised knowledge base of ece teaching in New Zealand. (See Appendix A for further details).

\subsection{Indications for further research}

Foucauldian analysis of contemporary ece assessment practices in specific ece centres would enable insights into the functions and effects of contemporary assessment discourse in New Zealand beyond those that have been provided by this study. Additional study of assessment related documents such as the Education Review Office's (2008) report The Quality of Assessment in Early Childhood Education would also provide further insights. An analysis of specific ece centre reviews that have been conducted by the Education Review Office would be particularly valuable. It could provide further insights into how quality ece practice is currently constructed, and it would give further indications about the subjects of education that are presumed and promoted by current ece discourse. 
This thesis also indicates that a genealogy of the subject of educational assessment in New Zealand, with a focus on both pre and compulsory schooling, would be valuable. There have been many instances in this study where it has not been possible to indicate the connections between ece assessment and broader educational discourses in New Zealand. Documents that indicate the emergence of contemporary assessment discourse in New Zealand as well as its construction with reference to discourses of lifelong learning, enterprise and knowledge/learning societies would be important to study (e.g., Ministerial Working Party, 1990; Ministry of Education, 1991). Attention to the New Zealand Curriculum Framework (Ministry of Education, 2007b), and its focus on learning competencies would also be useful. This curriculum framework has been explicitly linked with the focus on learning dispositions as educational outcomes in $T e$ Whāriki and Kei tua o te Pae (e.g., Maharey, 2006; Ministry of Education, 2010). Such a genealogical investigation could highlight the historical and contemporary connections between the subjects of education and various governmental rationalities.

Similarly, a genealogy of the child-subject of ece in New Zealand could support further critical appraisal of today's subject. This study has indicated that the competent, confident learner functions as a morally valorised, persuasive truth-object. By attending to the shifts over time in constructions of the child-subject of ece, the truth of today's subject and the mentalities of government that render such a subject conceivable and desirable could be further considered. There are elements of such genealogical work in the scholarship of Duhn (2006), Gibbons (2007a), and Loveridge (1999). May's histories of ece in New Zealand would provide helpful insights (e.g., 1997, 2000, 2009). However, this work, as well as extensive material held in National and other archives, is yet to be the subject of a sustained Foucualdian analysis.

\subsection{Closing comments}

This study suggests that contemporary ece assessment in New Zealand assumes and promotes highly specific norms for subjectivity and self government. As a normalsing technology of government it cuts experience in particular ways. It renders certain ways of 
seeing, speaking and acting as being in the true (Foucault, 1972, 1980a; Rose, 1999). It does not seem to be constructed by a plurality of social logics (Mouffe, 1992), but rather, it appears to be animated by those of advanced liberal governmentalities, which assume and promote the generalisation of market-like relations to all spaces and subjects of living (e.g., Edwards, 2004; Simons \& Masschelein, 2006; Tuschling \& Engemann, 2006).

I return to my own experiences of conducting ece assessment, having now conducted a discursive analysis of current ece assessment. The difficulties and ambivalence I described in the introductory chapter can be interpreted as an account that beings to document the regulatory effects of current ece assessment, as a regime of truth. In order to align my teacher voice with the truths that assessment constructs about children and experience, I needed to make sense of and speak about children and events in particular ways. Making authorised assessment statements involved a form of violence (Dahlberg \& Moss, 2005, pp. 64-85) — a cutting of experience in particular ways; a structuring of the field of possible actions according to particular truths and assumptions (Foucault, 1982; Rose, 1999). Events, happenings, emotions, desires and interactions needed to be accounted for according to the totalising logic of learning experience, and then instrumentalised with reference to the project of optimising and disciplining learning subjects, according to the norms of "permanent self performance" (Tuschling \& Engemann, 2006, p. 459).

Foucault's (1983) comments seem pertinent to this study and the meanings that I currently make from it: "An Other is always pushed aside, marginalized, forcibly homogenized and devalued as [Western] cognitive machinery does its work" (p. 19, cited in Dahlberg \& Moss, 2005, p. 78). The Other that is pushed aside by ece assessment, as a technology of advanced liberal governmentalities includes, for instance, other possibilities for subjectivity, other interpretive schemes, and other social logics.

By proposing that contemporary ece assessment in New Zealand does not depart from governing, but rather works to shape conduct according to new norms, I am not arguing for less government (Dean, 2010). From the Foucauldian position I have taken in this thesis this would be an impossibility. However, I am I arguing against ece assessment 
as a regime of truth, an authoritative discourse that is taken to be indicative of "right', 'best' and 'ethical'” practice (MacNaughton, 2005, p. 2) in early childhood spaces.

The ongoing status of contemporary ece assessment in New Zealand as a morally valorised, salvation practice that is underpinned by values such as social justice and plurality is problematic. It suggests that in early childhood, 'we' - those involved in teaching and researching in ece — have finally arrived, and reached a harmonious "unity of "the people"' (Mouffe, 2000, p. 16), through a socially just and empowering assessment practice that is based on Te Whāriki and focused on contextually specific, yet universal, learning desire. The assuredness of this sense of arrival stifles debate and contestation. But more than that, it is implicated in the constraint of a myriad of other possible relations of power, forms of subjectivity and approaches to the government of selves and others. 


\section{References}

Alcock, S. (2008). Young children being rhythmically playful: Creating musike together. Contemporary Issues in Early Childhood, 9(4), 328-338.

Anning, A., Cullen, J., \& Fleer, M. (2009). Research contexts across cultures. In A. Anning, J. Cullen \& M. Fleer (Eds.), Early childhood education: Society and culture (2nd ed., pp. 1-24). London: Sage.

Arribas-Ayllon, M., \& Walkerdine, V. (2008). Foucauldian discourse analysis. In C. Willig \& W. Stainton-Rogers (Eds.), The SAGE handbook of qualitative research in psychology (pp. 91-108). London: Sage.

Baker, B. M., \& Heyning, K. E. (2004). Dangerous coagulations? Research, education, and a traveling Foucault. In B. M. Baker \& K. E. Heyning (Eds.), Dangerous coagulations? The uses of Foucault in the study of education (pp. 1-79). New York: Peter Lang.

Bayes, C. (2006). Provocations of Te Whāriki and Reggio Emilia. In A. Fleet, C. Patterson \& J. Robertson (Eds.), Insights: Behind early childhood pedagogical documentation (pp. 289-299). Castle Hill: Pademelon Press.

Besley, T. A. C., \& Peters, M. A. (2007). Subjectivity \& truth: Foucault, education, and the culture of self. New York: Peter Lang.

Blaiklock, K. E. (2008). A critique of the use of Learning Stories to assess the learning dispositions of young children. New Zealand Research in Early Childhood Education, 11, 77-86.

Blaiklock, K. E. (2009). Reviewing the reviewers: Commentary on the Education Review Office's evaluation of assessment in early childhood settings. New Zealand Research in Early Childhood Education, 12, 3-10.

Bloch, M. N. (1992). Critical perspectives on the historical relationship between child development and early childhood education research. In S. Kessler \& B. B. Swadener (Eds.), Reconceptualizing the early childhood curriculum: Beginning the dialogue (pp. 3-20). New York: Teachers College Press.

Bone, J. (2001). Learning dispositions: Picking up the threads. Australian Journal of Early Childhood, 26(2), 25-30.

Bragg, S. (2007). Student voice and governmentality: The production of enterprising subjects? Discourse: Studies in the Cultural Politics of Education, 28(3), 343 358. 
Braun, V., \& Clarke, V. (2006). Using thematic analysis in psychology. Qualitative Research in Psychology, 3(2), 77-101.

Bredekamp, S. (Ed.). (1987). Developmentally appropriate practice in early childhood programs serving children from birth through age 8 (Expanded ed.). Washington, DC: National Association for the Education of Young Children.

Bredekamp, S., \& Rosegrant, T. (Eds.). (1992). Reaching potentials: Appropriate curriculum and assessment for young children (Vol. I). Washington, DC: National Association for the Education of Young Children.

Brennan, M. (2007). Beyond child care-how else could we do this? Sociocultural reflections on the structural and cultural arrangements of contemporary Western child care. Australian Journal of Early Childhood, 32(1), 1-9.

Broadfoot, P. (2007). An introduction to assessment. London: Continuum.

Buchanan, E. (2009). Sociocultural theory in New Zealand ece: Position Paper. Developmental Issues in Early Childhood Edcuation, EDUC 557. Victoria University, Wellington.

Burchell, G. (1996). Liberal government and techniques of the self. In A. Barry, T. Osborne \& N. Rose (Eds.), Foucault and political reason:Liberalism, neoliberalism, and rationalities of government (pp. 19-36). Chicago: University of Chicago Press.

Burman, E. (1994). Deconstructing developmental psychology. London: Routledge.

Burman, E. (2008). Deconstructing developmental psychology (2nd ed.). East Sussex: Routledge.

Campbell, S., \& Smith, K. (2001). Equity observation and images of fairness in childhood. In S. Grieshaber \& G. S. Cannella (Eds.), Embracing identities in early childhood education: Diversity and possibilities (pp. 89-102). New York: Teachers College Press.

Cannella, G. S. (1997). Deconstructing early childhood education: Social justice \& revolution. New York: Peter Lang.

Cannella, G. S. (1999). The scientific discourse of education: Predetermining the lives of others - Foucault, education, and children. Contemporary Issues in Early Childhood, 1(1), 36-44.

Cannella, G. S., \& Viruru, R. (2004). Childhood and postcolonization: Power, education, and contemporary practice. New York: RoutledgeFalmer. 
Carabine, J. (2001). Unmarried Motherhood 1830-1990: A genealogical analysis. In M. Wetherell, S. Taylor \& S. J. Yates (Eds.), Discourse as data: A guide for analysis (pp. 267-310). London: Sage.

Carr, M. (1998a). Assessing children's experiences in early childhood: Final report to the Ministry of Education. Wellington: Ministry of Education.

Carr, M. (1998b). Assessing children's learning in early childhood settings: A professional development programme for discussion and reflection. Wellington: New Zealand Council for Educational Research.

Carr, M. (1998c). Project for assessing children's experiences in early childhood settings. In M. Carr, H. May \& V. Podmore (Eds.), Learning and teaching stories: New approaches to assessment and evaluation in relation to Te Whäriki: Symposium for 8th European Conference on Quality in Early Childhood Settings, Santiago de Compostela, Spain, September 1998 (pp. 8-18). Wellington: Institute for Early Childhood Studies, Victoria University of Wellington.

Carr, M. (1999a). Being a learner: Five learning dispositions for early childhood. Early Childhood Practice, 1(1), 82-99.

Carr, M. (1999b). Some thoughts about effective assessment. Early Education, 21(Spring/Summer), 11-20.

Carr, M. (2001). Assessment in early childhood settings: Learning Stories. London: Paul Chapman.

Carr, M. (2009). Kei tua o te Pae: Assessing learning that reaches beyond the self and the horizon. Assessment Matters, 1, 20-46.

Carr, M., Cowie, B., Gerrity, B., Jones, C., Lee, W., \& Pohio, L. (2001). Democratic learning and teaching communities in early childhood: Can assessment play a role? In B. Webber \& L. Mitchell (Eds.), Early childhood education for a democratic society. Wellington: New Zealand Council for Educational Research.

Carr, M., Jones, C., \& Lee, W. (2005). Beyond Listening: Can assessment practice play a part? In A. Clark, A. T. Kjørholt \& P. Moss (Eds.), Beyond listening: Children's perspectives on early childhood services (pp. 129-150). Bristol: Policy Press.

Carr, M., \& May, H. (1993a). National curriculum guidelines for early childhood in Aotearoa-New Zealand. A philosophical framework for development. In M. Carr \& H. May (Eds.), Te Whāriki: Curriculum papers (pp. 1-24). Hamilton Early Childhood Curriculum Project. Waikato University.

Carr, M., \& May, H. (Eds.). (1993b). Te Whāriki: Curriculum papers. Hamilton Early Childhood Curriculum Project. Waikato University. 
Carr, M., \& May, H. (1996). Te Whāriki, Making a difference for the under-fives? The new national early childhood curriculum. Delta, 48(1), 101-112.

Carr, M., McGee, C., Jones, A., McKinley, E., Bell, B., Barr, H., et al. (2005). The effects of curricula and assessment on pedagogical approaches and on educational outcomes: Report to the Ministry of Education. Wellington: Ministry of Education.

Carter, M. (2008). From critique to possibility: New Zealand's radical approach to assessment. In A. Pelo (Ed.), Rethinking early childhood education (pp. 119-120). Milwaukee: Rethinking Schools.

Cederman, K. (2008). Not weaving but drowning? The child.com in New Zealand early childhood pedagogies. International Journal of Early Childhood, 40(2), 119-130.

Clark, A. (2005). Listening to and involving young children: A review of research and practice. Early Child Development and Care, 175(6), 489-505.

Clark, A., \& Moss, P. (2001). Listening to young children: The Mosaic approach. London: National Children's Bureau.

Clark, A., \& Moss, P. (2005). Spaces to play: More listening to young children using the Mosaic approach. London: National Children's Bureau.

Codd, J. (2005a). Education policy and the challenges of globalisation: Commercialisation or citizenship? In J. Codd \& K. Sullivan (Eds.), Education policy directions in Aotearoa New Zealand (pp. 3-17). Southbank:

Tomson/Dunmore Press.

Codd, J. (2005b). Is there a 'Third Way' for education policy? In J. Codd \& K. Sullivan (Eds.), Education policy directions in Aotearoa New Zealand (pp. xxi-xviii). Southbank: Tomson/Dunmore Press.

Cooper, M. (2009). Using Learning Stories effectively to support an infant's passion for learning. The First years: Ngā Tau Tuatahi. New Zealand Journal of Infant and Toddler Education, 11(2), 30-37.

Cowie, B., \& Carr, M. (2009). The consequences of sociocultural assessment. In A. Anning, J. Cullen \& M. Fleer (Eds.), Early childhood education: Society and culture (2nd ed., pp. 105-116). London: Sage.

Cruikshank, B. (1999). The will to empower. Ithaca: Cornell University Press.

Cullen, J. (2001). Ethics and assessment in early childhood programmes. Early Education, 27(Spring/Summer), 5-11. 
Dahlberg, G., \& Moss, P. (2005). Ethics and politics in early childhood education. Oxfordshire: RoutledgeFalmer.

Dahlberg, G., Moss, P., \& Pence, A. (1999). Beyond quality in early childhood education and care: Postmodern perspectives. London: Falmer Press.

Dahlberg, G., Moss, P., \& Pence, A. (2007). Beyond quality in early childhood education and care: Languages of evaluation ( 2 nd ed.). Abingdon: Routledge.

Davis, B., \& Harre, R. (1990). Positioning: The discursive production of selves. Journal for the Theory of Social Behaviour, 20(1), 43-63.

Davis, K. (2006). 'It's much more muddled-up than that': A study of assessment in an early childhood centre (Unpublished master's thesis). University of Canterbury, Christchurch.

Davis, K., Gunn, A., Purdue, K., \& Smith, K. (2007). Forging ahead: Moving towards inclusive and anti-discriminatory education. In L. Keesing-Styles \& H. Hedges (Eds.), Theorising early childhood practice: Emerging dialogues. Castle Hill: Pademelon Press.

Dean, M. (2010). Governmentality: Power and rule in modern society (2nd ed.). London: Sage.

Drummond, M. J. (2003). Assessing children's learning (2nd ed.). London: David Fulton.

Duhn, I. (2006). Cartographies of childhood: Mapping the modern/global child (Unpublished doctoral dissertation). University of Auckland. Retrieved from http://hdl.handle.net/2292/375

Duhn, I. (2009). Honouring the voices of children in Aotearoa New Zealand? Governing through learning and teaching in early childhood education. Paper presented at the LED 2007 2nd International Conference on Language, Education and Diversity, Hamilton, New Zealand.

Duncan, J. (2005). "She's always been, what I would think, a perfect day-care child": Constructing the subjectivities of a New Zealand child. European Early Childhood Education Research Journal, 13(2), 51-61.

Education Review Office (2008). The quality of assessment in early childhood education. Wellington: Author.

Edwards, R. (2004). Intellectual technologies in the fashioning of Learning Societies. Educational Philosophy and Theory, 36(1), 69-78. 
Farquhar, S. (2008). Narrative identity: Ricoeur and early childhood education (Unpublished doctoral dissertation). University of Auckland. Retrieved from http://hdl.handle.net/2292/2625

Farquhar, S., \& Fleer, M. (2007). Developmental colonisation of early childhood education in Aotearoa /New Zealand and Australia. In L. Keesing-Styles \& H. Hedges (Eds.), Theorising early childhood practice: Emerging dialogues (pp. 2749). Castle Hill: Pademelon Press.

Fejes, A., \& Nicoll, K. (2008). Preface. In A. Fejes \& K. Nicoll (Eds.), Foucault and lifelong learning: Govering the subject (pp. ix-xiv). Abingdon: Routledge.

Fendler, L. (1998). What is it impossible to think? A genealogy of the educated subject. In T. S. Popkewitz \& M. Brennan (Eds.), Foucault's challenge: Discourse, knowledge, and power in education (pp. 39- 63). New York: Teachers College Press.

Fendler, L. (2001). Educating flexible souls: The construction of subjectivity through developmentality and interaction. In K. Hultqvist \& G. Dahlberg (Eds.), Governing the child in the new millennium (pp. 119-142). New York: RoutledgeFalmer.

Fendler, L. (2010). Michel Foucault. London: Continuum.

Fleer, M. (1995a). Does cognition lead development, or does development lead cognition? In M. Fleer (Ed.), DAP centrism: Challenging developmentally appropriate practice (pp. 11-22). Watson: Australian Early Childhood Association.

Fleer, M. (1995b). Introduction. In M. Fleer (Ed.), DAP centrism: Challenging developmentally appropriate practice (pp. 1-10). Watson: Australian Early Childhood Association.

Fleer, M. (2002). Sociocultural theory: Rebuilding the theoretical foundations of early childhood education. Delta, 54(1\&2), 105-120.

Fleer, M., \& Robbins, J. (2004). Beyond ticking the boxes: From individual developmental domains to a sociocultural framework for observing young children. New Zealand Research in Early Childhood Education, 7(23-39).

Fleer, M., \& Surman, L. (2006). A sociocultural approach to observing and assessing. In M. Fleer (Ed.), Early childhood learning communities: Sociocultural research in practice (pp. 141-160). Frenchs Forest, NSW: Pearson Education Australia.

Fleet, A., Patterson, C., \& Robertson, J. (Eds.). (2006). Insights: Behind early childhood pedagogical documentation. Castle Hill: Pademelon Press. 
Foucault, M. (1972). The archaeology of knowledge. The discourse on language. New York: Pantheon Books.

Foucault, M. (1980a). Truth and power. In C. Gordon (Ed.), Power/Knowledge: Selected interviews and other writings 1972-1977 (pp. 109-133). New York: Pantheon Books.

Foucault, M. (1980b). Two lectures. In C. Gordon (Ed.), Power/Knowledge: Selected interviews and other writings 1972-1977 (pp. 78-108). New York: Pantheon Books.

Foucault, M. (1982). The subject and power. In H. L. Dreyfus \& P. Rabinow (Eds.), Michel Foucault: Beyond structuralism and hermeneutics (pp. 208-226). Brighton: The Harvester Press.

Foucault, M. (1995). Discipline and punish: The birth of the Prison (A. Sheridan, Trans.) (2nd ed.). New York: Vintage Books.

Foucault, M. (1997a). The ethics of the concern for self as a practice of freedom. In P. Rabinow (Ed.), Ethics: Subjectivity and truth (pp. 281-301). New York: The New Press.

Foucault, M. (1997b). On the government of the living. In P. Rabinow (Ed.), Ethics: Subjectivity and truth (pp. 81-85). New York: The New Press.

Foucault, M. (1997c). Subjectivity and truth. In P. Rabinow (Ed.), Ethics: Subjectivity and truth (pp. 87-92). New York: The New Press.

Foucault, M. (1997d). Technologies of the self. In P. Rabinow (Ed.), Ethics: Subjectivity and truth (pp. 223-251). New York: The New Press.

Foucault, M. (2000). Truth and juridicial forms. In J. D. Faubion (Ed.), Power (pp. 1-89). New York: The New Press.

Gallagher, M. (2008). Foucault, power and participation. International Journal of Children's Rights, 16(3), 395-406.

Gibbons, A. (2007a). The matrix ate my baby. Rotterdam: Sense.

Gibbons, A. (2007b). The politics of processes and products in education: An early childhood metanarrative crisis? Educational Philosophy and Theory, 39(3), 300311. 
Gilbert, J. (2005). Catching the knowledge wave? 'Knowledge society' and the future of public education. In J. Codd \& K. Sullivan (Eds.), Education policy directions in Aotearoa New Zealand (pp. 53-70). Southbank: Tomson/Dunmore Press.

Gould, K., \& Pohio, L. (2006). Stories from Aotearoa/NewZealand. In A. Fleet, C. Patterson \& J. Robertson (Eds.), Insights: Behind early childhood pedagogical documentation (pp. 76- 86). Castle Hill: Pademelon Press.

Graham, L. J. (2006). Discourse analysis and the critical use of Foucault. In P. L. Jeffrey (Ed.), Australian Association for Research in Education International Education Research Conference: UWS Parramatta: Papers collection (pp. 2-15). Melbourne: Australian Association for Research in Education. Retrieved from http://eprints.qut.edu.au/archive/00002689/01/2689.pdf

Graue, M. E. (1992). Meanings of readiness and the kindergarten experience. In S. Kessler \& B. B. Swadener (Eds.), Reconceptualizing the early childhood curriculum: Beginning the dialogue (pp. 62 - 90). New York: Teachers College Press.

Gunn, A. (2008). Heteronormativity and early childhood education: Social justice and some puzzling queries. (Unpublished doctoral dissertation). Waikato University, Hamilton. Retrieved from http://hdl.handle.net/10289/2671

Hanssen, B. (2000). Critique of violence: Between poststructuralism and critical theory. London: Routledge.

Hatherly, A. (2006). The stories we share: Using narrative assessment to build communities of literacy participants in early childhood centres. Australian Journal of Early Childhood, 31(1), 27-34.

Henriques, J., Hollway, W., Urwin, C., Venn, C., \& Walkerdine, V. (1984). Introduction: The point of departure. In J. Henriques, W. Hollway, C. Urwin, C. Venn \& V. Walkerdine (Eds.), Changing the subject: Psychology, social regulation and subjectivity (pp. 1-9). London: Methuen.

Hipkins, R. (2007). Assessing Key Competencies: Why would we? How could we? Wellington: Learning Media.

Holligan, C. (1999). Discipline and normalisation in the nursery: The Foucauldian gaze. Scottish Educational Review, 31(2), 137-148.

Hope, W., \& Stephenson, I. (2005). Global capitalism and the knowledge economy. In J. Codd \& K. Sullivan (Eds.), Education policy directions in Aotearoa New Zealand (pp. 19-37). Southbank: Tomson/Dunmore Press. 
Hultqvist, K. (1998). A history of the present on children's welfare in Sweden: From Frobel to present-day decentralization projects. In T. S. Popkewitz \& M. Brennan (Eds.), Foucault's challenge: Discourse, knowledge, and power in education (pp. 91- 116). New York: Teachers College Press.

Hultqvist, K. (2001). Bringing the gods and the angels back? A modern pedagogical saga about excess in moderation. In K. Hultqvist \& G. Dahlberg (Eds.), Governing the child in the new millennium (pp. 143-171). New York: RoutledgeFalmer.

Hultqvist, K. (2004). The traveling State, the Nation, and the subject of education. In B. M. Baker \& K. E. Heyning (Eds.), Dangerous coagulations? The uses of Foucault in the study of education (pp. 153-187). New York: Peter Lang

James, A. (2005). Foreword. In A. Clark, A. T. Kjørholt \& P. Moss (Eds.), Beyond listening: Children's perspectives on early childhood services (pp. iv-v). Bristol: Policy Press.

Janiewski, D., \& Morris, P. (2005). New rights New Zealand: Myths, moralities and markets. Auckland: Auckland University Press.

Johnson, B., \& Christensen, L. (2008). Educational research: Quantitative, qualitative, and mixed approaches (3rd ed.). Thousand Oaks: Sage.

Jones, A., Marshall, J., Matthews, K. M., Smith, G. H., \& Smith, L. T. (1995). Myths and realities: Schooling in New Zealand (2nd ed.). Palmerston North: The Dunmore Press.

Kessler, S., \& Swadener, B. B. (1992a). Epilogue. In S. Kessler \& B. B. Swadener (Eds.), Reconceptualizing the early childhood curriculum: Beginning the dialogue (pp. 289-294). New York: Teachers College Press.

Kessler, S., \& Swadener, B. B. (Eds.). (1992b). Reconceptualizing the early childhood curriculum: Beginning the dialogue. New York: Teachers College Press.

Loveridge, J. (1999). Becoming a parent: Discourses, experience and narratives (Unpublished doctoral dissertation). Massey University, Palmerston North.

MacNaughton, G. (2005). Doing Foucault in early childhood studies: Applying poststructural ideas. Abingdon: Routledge.

Maharey, S. (2006). Speech notes for the launch of the new Draft Curriculum, 31 July. Retrieved 6 December 2010, from http://www.beehive.govt.nz/speech/launchnew-draft-curriculum

Masschelein, J., \& Quaghebeur, K. (2005). Participation for better or for worse? Journal of Philosophy of Education, 39(1), 51-65. 
May, H. (1997). The discovery of early childhood: The development of services for the care and education of very young children, mid eighteenth century Europe to mid twentieth century New Zealand. Auckland: Auckland University Press; Bridget Williams Books with New Zealand Council for Educational Research.

May, H. (2000, August-September). Mapping some landscapes of colonial-global childhood.ece@2000.antipodes.europe. Paper presented at the 10th European Conference on the Quality of Early Childhood Education, London.

May, H. (2009). Politics in the playground: The world of early childhood in New Zealand (2nd ed.). Dunedin: Otago University Press.

May, H., \& Carr, M. (1998). Introduction: An update of Te Whāriki, the New Zealand national early childhood curriculum. In M. Carr, H. May \& V. Podmore (Eds.), Learning and teaching stories: New approaches to assessment and evaluation in relation to Te Whäriki: Symposium for 8th European Conference on Quality in Early Childhood Settings, Santiago de Compostela, Spain, September 1998 (pp. 1-7). Wellington: Institute for Early Childhood Studies, Victoria University of Wellington.

McHoul, A., \& Grace, W. (1998). A Foucault primer: Discourse, power and the subject. Dunedin: Otago University Press.

McMillan, B., \& Meade, A. (1985). Observation: The basic techniques. Set: Research information for teachers. No 1, Item 7, New Zealand Council for Educational Research.

Millei, Z. (2007). A genealogical study of 'the child' as the subject of pre-compulsory education in Western Australia (Unpublished doctoral dissertation). Murdoch University, Perth. Retrieved from http://researchrepository.murdoch.edu.au/203/

Mills, S. (2003). Michel Foucault. London: Routledge.

Ministerial Working Party (1990). Tomorrow's standards: Report of the Ministerial Working Party on assessment for better learning. Wellington: Ministry of Education.

Ministry of Education (1991). Education policy: Investing in people, our greatest asset. Wellington: New Zealand Government.

Ministry of Education (1993). Te Whāriki: He Whāriki matauranga mo nga mokopuna o Aotearoa: Draft guidelines for developmentally appropriate programmes in early childhood services. Wellington: Learning Media. 
Ministry of Education (1996a). Revised statement of desirable objectives and practices (DOPs) for chartered early childhood services in New Zealand. The New Zealand Gazette, 3 October.

Ministry of Education (1996b). Te Whāriki: He whāriki Mātauranga mō ngā Mokopuna o Aotearoa/Early Childhood Curriculum. Wellington: Learning Media.

Ministry of Education (2004). Kei Tua o te Pae Assessment for Learning: Early Childhood Exemplars. Wellington: Learning Media.

Ministry of Education (2006). Nga-arohaehae whai hua. Self-review guidelines for early childhood education. Wellington: Learning Media.

Ministry of Education (2007a). Kei Tua o te Pae Assessment for Learning: Early Childhood Exemplars. Wellington: Learning Media.

Ministry of Education (2007b). The New Zealand Curriculum. Wellington: Learning Media.

Ministry of Education (2008). Licensing Criteria for Early Childhood Education and Care Centres 2008, and the Early Childhood Education Curriculum Framework. Wellington: Author.

Ministry of Education (2009a). Kei Tua o te Pae Assessment for Learning: Early Childhood Exemplars. Wellington: Learning Media.

Ministry of Education (2009b). Te Whatu Pōkeka: Kaupapa Māori Assessment for Learning: Early Childhood Exemplars. Wellington: Learning Media.

Ministry of Education (September, 2010). Ministry of Education Position Paper: Assessment. Schooling Sector: Ministry of Education. Retrieved 20 November, 2010, from http://www.minedu.govt.nz/theMinistry/PublicationsAndResources/Assessment PositionPaper.aspx

Ministry of Education (2011). Introduction to Kei tua o te Pae. Retrieved 20 March 2011, from http://www.educate.ece.govt.nz/learning/curriculumAndLearning/Assessmentforl earning/KeiTuaotePae.aspx

Mitchell, L. (2008). Assessment practices and aspects of curriculum in early childhood education: Results of the 2007 NZCER national survey for ECE services. Wellington: New Zealand Council for Educational Research. 
Moss, P., Clark, A., \& Kjørholt, A. T. (2005). Introduction. In A. Clark, A. T. Kjørholt \& P. Moss (Eds.), Beyond listening: Children's perspectives on early childhood services (pp. 1-16). Bristol: Policy Press.

Moss, P., \& Dahlberg, G. (2008). Beyond quality in early childhood education and care Languages of evaluation. New Zealand Journal of Teachers' Work, 5(1), 3-12.

Moss, P., \& Petrie, P. (2002). From children's services to children's spaces: Public policy, children and childhood. London RoutledgeFalmer.

Mouffe, C. (1992). Preface: Democratic politics today. In C. Mouffe (Ed.), Dimensions of radical democracy: Pluralism, citizenship, community (pp. 1-14). London: Verso.

Mouffe, C. (2000). The democratic paradox. London: Verso.

Mozère, L. (2006). What's the trouble with identity? Practices and theories from France. Contemporary Issues in Early Childhood, 7(2), 109-118.

Nicoll, K., \& Fejes, A. (2008). Mobilizing Foucault in studies of lifelong learning. In A. Fejes \& K. Nicoll (Eds.), Foucault and lifelong learning: Govering the subject (pp. 1-18). Abingdon: Routledge.

Nuttall, J. (2003a). Exploring the role of the teacher within Te Whāriki: Some possibilities and constraints. In J. Nuttall (Ed.), Weaving Te Whāriki: Aotearoa New Zealand's early childhood curriculum document in theory and practice (pp. 269- 296). Wellington: New Zealand Council for Educational Research.

Nuttall, J. (2003b). Introduction: Weaving Te Whāriki. In J. Nuttall (Ed.), Weaving Te Whäriki: Aotearoa New Zealand's early childhood curriculum document in theory and practice (pp. 7-15). Wellington: New Zealand Council for Educational Research.

Nuttall, J. (2005). Educators and children learning together: Reflections on the early childhood assessment exemplars. Early Education, 38(Spr/Sum), 63-71.

Olssen, M. (2006). Michel Foucault: Materialism and education (2nd ed.). Boulder: Paradigm.

O'Neill, A.M. (2005). Individualism, enterprise culture and curriculum policy. In J. Codd \& K. Sullivan (Eds.), Education policy directions in Aotearoa New Zealand (pp. 71-86). Southbank: Tomson/Dunmore Press. 
Paki, V. A. (2007). Kimihia, rangahaua nga tikanga heke iho he taonga huahua e riro mai. Exploring whakapapa as a tool towards a kaupapa Maori assessment framework in early childhood education. (Unpublished master's thesis). University of Waikato, Hamilton. Retrieved from http://adt.waikato.ac.nz/public/adt-uow20070316.091756/index.html

Parker, I. (1992). Discourse dynamics: Critical analysis for social and individual psychology. London: Routledge.

Pascal, C., \& Bertram, T. (2009). Listening to young citizens: The struggle to make real a participatory paradigm in research with young children. European Early Childhood Education Research Journal, 17(2), 249-262.

Pena, K. S. (2006). No child left behind: The specters of almsgiving and atonement: A short genealogy of the saving grace of U.S. education. In M. N. Bloch, D. Kennedy, T. Lightfoot \& D. Weyenberg (Eds.), The child in the world, the world in the child: Education and the configuration of a universal, modern, and globalized childhood (pp. 177-194). New York: Palgrave Macmillan.

Peters, M. (2001). Education, enterprise culture and the entrepreneurial self: A Foucauldian perspective. The Journal of Educational Enquiry, 2(2), 58-71.

Peters, M. (2006). Editorial: The Learning society from the perspective of governmentality. Educational Philosophy \& Theory, 38(4), 413-414.

Popkewitz, T. S. (2003). Governing the child and pedagogicalization of the parent: A historical excursus into the present. In M. Bloch, K. Holmlund, I. Moqvist \& T. S. Popkewitz (Eds.), Governing children, families, and education: Restructuring the welfare state (pp. 35-62). New York: Palgrave Macmillan.

Popkewitz, T. S. (2004). The reason of reason: Cosmopolitanism and the governing of schooling. In B. M. Baker \& K. E. Heyning (Eds.), Dangerous coagulations? The uses of Foucault in the study of education (pp. 189-223). New York: Peter Lang.

Prout, A. (2003). Participation, policy and the changing conditions of childhood. In C. Hallett \& A. Prout (Eds.), Hearing the voices of children: Social policy for a new century (pp. 11-25). London: RoutledgeFalmer.

Rabinow, P. (1984). Introduction. In P. Rabinow (Ed.), The Foucault reader (pp. 3-29). New York: Pantheon Books.

Rogoff, B. (2003). The cultural nature of human development. Oxford: Oxford University Press.

Rose, N. (1996). Inventing our selves: Psychology, power, and personhood. Cambridge: Cambridge University Press. 
Rose, N. (1999). Powers of freedom: Reframing political thought. Cambridge:

Cambridge University Press.

Schurr, V. (2009). Assessment for learning in infant and toddler education and care: A study of teachers' talk and practice at one centre. Unpublished Research Project Submitted in partial fulfilment of the requirements for the Postgraduate Diploma in Teaching and Learning. University of Canterbury, Christchurch.

Silin, J. G. (1987). The early childhood educator's knowledge base: A reconsideration. In L. G. Katz (Ed.), Current topics in early childhood education (Vol. VII, pp. 1731). Norwood: Ablex Publishing.

Simons, M. (2006). Learning as investment: Notes on governmentality and biopolitics. Educational Philosophy and Theory, 38(4), 523-540.

Simons, M., \& Masschelein, J. (2006). The learning society and governmentality: An introduction. Educational Philosophy \& Theory, 38(4), 417-430.

Simons, M., \& Masschelein, J. (2008). The governmentalization of learning and the assemblage of a learning apparatus. Educational Theory, 58(4), 391-415.

Smith, A. B. (2007). Children's rights and early childhood education: Links to theory and advocacy. Australian Journal of Early Childhood, 32(3), 1-8.

Steele, L. (2007). Accessible portfolios: Making it happen in my centre: An action research study. (Unpublished master's thesis). Victoria University of Wellington). Retrieved from http://researcharchive.vuw.ac.nz/handle/10063/269

Stuart, D., Aitken, H., Gould, K., \& Meade, A. (2008). Evaluation of the Implementation of Kei Tua o te Pae Assessment for Learning: Early Childhood Exemplars: Impact evaluation of the Kei Tua o te Pae 2006 professional development. Wellington: Ministry of Education. Retrieved from http://www.educationcounts.govt.nz/publications/ece/26255/26256

Surtees, N. (2006). Sexualities matters in early childhood education: The management of children/bodies and their unsettling desires. (Unpublished master's thesis). University of Canterbury, Christchurch. Retrieved from http://hdl.handle.net/10092/2061

Taylor, S. (2001a). Evaluating and applying discourse analytic research. In M. Wetherell, S. Taylor \& S. J. Yates (Eds.), Discourse as data: A guide for analysis (pp. 311328). London: Sage. 
Taylor, S. (2001b). Locating and conducting discourse analytic research. In M. Wetherell, S. Taylor \& S. J. Yates. (Eds.), Discourse as data: A guide for analysis (pp. 5-48). London: Sage.

Te One, S. (2003). The context for Te Whāriki: Contemporary issues of influence. In J. Nuttall (Ed.), Weaving Te Whāriki: Aotearoa New Zealand's early childhood curriculum document in theory and practice (pp. 17-48). Wellington: New Zealand Council for Educational Research.

Te One, S. (2005). Children's rights and early childhood policy: A New Zealand story. European Early Childhood Education Research Journal, 13(2), 25-39.

Turnock, K. (2009). "It's a shift in thinking, a shift in practice": Moving to a new assessment framework in early childhood education. (Unpublished master's thesis, University of Canterbury). Retrieved from http://hdl.handle.net/10092/3077

Tuschling, A., \& Engemann, C. (2006). From education to lifelong learning: The emerging regime of learning in the European Union. Educational Philosophy \& Theory, 38(4), 451-469.

Vandenbroeck, M., \& Bouverne-De Bie, M. (2006). Children's agency and educational norms: A tensed negotiation. Childhood, 13, 127-143.

Walkerdine, V. (1984). Developmental psychology and the child-centred pedagogy: The insertion of Piaget into early education. In J. Henriques, W. Hollway, C. Urwin, C. Venn \& V. Walkerdine (Eds.), Changing the subject: Psychology, social regulation and subjectivity (pp. 153-202). London: Methuen.

Wellington Hutt and Rimutaka Kindergarten Associations (2008). Programme Notes. Wellington, Hutt, and Rimutaka Kindergarten Associations combined Kindergarten Teachers' Conference. Trentham Racecourse, Upper Hutt.

Wetherell, M. (2001a). Debates in discourse research. In M. Wetherell, S. Taylor \& S. Yates (Eds.), Discourse theory and practice: A reader (pp. 380-399). London: Sage.

Wetherell, M. (2001b). Editor's introduction. In M. Wetherell, S. Taylor \& S. Yates (Eds.), Discourse theory and practice: A reader (pp. 9-13). London: Sage.

Wetherell, M., Taylor, S., \& Yates, S. J. (Eds.). (2001a). Discourse as data: A guide for analysis. London: Sage.

Wetherell, M., Taylor, S., \& Yates, S. (2001b). Introduction. In M. Wetherell, S. Taylor \& S. Yates (Eds.), Discourse theory and practice: A reader (pp. 1-8). London: Sage. 
White, E. J. (2007). Assessment as aesthetic activity: A Bakhtinian approach. Paper presented at the Creativity, Enterprise, Policy: New directions in Education, Conference of the Philosophy of Education Society of Australasia, Wellington. Retrieved from http://www.pesa.org.au/html/documents/2007papers/White, \%20Jayne.pdf

White, E. J. (2009). Assessment in New Zealand early childhood education: A Bakhtinian analysis of toddler metaphoricity. (Unpublished doctoral dissertation). Monash University, Melbourne. Retrieved from http://arrow.monash.edu.au/hdl/1959.1/198069

White, J., \& Nuttall, J. (2007). Expanding intersubjectivity: The potential of Bakhtinian dialogism to inform narrative assessment in early childhood education. The First years: Ngā Tau Tuatahi. New Zealand Journal of Infant and Toddler Education, 9(1), 21-25.

Wilks, A. (1993). Assessment of children in kindergartens and childcare centres: Report to the Ministry of Education. Wellington: Ministry of Education.

Willig, C. (2008a). Discourse analysis. In J. A. Smith (Ed.), Qualitative psychology: A practical guide to research methods (2nd ed., pp. 160-185). Los Angeles: Sage.

Willig, C. (2008b). Introducing qualitative research in psychology (2nd ed.). Berkshire: Open University Press. 


\section{Appendix A: Reference details for discourse data}

\section{Scholarly 1}

Hatherly, A., \& Sands, L. (2002). So what is different about Learning Stories? The First years: Ngā Tau Tuatahi. New Zealand Journal of Infant and Toddler Education, $4(1), 8-12$.

\section{Scholarly 2}

Carr, M., Jones, C., \& Lee, W. (2005). Beyond Listening: Can assessment practice play a part ? In A. Clark, A. T. Kjørholt \& P. Moss (Eds.), Beyond listening: Children's perspectives on early childhood services (pp. 129-150). Bristol: Policy Press.

\section{Scholarly 3}

Hatherly, A., \& Richardson, C. (2007). Building connections: Assessment and evaluation revisited. In L. Keesing-Styles \& H. Hedges (Eds.), Theorising early childhood practice: Emerging dialogues (pp. 51-70). Castle Hill: Pademelon Press.

\section{Practitioner 1}

Carr, M., Hatherly, A., Lee, W., \& Ramsey, K. (2003). Te Whāriki and assessment: A case study of teacher change. In J. Nuttall (Ed.), Weaving Te Whāriki: Aotearoa New Zealand's early childhood curriculum document in theory and practice (pp. 187-214). Wellington: New Zealand Council for Educational Research.

\section{Practitioner 2}

Turnock, K. (2009). "It's a shift in thinking, a shift in practice": Moving to a new assessment framework in early childhood education. (Unpublished master's thesis). University of Canterbury, Christchurch. Retrieved from http://hdl.handle.net/10092/3077

\section{Exemplars}

Ministry of Education (2004). Kei Tua o te Pae Assessment for Learning: Early Childhood Exemplars. Book 4. Wellington: Learning Media. 
${ }^{* *}$ A search of international and national library data bases (e.g., OCLC FirstSearch World Cat) indicates that these Data items are held in the collections of all major universities in New Zealand, as well as some local libraries. The Practitioner 2 and Exemplars texts are available online. 


\section{Appendix B: Indication of working inductive analytical codes developed during}

analysis

$\boldsymbol{L} \& \boldsymbol{M}$ language and metaphors

e.g., Innovation pathway vision new ways

A argument, structure of text, rhetorical devices.

[ $\uparrow$ these codes were used in conjunction with those below in order to develop the analysis of the construction and effects of assessment discourse].

? What are the parameters for thinking feeling and action?

Code used to note ideas about the normalising effects of certain statements and techniques

\section{Visionary, better futures via assessment}

Code used to note enlightenment assumptions that were at work in the texts When current, new forms of assessment were being spoken of $\uparrow \downarrow$ 
+ / Enlightened, progressive practice and improved, better practice

Code used to note the frequent characterisation of ece assessment as both more enlightened (humane, just etc.) as well as producing better learning outcomes (e.g., reflective of a pragmatic, and technico-rationalist perspective).

$\neq \quad$ Is/ is not

Code used to note the binaristic construction of past and present assessment approaches.

$\emptyset \quad$ Learning- No off switch- continuous

Code used to note the extensive 'coverage' of learning as it was spoken about in the texts

Saga Sagas of transformation

Often used with the $L \& M$, and $A$ codes to indicate the narrative and rhetorical devices at work in the texts

\section{Good Teacher}

This code was used to indicate the ways that an image of an ideal teacher with correct vision was established via a range of statements in the documents 
